FABIANA MARIA DE SOUZA LEORATTI

\title{
Influência de variantes de receptores de reconhecimento padrão na suscetibilidade à malária
}

Tese apresentada à Faculdade de Medicina da Universidade de São Paulo para obtenção do título de Doutor em Ciências

Área de concentração: Fisiopatologia Experimental

Orientadora: Dra. Sandra do Lago Moraes

SÃO PAULO

2008 


\section{Dados Internacionais de Catalogação na Publicação (CIP)}

Preparada pela Biblioteca da

Faculdade de Medicina da Universidade de São Paulo

Creprodução autorizada pelo autor

\section{Leoratti, Fabiana Maria de Souza}

Influência de variantes de receptores de reconhecimento padrão na suscetibilidade à malária / Fabiana Maria de Souza Leoratti. -- São Paulo, 2008.

Tese(doutorado)--Faculdade de Medicina da Universidade de São Paulo

para obtenção do título de Doutor em Ciências.

Área de concentração: Fisiopatologia Experimental.

Orientadora: Sandra do Lago Moraes.

Descritores: 1.Malária 2.Polimorfismo genético 3.Receptores toll-like 4.Lectina de ligacão a manose 5.Receptores do complemento 3b.

USP/FM/SBD-287/08 
A Deus,

por me amparar com carinho nos momentos de dor e me ouvir a cada dia com paciência. Guiando-me no trilhar da vida com muito amor. 
Caminhando, não tenha medo de tropeçar. Tropeçando, não tenha medo de ferir. Ferindo-se, tenha coragem para corrigir algumas rotas da sua vida, mas não pense em recuar. Para não recuar, nunca deixe de amar o espetáculo da vida, porque, ao amá-lo, ainda que o mundo desabe, você jamais desistirá de caminhar...

A vida é simplesmente um espetáculo imperdível, uma aventura indescritível

Augusto Cury 
A minha querida mãezinha Rosa Maria de Souza pelo seu amor incondicional e por me ensinar na vida que temos que lutar muito, apesar dos tropeços constantes em nossas vidas e tornar os pequenos momentos da vida alegrias a luz do caminhar de cada dia. Dedico em sua memória este imenso esforço e trabalho.

A minha querida DINDA lolanda, ao meu querido DINDO Marcos e meu querido sobrinho postiço Luís Eduardo por me acolherem com muito amor e carinho, enfim pela amizade incondicional apesar das adversidades do longo caminhar da vida. 


\section{AGRADECIMENTOS}

À minha tia Sueli Aparecida de Souza e meu tio Benedito Barbosa de Souza pelo carinho e incentivo...

À minha orientadora Dra. Sandra do Lago Moraes pela dedicação e companheirismo na elaboração deste sonho, acreditando que tudo é possível, apesar das adversidades da vida.

Ao meu co-orientador Dr. Rajendranath Ramasawmy por me mostrar vários aspectos genéticos na malária e me auxiliado neste trabalho.

Aos meus queridos pupilos Lilian de Farias, Romualdo de Aragão Nascimento, Thais de Alcântara Aguilar e Wilson Domingues por estarem ao meu lado neste maravilhoso sonho.

À Dra. Martha C. Suárez-Mutis (FIOCRUZ-RJ), Prof. Dr. José Rodrigues Coura (FIOCRUZ-RJ), Dra. Fabiana Piovesan Alves (ICB-USP) e Prof. Dr. Erney Camargo (ICBUSP) por terem cedido às amostras de malária assintomática.

Aos membros da Banca de qualificação Profa. Dra. Anna Carla Renata Krepel Goldberg, Dra. Kellen Cristhina Faé e Profa. Dra. Márcia Dalastra Laurenti pelas sugestões construtivas realizadas no exame de qualificação.

À Dra. Silvia Figueiredo Costa e a Inneke Marie Van der Heijden do IMTSP por sempre serem solícitas na utilização do equipamento de fotoimagem.

À Profa. Dra. Maria Aparecida Basile agradeço pelo seu carinho, dedicação, paciência e ensinamentos durante o estágio supervisionado PAE. 
À Guita Rubinsky Elefant e a Maria Carmen Arroyo Sanchez, pelos ensinamentos, pelo carinho e atenção.

À Gladis do Santos secretária de graduação do Departamento de Moléstias Infecciosas e Parasitárias da FMUSP pelos momentos desconstraídos...

À minha querida amiga Kelly Aparecida Kanunfre pela amizade, pelo carinho e enfim por compartilhar momentos de alegrias e tristezas.

À Sarita Priscila Gobbo por se tornar uma amiga neste longo caminho de encontros e desencontros da vida, enfim pelo companheirismo e amizade...

À Edna Barbosa de Souza pelas palavras doces e encorajadoras de amizade.

Aos meus queridos amigos Adriano Cappellazzo Coelho e Erika Hellena Esther Hoffmann pela amizade e companheirismo de longos anos vividos.

À minha querida amiga Melissa da Silva Bastos por compartilhar momentos de descontraídos do dia-a-dia...

As minhas queridas amigas Sandra Trevisan Beck e Janaina Miranda Bezerra apesar da grande distância.

As meninas do Laboratório Alvina Clara, Amanda Farage, Camila Marques Ribeiro, Caroline Tanganelli, Cinthia Lanchotte, Elaine Lemos, Lília Targa.

Ao Prof. Dr. Antonio Walter Ferreira, Profa. Dra. Hiro Goto, Prof. Dr. Paulo Cotrim, Dr. José Angelo Lauletta Lindoso e a todos os colegas do Laboratório de Soroepidemiologia e Imunobiologia do IMTSP Piero Lourenço, Renata Tunis, Juliana Ide Aoki, Luciana Camizoti, Norival Kesper, Priscila Lariccia, Elisabete Ourique, Edite 
Kanashiro, Sueli Bastos, Tatiane Salvador, Larissa Giacon, Maria das Graças Prianti, Fabrício Petitto, Fábio Freitas, Sandra Regina, Arnaldo Silva, Beatriz Celeste, Camila Fazzani, Célia Vendrame, Eduardo Sanchez, Fernanda Signore, Luiza Reis, Mussya Rocha, Priscila Guedes, Taccyanna Ali, Renata Prado, Paulo de Oliveira, Nilzete Silva, Ione Sales (in memmorian), Renato Racickas, Eunice Bonfim pela troca de informações, convivências e conversas.

Ao Prof. Dr. Jorge Kalil e a todos os colegas do Laboratório de Imunologia do INCOR Maria Lúcia Marin, Fernanda Martello, Natalie Muller, Vanessa Leite, Luciana Nogueira.

À minha querida amiga Leila Oliveira da Rocha Perrone pela amizade que cresceu e por me aconselhar em momentos adversos da vida...

Aos meus queridos amigos Fábio Tarifa e Paula Tarifa pelo carinho, atenção e pela grande lição de vida.

A todos que de algum modo me incentivaram e contribuíram na realização deste trabalho.

\section{Muito obrigada.}


O presente trabalho foi realizado no Laboratório de Soroepidemiologia e Imunobiologia do Instituto de Medicina Tropical de São Paulo, sob apoio financeiro do Conselho Nacional de Desenvolvimento Científico e Tecnológico (CNPq) $\mathrm{n}^{\circ}$ 410491/2006-3 e da Fundação de Amparo à Pesquisa do Estado de São Paulo (FAPESP) n ${ }^{\circ}$ 05/51182-5 e do LIM/FMUSP-48. 


\section{SUMÁRIO}

\section{ABREVIATURAS e UNIDADES}

\section{LISTA DE FIGURAS}

LISTA DE TABELAS

\section{RESUMO}

\section{SUMMARY}

INTRODUÇÃO

1. Agente etiológico.................................................................................. 2

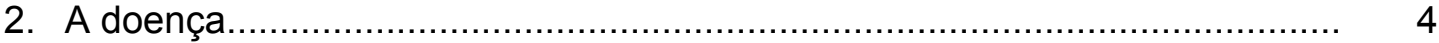

3. Imunidade na malária.................................................................. 5

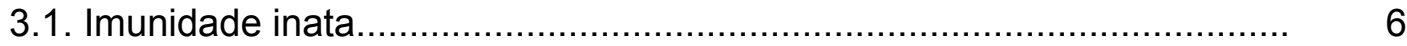

3.1.1 Receptores de reconhecimento padrão …..................................... 9

3.1.2. Células da imunidade inata....................................................... 11

3.2. Imunidade Adaptativa .................................................................. 14

4. Fatores genéticos de suscetibilidade à malária......................................... 17

5. Receptores de Reconhecimento Padrão (PRR) na Malária......................... 21

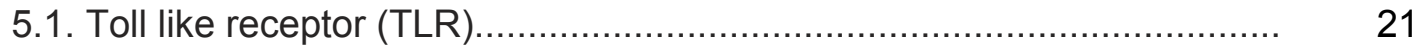

5.1.1. Polimorfismos de TLR e TIRAP 26

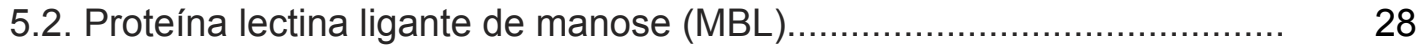

5.3. Receptor do complemento (CR-1) (CD35)......................................... 34

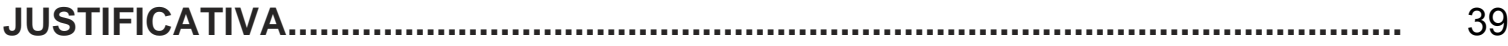

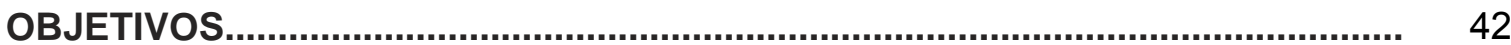

MÉTODOS

1. Indivíduos da Pesquisa....................................................................... 45

1.1. Características e procedência da população........................................... 45

1.2. Dados da População ............................................................................ 46

1.3. Aspectos Éticos da Pesquisa........................................................... 46

2. Determinação da parasitemia..................................................................... 47 
3. Extração do DNA genômico com fenol/clorofórmio..................................... 47

4. "Semi-Nested" PCR para a detecção de plasmódios.................................. 49

4.1. "Primers"

4.2. Reação de PCR .............................................................................. 49

4.3. Eletroforese em gel de agarose ................................................... 50

5. Genotipagem dos Polimorfismos......................................................... 51

5.1. Eletroforese em gel de agarose ................................................... 54

5.2. Eletroforese em gel de poliacrilamida.................................................. 54

6. Análise Estatística............................................................................. 55

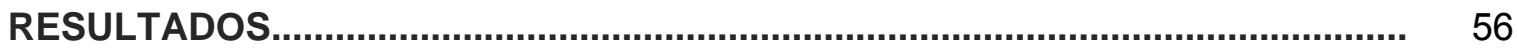

1. Polimorfismos de receptores padrão de reconhecimento da resposta imune inata

1.1. Distribuição genotípica e alélica de receptores Toll-like e da molécula adaptadora TIRAP.

1.2. Distribuição genotípica e alélica de polimorfismos da MBL

1.3. Distribuição genotípica e alélica do gene do receptor de complemento CR-1

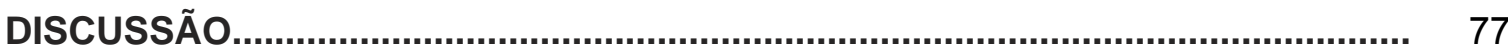

CONCLUSÕES................................................................................................... 90

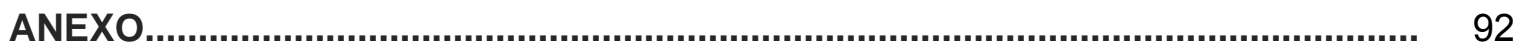

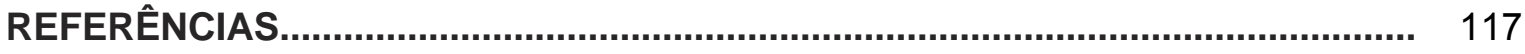




\section{LISTA DE ABREVIATURAS E MEDIDAS}

\begin{tabular}{|c|c|}
\hline $\mathrm{ADCl}$ & Antibody-dependent cellular inhibition \\
\hline APCs & Células apresentadoras de antígenos \\
\hline AS & Malária assintomática \\
\hline Asp & Aspartato \\
\hline ATP & Adenosina tri-fosfato \\
\hline $\mathrm{Cl}$ & Intervalo de confiança \\
\hline CMSP & Células mononucleares do sangue periférico \\
\hline CR1 & Receptor do complemento 1 \\
\hline Cys & Cisteína \\
\hline DC & Célula dendritíca \\
\hline DNA & Ácido desoxiribonucléico \\
\hline dNTP & desoxirribonucleosídeos trifosfatos \\
\hline EDTA & Ácido etileno diamino tetracético \\
\hline G6PD & Glicose- 6 -fosfato desidrogenase \\
\hline Glu & Glutamato \\
\hline Gly & Glicina \\
\hline GMCSF & Granulocytes-macrophage colony stimulating factor \\
\hline GPI & glicofosfatidilinositol \\
\hline $\mathrm{HBC}$ & Hemoglobina C \\
\hline HBS & Hemoglobina S \\
\hline HLA & Human leucocyte antigen \\
\hline ICAM1 & Intercellular adhesion molecule 1 \\
\hline IFN- $\gamma$ & Interferon- $\gamma$ \\
\hline iNOS & Óxido nítrico sintase induzível \\
\hline $\mathrm{KIR}$ & Killer cell immunoglobulin-like receptor \\
\hline LPS & Lipopolissacáride \\
\hline $\mathrm{LT}-\alpha$ & linfotoxina- $\alpha$ \\
\hline MAL & MyD88-adaptor-like \\
\hline MAP19 & Mannose - associated protein \\
\hline MASP & Mannose - associated serine protease \\
\hline MBL & Mannose binding lectin \\
\hline
\end{tabular}




\begin{tabular}{|c|c|}
\hline MDC & Célula dendrítica mielóide \\
\hline $\mathrm{MHC}$ & Major histocompatibility complex \\
\hline MS & Malária sintomática \\
\hline MyD88 & Myeloid differentiation factor 88 \\
\hline NF-кB & Fator nuclear $-\kappa B$ \\
\hline NK & Natural killer \\
\hline NLR & Nucleotide-binding oligomerization domain receptors \\
\hline NO & Óxido nitrico \\
\hline $\mathrm{NOI}$ & Radicais de nitrogênio \\
\hline ns & não significante \\
\hline OMS & Organização Mundial de Saúde \\
\hline OR & Odds ratio \\
\hline PAMPs & Pathogen associated molecular patterns \\
\hline PCR & Reação em Cadeia da Polimerase \\
\hline PCR-RFLP & Polymerase chain reaction - restriction fragment lenght polymorphism \\
\hline PDC & Célula dendrítica plasmocitóide \\
\hline PRR & Pattern recognition receptors \\
\hline RLR & Retinoic acid-inducible gene receptors \\
\hline RNA & Ácido ribonucléico \\
\hline ROI & Radicais de oxigênio \\
\hline SARM & Sterile $\alpha$ - and armadillo-motif containing - protein \\
\hline SDS & Dodecil sulfato de sódio \\
\hline SNP & Single nucleotide polymorphism \\
\hline SP & Proteína Surfactante \\
\hline TAE & Tampão Tris acetato/EDTA \\
\hline TBE & Tampão Tris borato/EDTA \\
\hline TGF- $\beta$ & Fator de transformador de crescimento- $\beta$ \\
\hline Th & T helper \\
\hline TIR/Toll & Domínios intracelulares do receptor de interleucina 1 \\
\hline TIRAP & TIR-domain containing adaptor protein \\
\hline TLR & Toll like receptor \\
\hline TNF- $\alpha$ & Fator de necrose tumoral- $\alpha$ \\
\hline
\end{tabular}




$\begin{array}{cl}\text { TRAM/ TICAM } 2 & \text { TRIF-related adaptor molecule } \\ T_{\text {reg }} & \text { Células T reguladoras } \\ \text { TRIF } & \text { TIR-domain-containing adaptor protein inducing IFN } \beta \\ \text { UV } & \text { ultravioleta } \\ \text { VCAM-1 } & \text { Vascular cellular adhesion molecule } \\ \mu \mathrm{g} & \text { micrograma } \\ \mu \mathrm{L} & \text { microlitro } \\ g & \text { aceleração da gravidade }\left(\cong 9,8 \mathrm{~m} / \mathrm{s}^{2}\right) \\ \mathrm{M} & \text { molar } \\ \mathrm{mg} & \text { miligrama } \\ \mathrm{mL} & \text { mililitro } \\ \mathrm{mM} & \text { milimolar } \\ \mathrm{pb} & \text { pares de base } \\ \mathrm{pMol} & \text { picomol } \\ \mathrm{U} & \text { unidade }\end{array}$




\section{LISTA DE FIGURAS}

Figura 1 Ciclo de vida de Plasmodium sp infectantes ao 4 homem.

Figura 2 Receptores Toll-Like humanos. Diagrama 23 esquemático que mostra moléculas adaptadoras, orientação celular e exemplos de ligantes.

Figura 3 Estrutura oligomérica de MBL

Figura 4 Organização da região promotora e do exon 1 do

Figura 5 Representação esquemática do gene de CR-1. Cada caixa representa um CCP (complementcontrol-protein repeats). Sítios 1 e 2 indicados. A identidade entre os sítios é caracterizada pelas cores das caixas (ex. CCP 3,10 e 17 diferem apenas por um aminoácido). Ct: cauda citoplasmática; $\mathrm{NH} 2$ região amino terminal; LHR (long homologous repeats); TM domínio transmembrânico 


\section{LISTA DE TABELAS}

Tabela 1 Receptores de reconhecimento padrão (PRRs) e seus ligantes.

Tabela 2 Desordens genéticas de hemoglobina associadas à 18 suscetibilidade à malária.

Tabela 3 Adaptada de Stevenson e Riley (2004) 20

Tabela 4 Estudos da literatura sobre a influência de polimorfismos de TLRs e TIRAP.

Tabela 5 Estudos da literatura sobre a influência de polimorfismos do gene 2 da lectina ligante à manose (MBL) na malária.

Tabela 6 Estudos da literatura sobre a influência de polimorfismos da molécula CR1.

Tabela 7 Características demográficas e resultado das espécies de Plasmodium encontradas pela gota espessa e/ou "Semi-Nested" PCR.

Tabela 8 Polimorfismos genéticos humanos estudados em população de áreas endêmicas de malária no Brasil.

Tabela 9

Condições da PCR para cada gene estudado $\left(\mathrm{H}_{2} \mathrm{O}\right.$ qsp $25 \mu \mathrm{L})$

Tabela 10 Condições de amplificação da PCR e enzima de restrição para cada gene estudado.

Tabela 11 Gel utilizado para a eletroforese de cada gene estudado.

Tabela 12 Freqüência genotípica e alélica de polimorfismos de TLR-1, TLR-4, TLR-6 e TLR-9 de indivíduos com (MS) e sem (AS) manifestações clínicas de malária.

Tabela 13

Freqüência genotípica e alélica de polimorfismos de TLR-1, TLR-4, TLR-6 e TLR-9 em indivíduos com (MS) e sem (AS) manifestações clínicas causadas por $P$. falciparum.

Tabela 14 Freqüências genotípicas e alélicas dos polimorfismos de TLR-1, TLR-4, TLR-6 e TLR-9 em indivíduos com manifestações clínicas de malária (MS) distribuídas pelo grau de parasitemia: alta $\left(>10.000\right.$ parasitas $/ \mathrm{mm}^{3}$ de sangue), baixa $\left(1000-10.000\right.$ parasitas $/ \mathrm{mm}^{3}$ de sangue) e muito baixa $\left(<1.000\right.$ parasitas $/ \mathrm{mm}^{3}$ de sangue).

Tabela 15 Freqüências genotípicas e alélicas dos polimorfismos de TLR-9 em indivíduos com manifestações clínicas de malária (MS) distribuídas pelo grau de parasitemia: alta (> 10.000 parasitas $/ \mathrm{mm}^{3}$ de sangue), baixa $(\leq 10.000$ parasitas $/ \mathrm{mm}^{3}$ de sangue). 
Tabela 16

Tabela 17

Tabela 18

Tabela 19

Tabela 20

Tabela 21

Tabela 22

Tabela 23

Tabela 24
Freqüência genotípica e alélica de polimorfismo S180L da molécula adaptadora MAL/TIRAP em indivíduos com (MS) e sem (AS) manifestações clínicas de malária.

Freqüência genotípica e alélica do polimorfismo S180L da molécula adaptadora MAL/TIRAP em indivíduos com manifestações clínicas de malária (MS) distribuídas pelo grau de parasitemia: alta (> 10.000 parasitas $/ \mathrm{mm}^{3}$ de sangue), baixa $(1000-10.000$ parasitas $/ \mathrm{mm}^{3}$ de sangue) e muito baixa $(<1.000$ parasitas $/ \mathrm{mm}^{3}$ de sangue).

Idade dos pacientes (valores medianos em anos e os percentis de $25 \%$ e $75 \%$ entre parêntesis) com manifestações clínicas de malária (sintomáticos) de acordo com os genótipos TLR-1 e de TLR-9 estratificados de acordo com os níveis de parasitemia.

Freqüência genotípica e alélica dos polimorfismos dos códons 52, 54 e 57 do exon 1 ( $B, C$ e $D),-221$ da região promotora e +4 da região não traduzida do gene 2 da MBL de todos indivíduos com (MS) e sem (AS) manifestações clínicas de malária.

Freqüência dos diplótipos do exon 1 e da posição -221 da região promotora do gene 2 da $M B L$ de todos os indivíduos com (MS) e sem (AS) manifestações clínicas de malária.

Freqüência genotípica e alélica dos polimorfismos dos códons 52, 54 e 57 do exon 1 ( $D, B$ e $C),-221$ da região promotora e +4 da região não traduzida do gene da MBL de indivíduos com (MS) e sem (AS) manifestações clínicas causadas por $P$. falciparum.

Freqüência dos diplótipos do exon 1 e -221 da região promotora do gene de indivíduos com (MS) e sem (AS) manifestações clínicas causadas por $P$. falciparum.

Freqüências genotípicas e alélicas dos polimorfismos dos códons 52, 54 e 57 do exon 1, -221 da região promotora e +4 da região não traduzida do gene 2 da MBL de indivíduos com manifestações clínicas de malária (MS) distribuídas pelo grau de parasitemia: alta (> 10.000 parasitas $/ \mathrm{mm}^{3}$ de sangue), baixa (100010.000 parasitas $/ \mathrm{mm}^{3}$ de sangue) e muito baixa ( $<1.000$ parasitas $/ \mathrm{mm}^{3}$ de sangue).

Freqüência do diplótipo do exon 1 e da posição -221 da região promotora do gene 2 da MBL de indivíduos com manifestações clínicas de malária (MS) distribuídas pelo grau de parasitemia: alta $(>10.000$ parasitas $/ \mathrm{mm}^{3}$ de sangue), baixa $(1000-10.000$ parasitas $/ \mathrm{mm}^{3}$ de sangue) e muito baixa $(<1.000$ parasitas $/ \mathrm{mm}^{3}$ de sangue). 
Tabela 25 Freqüência do diplótipo do exon 1 e da posição -221 da região promotora de gene de $M B L$ e do gene TLR1 com (MS) e sem (AS) manifestações clínicas de malária.

Tabela 26

Freqüência do diplótipo do exon 1 e da posição -221 da região promotora de gene 2 de $M B L$ e da região promotora -1486 do gene TLR9 em indivíduos com manifestações clínicas de malária (MS) distribuídas pelo grau de parasitemia: alta $\left(>10.000\right.$ parasitas $/ \mathrm{mm}^{3}$ de sangue), baixa ( $\leq 10.000$ parasitas $/ \mathrm{mm}^{3}$ de sangue).

Tabela 27 Freqüência genotípica e alélica do polimorfismo C5507G do receptor de complemento CR-1 em indivíduos com (MS) e sem (AS) manifestações clínicas.

Tabela 28

Freqüência genotípica e alélica do polimorfismo C5507G do receptor de complemento CR-1 em indivíduos com (MS) e sem (AS) manifestações clínicas causadas por $P$. falciparum.

Tabela 29 Freqüência genotípica e alélicas do polimorfismo C5507G do receptor de complemento CR-1 em indivíduos com manifestações clínicas de malária (MS) distribuídas pelo grau de parasitemia: alta $(>10.000$ parasitas $/ \mathrm{mm}^{3}$ de sangue), baixa $(1000-10.000$ parasitas $/ \mathrm{mm}^{3}$ de sangue) e muito baixa $\quad(<1.000$ parasitas $/ \mathrm{mm}^{3}$ de sangue). 


\section{RESUMO}

Leoratti FMS. Influência de variantes de receptores de reconhecimento padrão na suscetibilidade à malária humana [tese]. São Paulo: Faculdade de Medicina, Universidade de São Paulo; 2008. 147p.

Malária é uma das principais causas de doença e morte no mundo, principalmente de crianças. É considerada a força de seleção evolucionária mais forte que se conhece na história recente do genoma humano. Além dos fatores ambientais e do próprio parasito, fatores genéticos do hospedeiro têm um papel fundamental tanto na suscetibilidade como na evolução clínica da infecção. O sistema imune inato reconhece os plasmódios através de um número limitado de receptores de reconhecimento padrão (PRRs) e inicia vários mecanismos de defesa que resultam no desenvolvimento de inflamação e resistência do hospedeiro à infecção. Mas, a eliminação completa do parasito requer respostas imunes adaptativas que são amplificadas pela ativação do sistema imune inato. As manifestações clínicas de malária são dependentes dos níveis de citocinas próinflamatórias circulantes produzidas, as quais em níveis altos contribuem para a imunopatologia da doença. $O$ balanço entre respostas pró e antiinflamatórias dirigidas contra o parasito é considerado crítico para a proteção clínica, assim a resposta imune inata pode contribuir tanto para proteção da malária como para modular a resposta imune adaptativa. Neste estudo, nós investigamos polimorfismos de um único nucleotídeo (SNP) dos genes de três PRRs: TLR, MBL e CR1 de indivíduos infectados por Plasmodium e residentes em áreas endêmicas de malária no Brasil. Os SNPs TLR1 (I602S), TLR4 (D229G), TLR6 (S249P), TLR9 (T-1237C/ -1486C), MBL [exon 1 nos códons 52, 54, e $57\left(M B L 2^{*} A\right.$ ou $D, A$ ou $B$ e $A$ ou $C$, respectivamente); na região do promotor na posição $-221\left({ }^{*} X\right.$ ou $\left.{ }^{*} Y\right)$; e na posição +4 da região não traduzida $\left({ }^{*} P\right.$ ou $\left.{ }^{*} Q\right)$ ] e $C R-1(C 5507 G)$ foram determinados por PCR-RFLP. Nós observamos associações entre os polimorfismos TLR1 I602S, TLR6 S249P e da região não traduzida $+4\left({ }^{*} Q\right)$ e manifestações clínicas de malária e entre os polimorfismos TLR9 T-1486C, $T L R$ T-1237C, $M B L{ }^{*} D$ (códon 52) e do diplótipo de produção insuficiente de MBL $(X A+O / O)$ e parasitemias mais altas. Nenhuma associação foi observada entre o polimorfismo CR-1 C5507G e manifestações clínicas de malária ou com parasitemia. Ao analisarmos juntos os polimorfismos de MBL e TLR, observamos que indivíduos com diplótipo de produção suficiente de MBL $(Y A / Y A+Y A / X A+Y A / O+X A / X A)$ TLR1 I602S tinham menos manifestações clínicas de malária e indivíduos com diplótipo de produção suficiente de MBL e não carreadores do alelo TLR9 -1486C tinham parasitemias mais baixas do que os indivíduos com diplótipo de produção insuficiente de MBL e carreadores dos alelos variantes de TLR1 I602S e TLR9-1486C, respectivamente. 
Juntos, nossos dados indicam que polimorfismos do promotor de TLR-9 e os diplótipos de produção insuficiente de $\mathrm{MBL}(X A+O / O)$ devem de algum modo controlar o nível de parasitemia por plasmódios enquanto a deficiência de TLR1 parece predispor para a presença de manifestações clínicas de malária. Também, podemos sugerir que existe uma cooperação entre TLR1, TLR9 e MBL na ativação da resposta imune inata na malária. Estes achados genéticos devem contribuir para o entendimento da patogênese da malária e levantar uma questão potencialmente interessante que é digna de investigações posteriores em outras populações a fim de validar a contribuição genética destes loci na patogênese da malária.

Descritores: malária, polimorfismos, receptores Toll like, lectina de ligação a manose, receptores do complemento C3b 


\section{SUMMARY}

Leoratti FMS. Influence of point variants of pattern recognition receptors in the susceptibility to human malaria [thesis]. São Paulo: "Faculdade de Medicina, Universidade de São Paulo"; 2008. 147p.

Malaria is one of the major causes of disease and death worldwide, mainly of children. It is also the strongest known force for evolutionary selection in the recent history of the human genome. Besides environmental and parasite factors, host genetic factors play a major role in determining both susceptibility to malaria and the course of infection. Innate immune mechanisms directed against Plasmodium parasites both contribute to protection from malaria and modulate adaptive immune responses. The innate immune system recognizes Plasmodium via a limited number of pattern-recognition receptors (PRRs) and initiates a broad spectrum of defense mechanisms that result in the development of inflammation and host resistance to infection. But, the complete control of the infection requires adaptive immune responses; and the innate immune system is also very efficient in 'instructing' the cellular mediators of adaptive immunity to lead a powerful additional 'strike force' against the parasite. Clinical malaria is characterized by high levels of circulating proinflammatory cytokines, which are thought to contribute to the immunopathology of the disease. The balance between pro- and anti-inflammatory responses toward the parasite is considered critical for clinical protection. The innate immune system initiates and thus sets the threshold of immune responses. In this study, we investigated single nucleotide polymorphisms (SNP) in the genes of three PRRs: TLR, MBL and CR1 in Plasmodium-infected individuals living in endemic areas of Brazil. The SNPs TLR1 (I602S), TLR4 (D229G), TLR6 (S249P), TLR9 (T-1237C/ -1486C), MBL [in the coding sequence of exon 1 at codons 52,54 , and $57\left(M B L 2^{*} A\right.$ or $D, A$ or $B$, and $A$ or $C$, respectively); in the promoter region at position $-221\left({ }^{*} X\right.$ or $\left.{ }^{*} Y\right)$; and in the untranslated sequence at position $+4\left({ }^{*} P\right.$ or $\left.{ }^{*} Q\right)$ ] and $C R-1(C 5507 G)$ were determined by PCR-RFLP. We observed associations of the TLR1 I602S, TLR6 S249P and untranslated sequence at position $+4 M B L\left({ }^{*} Q\right)$ variants with clinical manifestations of malaria and of the TLR9 T-1486C, TLR9 T-1237C, MBL2*D and $\mathrm{MBL}$-insufficient diplotype $(X A+O / O)$ with higher parasitemias. No association was observed to the CR-1 C5507G ) and clinical manifestations of malaria or parasitemia. Also, we observed that individuals with MBLsufficient haplotype $(Y A / Y A+Y A / X A+Y A / O+X A / X A)$ and not bearing the allele TLR1 I602S had less clinical manifestations of malaria and individuals with MBL-sufficient haplotype and not bearing TLR9 -1486C had lower parasitemias when compared to individuals with $\mathrm{MBL}$-insufficient diplotype and bearing the variant alleles TLR1 I602S and TLR9-1486C, respectively.

Altogether, our data indicate that TLR-9 promoter and MBL-insufficient haplotype $(X A+O / O)$ polymorphisms to some extent may control the level of Plasmodium parasitemia while TLR1 deficiency seems to predispose to mild 
malaria. Also, they could suggest cooperation among TLR1, TLR9 and MBL in the immune response against malaria. These genetic findings may contribute to the understanding of the pathogenesis of malaria and raise a potentially interesting issue that is worthy of further investigation in other population in order to validate the genetics contribution of these loci to the pathogenesis of malaria.

Descriptors: malaria, polymorphism, Toll like receptor, mannose binding lectin, receptors complement $3 b$ 

INTRODUÇÃO 
A malária ainda é uma das maiores endemias do mundo e um grande obstáculo ao desenvolvimento econômico de comunidades e nações. Segundo dados da Organização Mundial de Saúde (OMS), 40\% da população mundial habitam áreas de risco da doença, que causa de 300 a 500 milhões de casos clínicos por ano, com mais de um milhão de mortes, principalmente de crianças com menos de cinco anos de idade. Além das crianças, as gestantes e pessoas vivendo com HIVIAIDS também são grupos de alto risco de mortalidade por malária. A maior proporção da mortalidade causada pela malária ocorre na África (89\%), seguida pela Ásia (10\%) e por último, as Américas $(1 \%)^{1}$.

No Brasil, no ano de 2006 foram relatados 550.576 casos de malária, sendo que mais de $99 \%$ dos casos ocorreram na Região Amazônica. A espécie predominante é $P$. vivax, embora no período de 1999 a 2006, tenha ocorrido um aumento na proporção de malária por $P$. falciparum de $18,6 \%$ para 24,9\%; este aumento é preocupante, pois a malária falciparum é a responsável pela grande maioria das formas graves e dos óbitos ${ }^{2}$.

\section{Agente etiológico}

A malária é uma doença infecciosa causada por protozoários do gênero Plasmodium, sendo quatro as espécies infectantes ao homem: $P$. falciparum, $P$. vivax, $P$. malariae e $P$. ovale ${ }^{3}$.

O ciclo de vida do parasito no hospedeiro vertebrado se inicia pela inoculação de esporozoítos através da picada de mosquito fêmea do gênero Anopheles (Figura 1). Nos hepatócitos, ocorre a esquizogonia, um ciclo 
assexuado de reprodução, em que os esporozoítos se desenvolvem e originam os esquizontes, os quais amadurecem e liberam milhares de merozoítos na corrente sangüínea (ciclo hepático). Nas infecções por $P$. vivax e por P. ovale, alguns esporozoítos permanecem em estágio latente no fígado por semanas a anos, quando são chamados hipnozoítos; estes podem ser reativados e provocar recidivas da doença.

Os merozoítos liberados na circulação invadem as hemácias e iniciam nova esquizogonia, transformando-se em trofozoítos, que amadurecem e se dividem, gerando os esquizontes. Os esquizontes amadurecidos rompem os eritrócitos e liberam merozoítos que invadem novos eritrócitos ou alguns, se diferenciam em gametócitos macho e fêmea. Estes quando ingeridos pelo mosquito Anopheles no repasto sangüíneo sofrem um ciclo sexuado no intestino do mosquito, com a fusão dos gametas para formação dos oocinetos que penetram na parede intestinal e geram oocistos. Os oocistos se dividem por esporogonia, originando milhares de esporozoítos que chegam à glândula salivar do mosquito. Quando o mosquito carregando esporozoítos nas glândulas salivares se alimentar novamente, irá infectar outro hospedeiro e iniciar um novo ciclo no hospedeiro vertebrado ${ }^{4}$. 


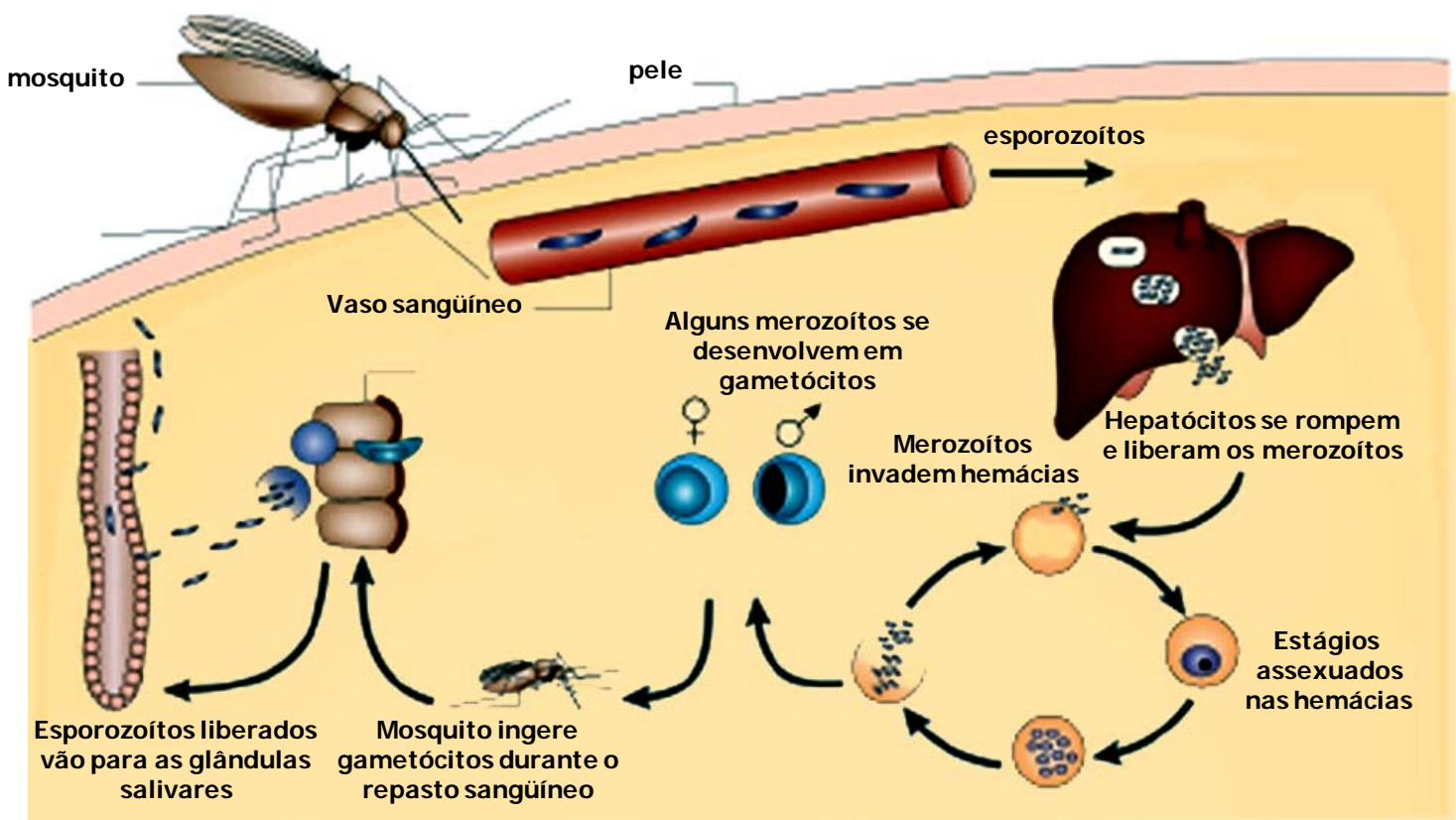

Figura 1. Ciclo de vida de Plasmodium sp infectantes ao homem (Adaptado de Good, 2001) ${ }^{5}$.

\section{A DOENÇA}

As manifestações clínicas da malaria variam de infecção assintomática a complicações graves ${ }^{6}$. Os sinais e sintomas mais comuns da malária, como febre, náusea, dor de cabeça, iniciam-se com a ruptura dos esquizontes eritrocíticos e são característicos de respostas com altos níveis de citocinas pró-inflamatórias circulantes ${ }^{7}$. As manifestações graves, como anemia, acidose metabólica, malária cerebral, hipoglicemia, distúrbios respiratórios e insuficiência de múltiplos órgãos são decorrentes da hiperparasitemia e aumento do metabolismo do parasito, supressão da medula óssea, hipóxia, e aderência de eritrócito ao endotélio vascular ${ }^{8,9}$. O balanço entre respostas pró e anti-inflamatórias contra o parasito é crítico para se ter proteção 
clínica, ou seja, pouca ativação imune não consegue inibir o crescimento do parasito, enquanto muita ativação pode levar à imunopatologia ${ }^{10}$.

As infecções por $P$. malariae e $P$. ovale não causam morbidade, enquanto o $P$. vivax causa febre aguda, grave e com alta morbidade, principalmente na Ásia e na América do Sul, mas raramente é fatal. A grande maioria dos casos graves e mortes é causada por $P$. falciparum, que é endêmico na África Sub-Saariana e em muitas outras regiões tropicais do mundo.

\section{IMUNIDADE NA MALÁRIA}

A imunidade protetora na malária é estágio e espécie-específica e bastante complexa. Em áreas de alta transmissão de malária, observa-se o desenvolvimento gradual de imunidade clínica nos indivíduos com múltiplas infecções pregressas. A aquisição deste tipo de proteção natural é lábil e é dependente da exposição do indivíduo ao parasito $^{11}$, da exposição a variantes antigênicas múltiplas dos plasmódios e da maturação do sistema imune. Altas parasitemias com sinais e sintomas clínicos da doença são comuns em crianças com menos de cinco anos de idade. Os adultos, com exceção de gestantes, desenvolvem uma imunidade não esterilizante com níveis sub-patentes de parasitemias e sem sintomas da doença ${ }^{12}$. Existem também evidências de proteção em adultos não imunes, com exceção de crianças, após um ano de muita exposição, sugerindo um modo alternativo de aquisição de imunidade antimalárica ${ }^{13,14}$. Mecanismos imunes inatos e adaptativos participam do controle das altas parasitemias e das 
manifestações clínicas, mas podem não eliminar completamente a infecção, o que leva à persistência de baixas parasitemias por muitos meses ou anos e mantém a alta prevalência de indivíduos assintomáticos.

Ainda não se tem uma vacina eficaz contra a malária, a despeito de muitas pesquisas e de vários ensaios clínicos realizados nas últimas três décadas. Pesquisas relacionadas à vacina têm como foco principal a identificação de antígenos alvos de imunidade protetora, e como conseqüência a imunidade adaptativa na malária tem sido exaustivamente estudada. Estudos mais recentes de mecanismos efetores imunes antimaláricos têm mostrado o papel de citocinas inflamatórias derivadas tanto da imunidade inata como da adaptativa como mediadores de imunidade

protetora e/ou de patologia. Assim, torna-se importante melhorar o entendimento sobre a contribuição da imunidade inata nas respostas próinflamatórias na malária ${ }^{15}$.

\subsection{IMUNIDADE INATA}

A resposta imune inata é essencial para limitar a fase inicial de replicação dos plasmódios até que o hospedeiro desenvolva uma resposta imune adaptativa capaz de eliminar a infecção. Ao reduzir a probabilidade de morte do hospedeiro, aumenta a chance de transmissão do parasito a outro hospedeiro, o que sob o aspecto evolucionário é vantajoso tanto para o hospedeiro como para o parasito ${ }^{16}$. Também a imunidade inata é requerida no controle de reinfecções com genótipos variantes de plasmódios até que novas respostas adaptativas sejam geradas. 
Em modelos murinos, a resistência à malária é dependente de sinais mediados por interferon- $\gamma(\text { IFN- } \gamma)^{17}$ e um fator determinante e diferenciador das infecções não letais das letais é a capacidade de produzir precocemente as citocinas pró-inflamatórias IL-12, IFN- $\gamma$ ou fator de necrose tumoral- $\alpha$ $(\mathrm{TNF}-\alpha)^{18-20}$. TNF- $\alpha$ e IFN- $\gamma$ agem sinergisticamente para aumentar a produção de óxido nítrico $(\mathrm{NO})^{21}$, que está envolvido diretamente na morte do parasito $^{22}$. A sobrevivência do animal depende da sua capacidade de controlar a replicação dos estágios sangüíneos do parasito nos primeiros 7 a 14 dias após a infecção ${ }^{16}$.

Na fase aguda da infecção de camundongos C57BL/6 por $P$. chabaudi chabaudi AS, a parasitemia é controlada por mecanismos dependentes de IFN- $\gamma$, IL-12 e células T CD4 ${ }^{+}$e independentes de anticorpos. O clareamento do parasito ocorre na fase crônica como conseqüência de mecanismos que requerem tanto células $\mathrm{T} \mathrm{CD}^{+}$como anticorpos específicos. Células $\mathrm{T}$ үठ ajudam, mas não são essenciais para a resolução da parasitemia ${ }^{16}$. Na ausência de células natural killer (NK), o pico de parasitemia é mais alto durante a fase aguda e ocorre recrudescência de parasitemia na fase crônica ${ }^{23}$. A produção precoce de IFN- $\gamma$ por células NK mostrou-se associada à resolução espontânea de infecções por várias espécies de plasmódios de roedores, enquanto na ausência de IFN- $\gamma$ produzido por células NK observou-se infecção letal ${ }^{23,20}$.

Estudos in vitro mostraram que eritrócitos humanos infectados por $P$. falciparum induziram células mononucleares do sangue periférico (CMSP) 
de indivíduos não imunes a produzirem TNF- $\alpha$, IL-12 e IFN- $\gamma$ num período de 10 horas $^{24}$.

Resultados in vivo obtidos de infecções experimentais de indivíduos não imunes à malária têm corroborado com muitos dos resultados obtidos nos estudos in vitro e em modelos murinos. Voluntários não imunes infectados experimentalmente com $P$. falciparum mostraram aumento coordenado de citocinas pró-inflamatórias, IFN- $\gamma$, IL-12p40 e IL-8 no soro, coincidente com o momento em que os parasitos foram detectados nos eritrócitos ${ }^{25}$. A cinética da resposta de citocinas sistêmicas durante o período pré-patente da infecção foi determinada em 18 indivíduos não imunes infectados experimentalmente com $P$. falciparum. Foram observadas variações interindividuais qualitativas e quantitativas da resposta imune inata que permitiram dividir os indivíduos em três grupos: 1). secretores de níveis moderados de IFN- $\gamma$ e IL-10, mas não secretores de IL-12p70; 2). secretores de IL-12p70 e de altos níveis de IFN- $\gamma$ e IL-10 e 3). não secretores de citocinas pró-inflamatórias mas secretores de altos níveis de fator de transformação de crescimento- $\beta$ (TGF- $\beta$ ). As respostas pró-inflamatórias foram associadas com um controle mais rápido da parasitemia mesmo com o desenvolvimento de sintomas clínicos ${ }^{26}$.

Um modelo matemático baseado em observações de populações expostas a infecções repetidas de malária sugere que os mecanismos da imunidade inata são induzidos quando a densidade parasitária alcança um limiar pré-definido ${ }^{27}$. As densidades de parasitos no sangue oscilam entre níveis mais baixos (nos quais as respostas imunes não são induzidas) e 
níveis mais altos (quando se induz os mecanismos efetores inatos e o clareamento parcial das células infectadas). Este modelo também mostra que os mecanismos imunes inatos funcionam para limitar a densidade parasitária máxima, mas gradualmente os mecanismos adaptativos são requeridos para a completa eliminação do parasito ${ }^{28,29}$.

\subsubsection{RECEPTORES DE RECONHECIMENTO PADRÃO}

A resposta imune inata é desencadeada por receptores de reconhecimento padrão (PRR - pattern recognition receptors), tais como:

- receptores Toll-like (TLR, do inglês Toll-like receptors): já foram descritos dez TLRs humanos funcionais (TLR-1 a TLR-10)

- receptores Nod-like (NLR, do inglês Nucleotide-binding oligomerization domain receptors)

- receptores RIG-I-like (RLR, do inglês Retinoic acid-inducible gene receptors)

- proteínas com hélices triplas de colágeno (conhecidas como colágeno de defesa) - lectina de ligação à manose (MBL- mannose binding lectin), componente do complemento C1q, proteínas surfactantes A (SP-A) e D (SP-D), CL-L1, CL-P1, ficolinas 1, -2, -3

- receptores de complemento (ex. CR1)

- receptores scavenger (CD36)

- proteína $\mathrm{C}$ reativa

Os PRRs reconhecem padrões moleculares associados à patógenos (PAMPs- pathogen associated molecular patterns) como açúcares, ácidos 
nucléicos, proteínas, lipídeos, peptídeos ou combinação dos mesmos ${ }^{30}$ (tabela 1). Os PAMPs apresentam características comuns: a). são expressos normalmente por microrganismos e não por células do hospedeiro; b). mostram pouca variação entre os microrganismos e c). a sua expressão é essencial para a sobrevivência do microrganismo ${ }^{31}$.

Tabela1. Receptores de reconhecimento padrão (PRRs) e seus ligantes.

\begin{tabular}{cc}
\hline RECEPTORES & LIGANTES \\
TLR1+TLR2 & Triacil lipopeptídeos, GPI* \\
TLR2 & Zymosan \\
TLR3 & RNA* de dupla fita $^{*}$ \\
TLR4 & LPS* \\
TLR5 & Flagelina \\
TLR6+TLR2 & Diacil lipopeptideos \\
TLR7 & RNA de simples fita \\
TLR8 & RNA de simples fita \\
TLR9 & DNA*, hemozoína - malária \\
TLR10 & Desconhecido \\
TLR11 & Proteína profilina \\
\hline Nod-like & \\
NOD 1 & Peptídeoglicano \\
NOD 2 & Peptídeoglicano \\
NOD 3 & RNA de bactéria, ATP*, ácido úrico \\
\hline RIG-I-like & RNA de simples fita e dupla fita \\
\hline MBL & Carboidratos \\
\hline CD36 & Eritrócitos infectados com Plasmodium \\
\hline \hline SPI
\end{tabular}

* GPI (glicofosfatidilinositol); RNA (ácido ribonucléico); LPS (lipopolissacarídeo); DNA (ácido desoxiribonucleico), ATP (adenosina tri-fosfato)

As principais funções dos PRRs são: opsonização, ativação do complemento e cascatas da coagulação, ativação da fagocitose, ativação na sinalização da síntese de citocinas e na indução da apoptose. Uma grande variedade de células, tais como: neutrófilos, macrófagos, células dendríticas (DC), células NK, NKT e células endoteliais expressam PRRs e ao 
reconhecerem os PAMPs iniciam os mecanismos de defesa da resposta imune inata.

\subsubsection{CÉlULAS DA IMUNIDADE INATA}

As células dendríticas (DC) fazem a ligação entre a resposta imune inata e a resposta adaptativa. São responsáveis pela apresentação de antígenos, ativação de células $\mathrm{T}$ naive $\mathrm{e}$ aumento na produção de anticorpos. A maturação das DC é caracterizada pela expressão de moléculas do complexo principal de histocompatibilidade (major histocompatibility complex- $\mathrm{MHC}$ ) de classe II, moléculas de adesão e moléculas co-estimulatórias e pela secreção de citocinas que ativam células do sistema imune.

Quando ativadas via TLR-2 e TLR-4, as DC mielóides (MDC) $\left(\mathrm{CD} 11^{+} \mathrm{CD} 23^{-}\right)$produzem TNF- $\alpha$, IL-6 e IL-12 ${ }^{32}$, e via TLR-9, as DC

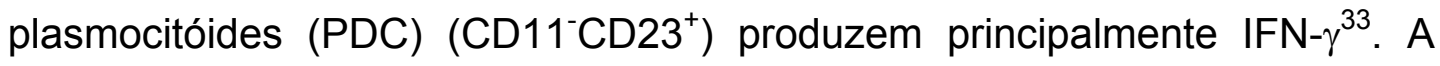
ativação via TLR-7 induz a produção específica de IL-12 e IFN- $\gamma$ por MDC e PDC, respectivamente ${ }^{34}$. IL-12 ativa células NK a produzirem IFN- $\gamma$ e induz a diferenciação das células T CD4 ${ }^{+}$helper 1 (Th1).

Urban et al. (1999) ${ }^{35}$ observaram que eritrócitos infectados por $P$. falciparum, ao se ligarem em DC via CD36, inibem o aumento, induzido por lipopolissacárides (LPS), da expressão de moléculas MHC classe II e de moléculas co-estimulatórias, como molécula de adesão intercelular (intercellular adhesion molecule 1- ICAM1), CD40, CD80, CD83 e CD86. DCs expostas a $P$. falciparum secretam mais IL-10 que IL-12, o que 
desencadeia uma redução na resposta inflamatória e ameniza os sintomas clínicos durante a infecção no hospedeiro. Já em modelos experimentais de malária por $P$. yoelii e $P$. chabaudi chabaudi, nem a maturação nem a ativação das DCs, tanto in vitro como in vivo, foram prejudicadas quando expostas a estágios sangüíneos do parasito, com secreção de IL-12, IFN- $\gamma$ e TNF- $\alpha^{36}$

Os macrófagos participam no controle da infecção malárica, por mecanismos dependentes de anticorpos e independentes (via CD36), na fagocitose e na secreção de fatores solúveis direta ou indiretamente, como as citocinas IL-1, TNF- $\alpha$, fator estimulatório da colônia de granulócitos e macrófagos (granulocytes-macrophage colony stimulating factor- GMCSF), reativos de nitrogênio (NOI) e radicais de oxigênio (ROI) ${ }^{37-39}$.

$\mathrm{Na}$ infecção malárica, a função dos macrófagos pode ser prejudicada pelo acúmulo de hemozoína. A hemozoína é um pigmento malárico resultante da degradação das moléculas heme que persistem no vacúolo digestivo de Plasmodium e, quando ingerida pelo macrófago, afeta a apresentação de antígenos e reage com fosfolipídios da membrana, gerando ácidos graxos hidroxi-poliinsaturados que inibem as funções dos macrófagos, como fagocitose, produção de citocinas e geração do burst oxidativo $^{40,41}$.

As células NK reconhecem e destroem células aberrantes, como células infectadas por vírus, bactérias e protozoários. As células NK são as primeiras células a produzirem IFN- $\gamma$ em resposta a eritrócitos infectados. 
NK secretam outras citocinas pró-inflamatórias, particularmente linfotoxina- $\alpha$ (LT- $\alpha)$, GM-CSF, IL-3, quimiocina e TGF- $\beta$.

A citoxicidade de células NK e a produção de IFN- $\gamma$ são induzidas pela infecção de murinos com $P$. chabaudi chabaudi, $P$. berghei ou $P$. yoelii. A secreção de IFN- $\gamma$ é essencial para o desenvolvimento de uma imunidade protetora. A depleção de células NK provoca um rápido aumento na parasitemia em camundongos C57BL/6 infectados com $P$. chabaudi chabaudi e uma alta mortalidade em camundongos SCID infectados com $P$. yoelii ${ }^{20,23,42-44}$.

Artavanis-Tsakonas et al. $(2003)^{45}$ observaram que células NK humanas de indivíduos não imunes são as primeiras a produzirem IFN- $\gamma$ in vitro em resposta a eritrócitos infectados por $P$. falciparum. Um estudo realizado em mulheres grávidas no Gabão mostrou o decréscimo da atividade citotóxica das células NK contra eritrócitos infectados por $P$. falciparum. A citoxicidade mediada pelas células NK foi menor nas grávidas primo-infectadas ${ }^{46}$.

As células NKT co-expressam receptores de células T e marcadores de NK. As células NKT reconhecem glicolipídeos apresentados via CD1 que estão expressos em células apresentadoras de antígenos (APCs), ou seja, DCs, macrófagos e células $B$, e secretam IFN- $\gamma$ e IL-4. Em modelo experimental, administração de $\alpha$-galactosilceramida ( $\alpha$-Gal Cer) (glicolipídeo extraído de esponjas marinhas, ligante de CD1d e $\mathrm{V} \alpha 14$ das células NKT) em camundongos infectados com esporozoítos irradiados de $P$. yoelii estimula a ativação de células NKT, inibindo o estágio hepático e o desenvolvimento do estágio eritrocítico ${ }^{47}$. 
As células $\mathbf{T} \gamma \delta$ representam apenas $5 \%$ das células $\mathrm{T}$ no sangue periférico de indivíduos normais. As células $T \gamma \delta$ expandem na fase aguda na malária e inibem a replicação do parasito in vitro auxiliando na proteção à infecção ${ }^{48,49}$. Células $T \gamma \delta$ não produzem exclusivamente citocinas próinflamatórias, sugerindo que estas células apresentam funções regulatórias e citotóxicas na proteção à malária ${ }^{50}$.

\subsection{IMUNIDADE ADAPTATIVA}

Os mecanismos efetores da imunidade inata são importantes, mas não suficientes para controlar a malária. Portanto é necessária a participação da resposta imune adaptativa que envolve células T e B.

Os antígenos da fase hepática são processados e apresentados, via MHC classe I. Essa apresentação leva à ativação de células T CD8 ${ }^{+}$ citotóxicas e morte da célula infectada pela liberação de granzima e perforina e/ou ativação de células $\mathrm{T} \mathrm{CD4}^{+}$que auxiliam a resposta com a secreção de citocinas como IFN- $\gamma$, inibindo o crescimento do parasito ${ }^{51}$.

As células $\mathrm{TCD}^{+}$desempenham funções regulatórias e efetoras no estágio eritrocítico. A malária induz células Th1 e Th2, com distinta produção de citocinas. As células Th1 contribuem para o clareamento da parasitemia, enquanto as células Th2 induzem a diferenciação de células B para a produção de anticorpos específicos e inibem o desenvolvimento e proliferação das células Th1. O equilíbrio das citocinas produzidas por estas células é importante na determinação do espectro clínico observado na malária, de infecção assintomática a manifestações graves ${ }^{52,53}$. 
As células $\mathrm{T} \mathrm{CD} 4^{+}$regulatórias $\left(\mathrm{T}_{\text {reg }}\right)\left(\mathrm{Foxp}^{+} \mathrm{CD} 4^{+} \mathrm{CD} 25^{+}\right)$suprimem a resposta imune pela secreção de citocinas supressoras como IL-10, TGF- $\beta$ ou pela interação célula-célula. A secreção de TGF- $\beta$ induz apoptose de células endoteliais in vitro ${ }^{54}$ e $\mathrm{IL}-10$ inibe a produção de citocinas próinflamatórias ${ }^{55}$. Estas duas citocinas auxiliam no equilíbrio entre proteção e progressão da doença.

Interações entre as células $T_{\text {reg }}$ e patógenos podem ser benéficas ao hospedeiro e ao patógeno, como demonstrado em modelos experimentais de camundongos resistentes infectados com Leishmania major ${ }^{56}$ e de camundongos infectados com vírus Herpes simplex ${ }^{57}$.

Na malária murina, foi observado que camundongos depletados de células $\mathrm{T}_{\text {reg }} \mathrm{e}$ infectados com $P$. yoelii foram protegidos da morte por conseguirem erradicar o parasito $^{58}$. Em humanos, células $T_{\text {reg }}$ se correlacionaram com rápido crescimento do parasito ${ }^{26}$. Juntos, estes dados sugerem que células $T_{\text {reg }}$ são ativadas pelo parasito como um mecanismo de escape imune.

As células $B$ e anticorpos desempenham papéis importantes na imunidade à malária. A resposta imune humoral é caracterizada pelo aumento e produção policlonal de anticorpos $\lg M$ e $\operatorname{lgG}$, mas também de outros isotipos de anticorpos ${ }^{52,53}$.

A transferência passiva de anticorpos $\lg G$ a indivíduos não imunes resultou na redução da parasitemia e sintomas clínicos ${ }^{59}$. Em área endêmicas, anticorpos citofílicos, lgG1 e lgG3, estão associados com redução da parasitemia e gravidade da doença ${ }^{60-61}$. Os anticorpos citofílicos 
agem em colaboração com células efetoras tais como monócitos e macrófagos mediando opsonização e inibição celular dependente de anticorpos (antibody-dependent cellular inhibition- ADCI).

Os anticorpos não citofílicos, IgG2 e lgG4, podem bloquear os mecanismos efetores dos anticorpos citofílicos pela competição dos mesmos domínios. Recentes observações, sugerem que lgG2 pode também participar na proteção contra o parasito, devido a presença de um alelo mutante no receptor FcyRIIA permitindo que os anticorpos IgG2 participem na opsonização ${ }^{62}$.

Além dos anticorpos $\lg \mathrm{M}$ e $\lg \mathrm{g}$, os níveis de anticorpos lgE também estão aumentados na malária. Os anticorpos lgE podem proteger ou participar na patogênese da doença. Sua função depende da expressão de receptores Fc em basófilos e mastócitos, bem como em eosinófilos, monócitos/macrófagos, linfócitos B e plaquetas. IgE regula positivamente

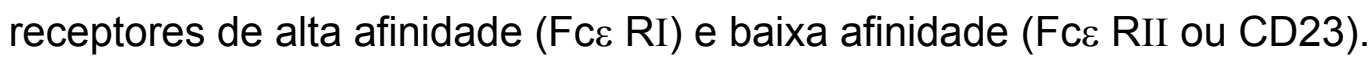

Alguns trabalhos mostraram que anticorpos IgE se correlacionam com gravidade da doença o que sugere um papel patogênico ${ }^{63-66}$. Embora outros, sugerem papel protetor de IgE em indivíduos com malária grave não $\operatorname{comatosos}^{67}$ e a contribuição de anticorpos IgE no controle da parasitemia de indivíduos assintomáticos e malária não complicada quando comparada a do grupo de indivíduos com malária grave ${ }^{68}$. 


\section{Fatores GenÉticos de Suscetibilidade À MaLÁria}

A alta mortalidade causada pela malária nos últimos 6.000 anos resultou numa forte pressão seletiva, resultando em diversos polimorfismos genéticos que modificam a resposta individual à doença e com efeitos profundos na constituição genética das populações expostas. Em termos evolucionários, o aparecimento de polimorfismos genéticos que conferem resistência à malária coincide com as estimativas da dispersão de $P$. falciparum derivadas de estudos de sistemas polimórficos do parasito. Por exemplo, análises de 25 seqüências de introns de $P$. falciparum, envolvendo em geral genes metabólicos e housekeeping e de genes polimórficos sugerem que o parasito tenha se originado entre $9000-20000$ anos ${ }^{69,70}$. Este é o tempo aproximado do início do que se calcula ter ocorrido o desenvolvimento da agricultura, entre 5000-10000 anos, o que criou condições necessárias para a dispersão da malária.

Haldane $^{71}$ foi o primeiro, ainda em 1948, a associar variações no gene da globina com resistência à malária. Hoje se sabe que a exposição à malária deixou em seu caminho não apenas as desordens genéticas de hemoglobina, mas também vários outros polimorfismos que podem estar associados à proteção de formas graves da doença.

Polimorfismos de genes que controlam a expressão fisiológica ou patológica de constituintes das hemácias podem afetar a penetração dos merozoítos ou mesmo o crescimento desses nas hemácias ${ }^{72}$. A sobreposição de áreas geográficas com alta prevalência de malária e desses 
polimorfismos genéticos relacionados à proteção ou suscetibilidade resultou da seleção evolucionária por malária ${ }^{72}$ (sumarizados na tabela 2).

Tabela 2. Desordens genéticas de hemoglobina associadas à suscetibilidade à malária.

\begin{tabular}{lllc}
\hline \hline \multicolumn{1}{c}{ DESORDENS GENÉTICAS } & ASSOCIAÇÃo COM MALÁRIA & REFERÊNCIAS \\
\hline TALASSEMIAS: anormalidades nos & $\begin{array}{l}\text { Altas freqüências de talassemias } \\
\text { genes que codificam para em populações protegidas de }\end{array}$ & \multirow{2}{*}{ em d1,73,74 } \\
hemoglobina que levam à redução & malária grave. & \\
ou a perda na síntese das cadeias $\alpha$ & & & \\
e $\beta$ de globina. & & & \\
\hline
\end{tabular}

ANEMIA FALCIFORME: causada pela presença de uma hemoglobina anormal, a hemoglobina $\mathrm{S}(\mathrm{HbS})$ nas hemácias dos pacientes, resultante da substituição do ácido glutâmico pela valina na posição 6 no gene da cadeia $\beta$ da hemoglobina.
Crianças heterozigotas para o gene de anemia falciforme apresentam risco reduzido de morte por $P$. falciparum quando comparado a crianças homozigotas para o gene normal.
75

Heterozigose (AC) e homozigose

(CC) associadas com proteção contra formas graves da malária.
Hemoglobina C (HBC): presença de hemoglobina anormal decorrente da substituição do ácido glutâmico por lisina na posição 6 no gene da cadeia $\beta$.
76,77
OVALOCITOSE (BANDA 3): caracterizase pela deleção de 27 pares de base no cromossomo 17 da proteína banda 3 da membrana do eritrócito.
Proteção contra malária grave, provavelmente por causar defeitos na membrana do eritrócito e conseqüentemente alterando a aderência dos eritrócitos ao endotélio vascular.
$78-80$

\section{Antí́genos DuFFY: membro da Indivíduos homozigotos para o família dos receptores de quimiocinas e é caracterizado por três alelos principais $F Y^{*} A, F Y^{*} B$ e \\ alelo $\mathrm{FY}^{*} \mathrm{O}$ (ausência do antígeno \\ Duffy) são completamente resistentes à malária vivax.} $F Y^{*} \mathrm{O}$. Utilizado por $P$. vivax para invasão nos eritrócitos.
83,84

relacionada à deficiência de G6DP.

Crescimento normal do parasito.

Crianças do sexo feminino heterozigotas para G6PD A- eram mais resistentes à malária sintomática em relação às crianças homozigotas. 
Polimorfismos de um único nucleotide (single nucleotide polymorphismsSNPs) são variantes comuns encontradas numa freqüência acima de $1 \%$ dentro de uma população ${ }^{87}$. SNPs podem alterar a sequência de aminoácidos (SNPs não-sinônimos), afetar as características do promotor ou ainda ser completamente silenciosos. Estas mutações não ocorrem ao acaso dentro do genoma, mas dependem da região genômica em particular e também da pressão seletiva ${ }^{88}$. Portanto é de se esperar que os genes que codificam para proteínas envolvidas em imunidade ou resistência a doenças tenham um alto número de polimorfismos, uma hipótese que tem sido fortalecida pelos resultados obtidos dos seqüenciamentos de genomas ${ }^{89,90}$. Dentro dos genes envolvidos no reconhecimento imune, diversos SNPs não sinônimos têm sido descritos e estudados quanto à sua influência na resposta imune à malária. Na tabela 3 sumarizamos alguns destes polimorfismos, sendo que os polimorfismos de MBL, TLR e CR-1 serão discutidos com maiores detalhes adiante. 
Tabela 3. Adaptada de Stevenson e Riley (2004) ${ }^{16}$

\begin{tabular}{|c|c|c|c|c|}
\hline COMPONENTES & MOLÉCULA & GeNE/ALELo & EFEITO/ MECANISMO & REFERÊNCIAS \\
\hline \multirow{4}{*}{ PRRs } & $\begin{array}{c}\text { Deficiência em } \\
\text { MBL }\end{array}$ & $M B L$ & $\begin{array}{l}\text { Baixos níveis séricos } \\
\text { de } \mathrm{MBL} \text { associados ao } \\
\text { maior risco de malária } \\
\text { grave. }\end{array}$ & 91 \\
\hline & \multirow[t]{2}{*}{ TLR } & $\begin{array}{l}\text { TLR4 } \\
\text { Asp299Gly }\end{array}$ & $\begin{array}{l}\text { Associação de risco } \\
\text { em crianças com } \\
\text { malária grave. } \\
\text { Risco de anemia em } \\
\text { mulheres grávidas } \\
\text { com malária. }\end{array}$ & 92,93 \\
\hline & & TLR9 -1486 & $\begin{array}{l}\text { Baixo peso em recém } \\
\text { nascidos nas mulheres } \\
\text { heterozigotas } \\
\text { homozigotas } \\
\text { malária. }\end{array}$ & 93 \\
\hline & CR-1 & CR-1 & $\begin{array}{l}\text { Baixa expressão de } \\
\text { CR1 (LL) associou } \\
\text { com malária grave. }\end{array}$ & 94 \\
\hline Enzimas & $\begin{array}{l}\text { Óxido-nítrico } \\
\text { sintase } \\
\text { induzível }\end{array}$ & NOS2 (iNOS) & $\begin{array}{l}\text { Associação iNOS- } \\
1659 T \text { com malária } \\
\text { grave. } \\
\text { Associação iNOS }-954 \\
\text { e }-1173 \text { com proteção } \\
\text { aos sintomas e } \\
\text { anemia. }\end{array}$ & $95-98$ \\
\hline \multirow{7}{*}{$\begin{array}{l}\text { Moléculas da } \\
\text { superfície } \\
\text { celular }\end{array}$} & \multirow{4}{*}{ HLA } & $\begin{array}{l}\text { HLA-Bw53 } \\
\text { haplótipo } \\
\text { DRB1*1302/ } \\
\text { HLA- } \\
\text { DQB1*0501 }\end{array}$ & $\begin{array}{l}\text { Associado com risco } \\
\text { reduzido de malária } \\
\text { grave. }\end{array}$ & 99 \\
\hline & & $\begin{array}{l}\text { HLA- } \\
\text { DQB1*0501 }\end{array}$ & $\begin{array}{l}\text { Associado à proteção } \\
\text { de anemia grave em } \\
\text { reinfecções. }\end{array}$ & 100 \\
\hline & & Dqw2 & $\begin{array}{l}\text { Altos níveis de } \\
\text { anticorpos contra as } \\
\text { seqüências EENV da } \\
\text { proteína Pf155/RESA. }\end{array}$ & 101 \\
\hline & & HLA-DR4 & $\begin{array}{l}\text { Associação } \text { com } \\
\text { baixas respostas de } \\
\text { anticorpos à vacina } \\
\text { SPf66. }\end{array}$ & 102 \\
\hline & $\begin{array}{l}\text { Receptor de } \\
\text { IFN- } \gamma\end{array}$ & IFNGR-56 & $\begin{array}{l}\text { Indivíduos } \\
\text { heterozigotos } \\
\text { protegidos a malária } \\
\text { grave. }\end{array}$ & 103 \\
\hline & $\begin{array}{l}\text { Receptor de } \\
\text { IFN- } \alpha\end{array}$ & IFNGR1 & $\begin{array}{lr}\text { Associação } & \text { com } \\
\text { proteção a } \\
\text { cerebral. }\end{array}$ & 104 \\
\hline & $\begin{array}{l}\text { CD36/receptor } \\
\text { scavenger }\end{array}$ & $\begin{array}{l}-14 C \rightarrow T \\
-53 G \rightarrow T\end{array}$ & $\begin{array}{l}\text { - Associação a malária } \\
\text { grave, malária cerebral } \\
\text { e suscetibilidade a } \\
\text { malária grave }\end{array}$ & $105-107$ \\
\hline
\end{tabular}




\begin{tabular}{|c|c|c|c|c|}
\hline & KIR & KIR3DL2 & $\begin{array}{l}\text { - Associação } \text { na } \\
\text { produção de IFN- } \gamma \\
\text { pelas células NK. }\end{array}$ & 45 \\
\hline & CD40L & CD40L 726C & $\begin{array}{l}\text { Redução no risco de } \\
\text { malária grave. }\end{array}$ & 108 \\
\hline \multirow[b]{3}{*}{ Citocinas } & TNF & TNF2 & $\begin{array}{ll}\text { Associação } & \text { com } \\
\text { malária cerebral. } & \\
\end{array}$ & 109,110 \\
\hline & IL-4 & IL4-524T & $\begin{array}{l}\text { Aumento nos níveis de } \\
\text { anticorpos anti- } \\
\text { Plasmodium. }\end{array}$ & 111 \\
\hline & IL-12p40 & $I L-12 B$ & 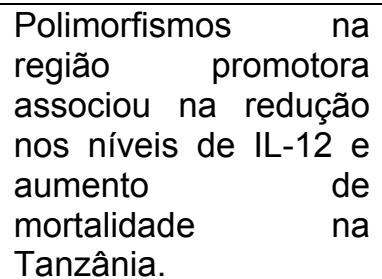 & 112 \\
\hline
\end{tabular}

\section{RECEPTORES DE RECONHECIMENTO PADRÃO (PRR) NA MALÁRIA}

A resposta imune inata é orquestrada principalmente por monócitos/macrófagos, granulócitos e células dendríticas, que são a primeira linha de defesa contra um microrganismo invasor ${ }^{113}$. Como referido anteriormente, os PRRs capacitam o hospedeiro na discriminação do nãopróprio do próprio ao reconhecerem os PAMPs presentes nos organismos estranhos.

\subsection{TOLL LIKE RECEPTOR (TLR)}

TLRs de mamíferos são uma família de pelo menos 12 proteínas transmembrânicas conservadas na evolução e que foram identificadas em vertebrados pela homologia com Toll, uma molécula que estimula as proteínas antimicrobianas em Drosophila melanogaster ${ }^{113,114}$. A ativação de respostas imunes inatas por TLRs envolve pelo menos cinco proteínas

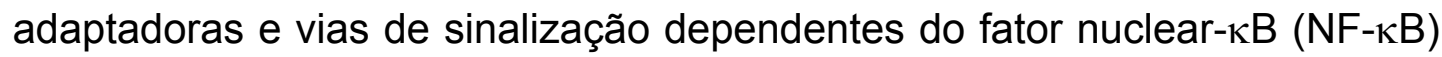
e dependentes de membros da família do fator regulatório de IFN (IRF) ${ }^{115}$. 
Os TLRs contêm ectodomínios com motivos repetitivos ricos em leucina envolvidos diretamente ou através de moléculas acessórias no reconhecimento de uma variedade de PAMPs e domínios intracelulares do receptor de interleucina 1 (TIR)/Toll, que interagem com moléculas adaptadoras contendo o domínio $\operatorname{TIR}^{116}$. As moléculas adaptadoras são o fator de diferenciação mielóide (Myeloid differentiation factor 88-MyD88), a molécula semelhante à MyD88 (MyD88-adaptor-like -MAL, também conhecida como proteína adaptadora contendo o domínio TIR (TIR-domain containing adaptor protein- TIRAP) (MAL/TIRAP), proteína adaptadora contendo o domínio TIR indutora de IFN- $\beta$ (TIR-domain-containing adaptor protein inducing IFN $\beta$ - TRIF), molécula adaptadora relacionada a TRIF (TRIF-related adaptor molecule- TRAM, também conhecida como TICAM2TRAM/TICAM 2) e a proteína contendo motivo a e armadillo estéril (sterile $\alpha$ and armadillo-motif containing - protein- SARM) ${ }^{117}$.

Os TLRs são classificados em dois grupos de acordo com sua localização (figura 2). O primeiro grupo inclui TLR-3, TLR-7, TLR-8 e TLR-9, que estão localizados em compartimentos intracelulares como endossomas ou membranas lisossomais e utilizam as moléculas adaptadoras MyD88 e/ou TRIF. E o segundo grupo inclui TLR-1, TLR-2, TLR-4, TLR-5, TLR-6 e TLR10 que estão presentes na superfície da membrana plasmática e utilizam outras moléculas adaptadoras, MAL/TIRAP e/ou TRAM/TICAM2. A molécula adaptadora SARM regula negativamente TRIF $^{118}$. TLR2 forma um heterodímero com TLR1 ou TLR6. A molécula adaptadora MAL é ativada via TLR2 ou TLR4. 


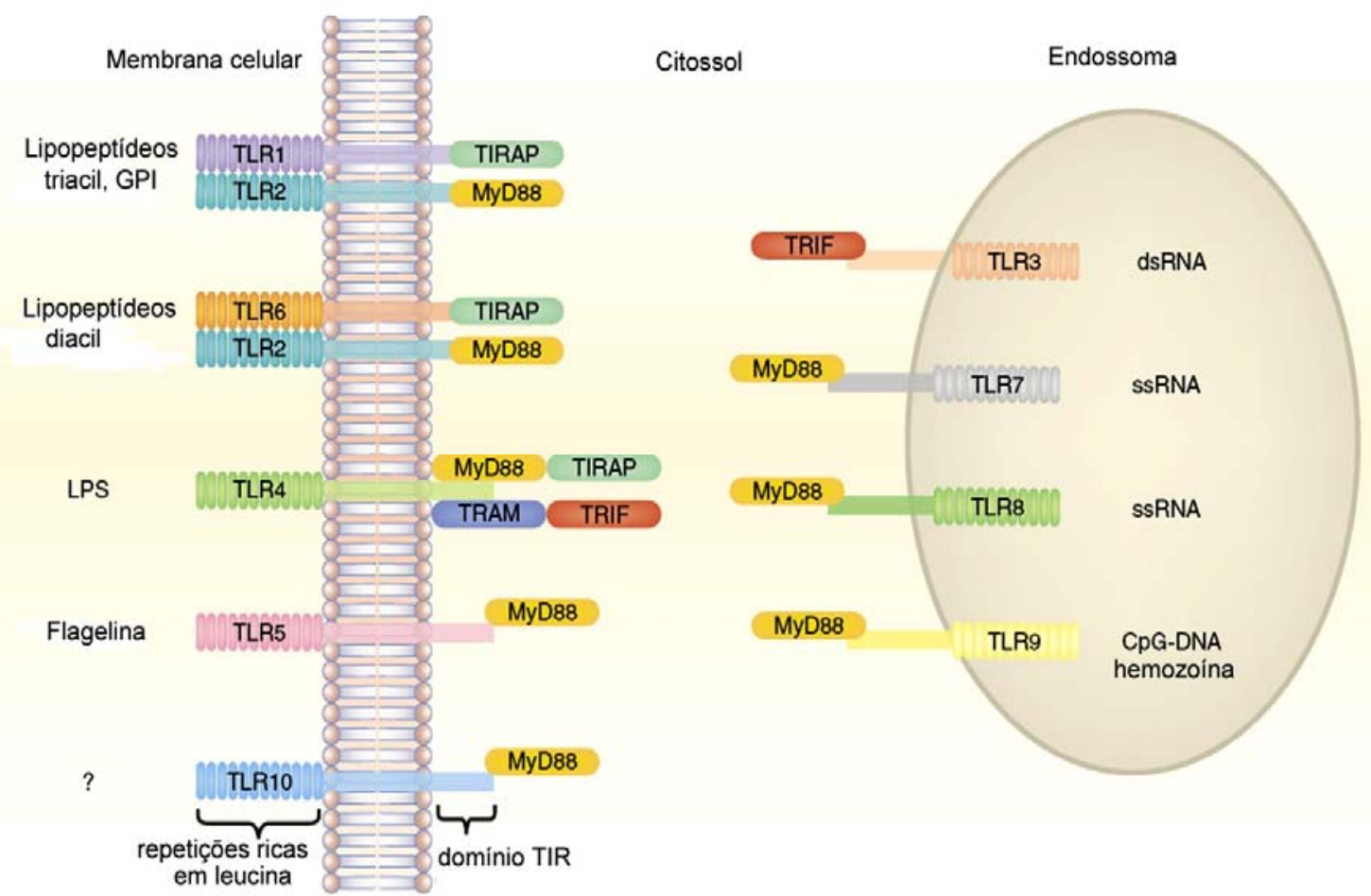

Figura 2. Receptores Toll-Like humanos. Diagrama esquemático que mostra moléculas adaptadoras, orientação celular e exemplos de ligantes. (Adaptado de Kanzler et al., 2007 e Coban et al., 2005) ${ }^{119,120 .}$

A interação entre domínios TIR de TLRs e as moléculas adaptadoras desencadeia a ativação da cascata de sinalização que culmina na produção de citocinas pró-inflamatórias, quimiocinas, IFN tipo I, peptídeos antimicrobianos, moléculas co-estimulatórias e moléculas $\mathrm{MHC}^{121-123}$.

Lisofosfatidilserina de Schistosoma. mansoni, âncoras de glicofosfatidilinositol (GPI) e Tc-52 de Trypanosoma cruzi são capazes de sinalizar TLR-2 ${ }^{124-126}$. Estudos utilizando camundongos deficientes em MyD88 mostraram que TLR é de suma importância para o desencadeamento da resposta imune inata ao Toxoplasmose gondii ${ }^{127}$. 
Dados recentes sugerem a ativação de citocinas pró-inflamatórias via TLRs também na malária. O reconhecimento por TLR2, 4 e 9 de estruturas moleculares de $P$. falciparum levando à secreção de citocinas próinflamatórias por células do hospedeiro foi demonstrado in vitro ${ }^{128-130}$.

GPI, que funciona com uma âncora de membrana de proteínas de $P$. falciparum, pode mediar respostas imunes celulares via TLRs. Estudos in vitro prévios demostram a importância da GPI de $P$. falciparum na ativação da resposta imune inata do hospedeiro, com a observação da produção de TNF- $\alpha$ e IL-1, a expressão de óxido nítrico sintase induzível (iNOS) em macrófagos e células endoteliais, o aumento da expressão de moléculas de adesão (ICAM-1, VCAM-1 e E-selectina) em leucócitos e células endoteliais $^{131-133}$.

Âncoras de GPI de plasmódios são preferencialmente reconhecidas in vitro por TLR-2 e em menor extensão por TLR-4, envolvendo a ativação dependente de MyD88 de vias de sinalização específicas que conduzem à produção de citocinas pró-inflamatórias, como TNF-a, IL-1 e IL-12 e NO por macrófagos murinos e monócitos do sangue periférico humano in vitro ${ }^{134,135}$. A indução de citocinas por GPI do parasita também causa pirexia e hipoglicemias transitórias em camundongos ${ }^{131}$.

O dano hepático causado pela infecção por $P$. berghei em camundongos dependente de altos níveis de IL-12 é caracterizado pela presença de hepatócitos apoptóticos e necróticos e densa infiltração de linfócitos. Camundongos deficientes de MyD88 infectados com $P$. berghei NK65 não apresentaram dano hepático nem produção de IL-12, o que indica que a via 
de sinalização TLR-MyD88 está ativada na infecção por $P$. berghei resultando na ativação de $\mathrm{IL}-12^{136}$. Ainda, corroborando com esses dados, foi observada redução da mortalidade de camundongos deficientes em MyD88 infectados com $P$. berghei ANKA quando comparados com camundongos selvagens $^{129}$ e redução dos níveis de TNF- $\alpha$ e de malária cerebral em camundongos deficientes em JNK2 (fator de transcrição) infectados com $P$. berghei ANKA ${ }^{137}$.

O pigmento malárico hemozoína foi descrito como um novo ligante para TLR9 ${ }^{129}$. Mais recentemente, mostrou-se que de fato o que se liga a TLR-9 são os ácidos nucléicos do parasito ligados à hemozoína, ou seja, a hemozoína funciona como um carreador que internaliza o DNA do plasmódio para o compartimento intracelular onde este pode ser reconhecido por TLR9 ${ }^{130}$. A interação de hemozoína-DNA com TLR-9 ativa a resposta imune inata tanto in vivo como in vitro, resultando na produção de citocinas e quimiocinas e no aumento de moléculas co-estimulatórias ${ }^{129}$. Hemozoína não apenas induz monócitos a liberarem altos níveis de TNF- $\alpha$ e IL-1 $\beta$, mas também aumenta maturação de $\mathrm{MDC}^{138,139}$. Anteriormente, já se tinha observado que esquizontes sanguíneos de $P$. falciparum (lisado solúvel) podiam ativar PDC a produzirem IFN- $\gamma$ através de uma via dependente de TLR-9, que pode estimular células $\mathrm{T} \mathrm{CD}^{+}$a produzirem IFN- $\gamma^{139}$ Recentemente foi demonstrado que na infecção experimental de camundongos com $P$. yoelii ocorre ativação de $\mathrm{T}_{\text {regs }}$ por células dendríticas após sinalização de TLR9, como um mecanismo de escape imune do parasito $^{140}$. 
Outros estudos apresentam resultados que se contrapõem aos anteriores. Camundongos deficientes em TLR-1, -2, -3, -4, -6, -7 ou -9 ou moléculas adaptadoras MyD88, TIRAP ou TRIF desenvolveram malária cerebral como os camundongos selvagens e ainda apresentaram dano microvascular e hemorragia cerebral e pulmonar ${ }^{141}$. A resposta imune inata, a malária cerebral e as taxas de sobrevivência em camundongos deficientes de TLR-2,-4 e -9 (knockout triplo) foram similares aos dos camundongos selvagens ${ }^{142}$

Loharungsikul et al. (2007) $)^{143}$ observaram aumento na expressão de TLR-2 e TLR-4 em monócitos e MDC e diminuição na expressão intracelular de TLR-9 nas PDC em indivíduos da Tailândia com malária grave e malária moderada quando comparados aos indivíduos saudáveis.

A investigação das respostas de TLR durante a infecção experimental por $P$. falciparum de 15 voluntários não imunes à malária mostrou um aumento significante da produção de citocinas pró-inflamatórias durante a infecção quando se estimulou sangue total ex vivo com ligantes de TLR-4, enquanto ligantes de TLR-2/TLR-1 estimularam tanto a produção de citocinas pró-inflamatórias como de anti-inflamatórias. Respostas através de outros TLRs foram menos modificadas pela infecção malárica ${ }^{10}$.

\subsubsection{Polimorfismos de TLRs E TIRAP (MAL)}

Vários SNPs em TLRs estão associados na suscetibilidade a doenças infecciosas, doenças inflamatórias crônicas, aterosclerose e asma ${ }^{87,144,145}$. SNP na molécula adaptadora TIRAP associou-se com proteção a várias 
doenças infecciosas ${ }^{146}$. Sumarizamos na tabela 4 alguns polimorfismos encontrados de TLRs e TIRAP.

Tabela 4. Estudos da literatura sobre a influência de polimorfismos de TLRs e TIRAP.

\begin{tabular}{|c|c|c|c|}
\hline TLR & VARIANTE & AssociaÇÃo & REFERÊNCIAS \\
\hline TLR1 & $1602 S$ & Redução nos níveis de IL-6 & 147 \\
\hline TLR2 & C597T & $\begin{array}{l}\text { Suscetibilidade na tuberculose e } \\
\text { lepra }\end{array}$ & 148,149 \\
\hline \multirow[t]{2}{*}{ TLR4 } & Asp299G/y & $\begin{array}{l}\text { Baixo peso em recém nascidos } \\
\text { de mães com malária }\end{array}$ & \multirow{2}{*}{92,93} \\
\hline & & $\begin{array}{l}\text { Risco de anemia em mulheres } \\
\text { grávidas }\end{array}$ & \\
\hline TLR6 & S249P & Associação com asma & 150 \\
\hline TLR9 & -1486 & $\begin{array}{l}\text { Baixo peso em recém nascidos } \\
\text { nas mulheres heterozigotas e } \\
\text { homozigotas com malária }\end{array}$ & 93 \\
\hline Tirap/MAL & S180L & $\begin{array}{l}\text { Associação com proteção de } \\
\text { malária grave e não complicada, } \\
\text { bacteremia, tuberculose e } \\
\text { doença pneumocócica }\end{array}$ & 146 \\
\hline
\end{tabular}

Muitos trabalhos mostram que variantes de TLRs estão relacionadas a um aumento na suscetibilidade de infecções, mas em outros trabalhos não conseguem demonstrar associações entre a variante e a infecção ${ }^{151-153}$.

O SNP TLR4 D399G conferiu um risco de malária grave em crianças na região norte de Gana $^{92}$ e em outro estudo em Gana, mas na região sul observou que o polimorfismo TLR4 Asp299Gly estava associado ao maior risco de anemia em mulheres grávidas com malária e ao baixo peso nos respectivos recém-nascidos ${ }^{93}$. 
Mockenhaupt et al. $(2006)^{93}$ investigaram polimorfismos na região promotora de $T L R 9$ (T-1237C e $T-1486 C)$ e observaram que o alelo -1486C associou-se a baixo risco no peso nos recém-nascidos nas mulheres heterozigotas ou homozigotas.

\subsection{Proteína lectina ligante de manose (MBL)}

A proteína lectina ligante de manose ( $M B L)$, também chamada de proteína ligante de manose ou lectina-1, é uma proteína sérica sintetizada no fígado e subseqüentemente liberada na circulação sangüínea imune inata $^{154,155}$. Os ligantes de MBL são oligossacarídeos ricos em manose, Nacetilglicosamina, $\mathrm{N}$-acetilmanosamina, fucose e glicose presentes em uma grande variedade de microrganismos, como bactérias ${ }^{156}$, fungos ${ }^{157}$ e parasitos tais como, Leishmania spp ${ }^{158,159}$, Schistosoma mansoni ${ }^{160} \mathrm{e}$ Trypanosoma cruzi ${ }^{161}$.

Após a ligação, a MBL ativa o sistema complemento via interação com serina-proteases MASP-1, -2, -3 (Mannose - associated serine protease) e a proteína não enzimática MAP19 (Mannose - associated protein) e destroem o parasito pela ação do complexo de ataque à membrana ou medeiam fagocitose pela deposição de fragmentos C3 (opsonização) e modulam a liberação de citocinas pró-inflamatórias. Com estes mecanismos, a MBL tem um importante papel na resposta imune inata ${ }^{162}$. A ativação do sistema complemento via MBL-MASP cliva especificamente C4 e C2 gerando C3 convertase $^{163}$. 
A MBL humana é codificada apenas por um gene (MBL2) no cromossomo $10^{164,165}$. O gene $M B L 2$ contêm 4 exons: exon 1 codifica a região rica em cisteína, parte da região rica em glicina e parte da região semelhante ao colágeno. $\mathrm{O}$ exon 2 codifica o restante da região semelhante ao colágeno. O exon 3 codifica a região neck e o exon 4 codifica o domínio de reconhecimento do carboidrato (CRD) ${ }^{164,165}$.

A MBL é um complexo de estruturas de hélices triplas e cada cadeia polipeptídica contém quatro domínios: (1) uma região $\mathrm{N}$-terminal rica em cisteínas, de 21 aminoácidos, envolvida na oligomerização pela formação de pontes dissulfídicas intra e inter-subunidade, (2) um domínio semelhante a colágeno, de 59 aminoácidos, consistindo de 20 repetições de glicina-XaaYaa (X corresponde ao aminoácido prolina e $\mathrm{Y}$ corresponde ao aminoácido hidroxilisina ou hidroxiprolina) (exceto 8 repetições que consistem de apenas Glicina-Glutamina) que corresponde à haste longa da molécula , (3) um domínio coil-coil neck hidrofóbico , helicoidal de 30 aminoácidos, crucial para a inicialização da oligomerização e (4) um domínio C-terminal de reconhecimento de manose de 188 aminácidos (Figura 3). MBL pode formar oligômeros de vários tamanhos. 


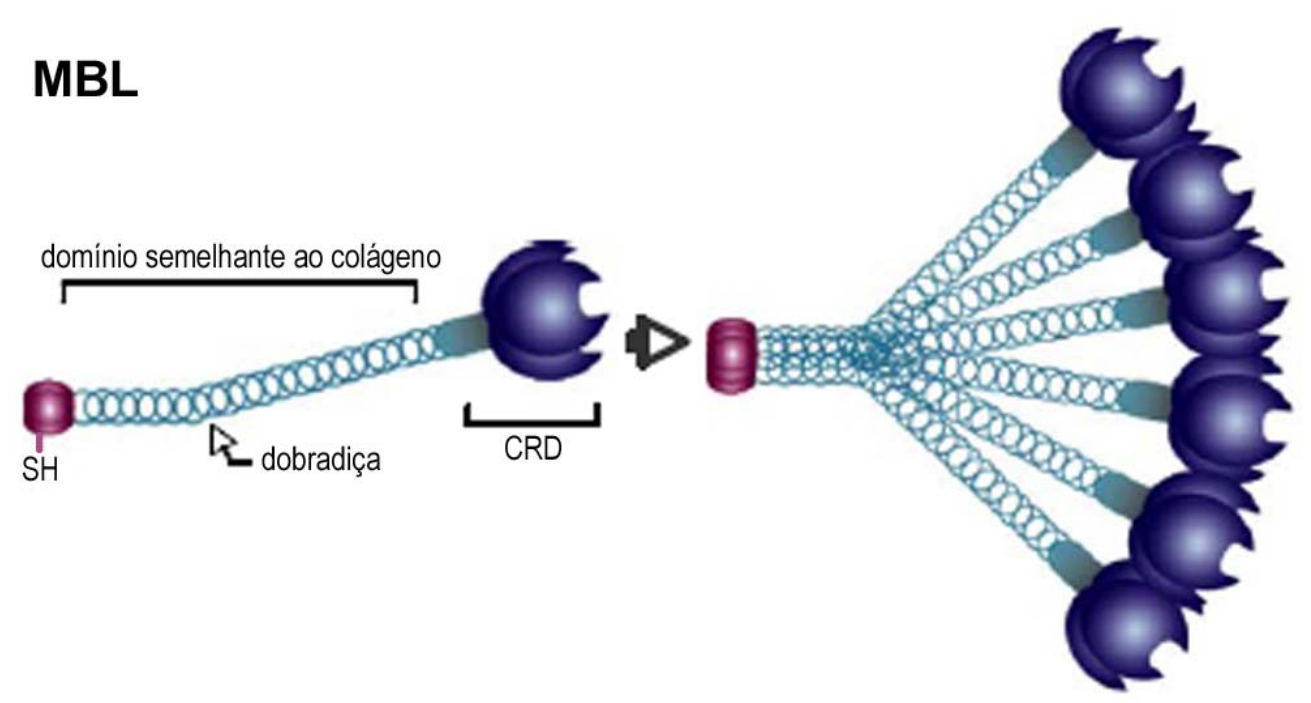

Figura 3. Estrutura oligomérica de MBL (Adaptado de Endo et al., 2006) ${ }^{166}$.

$\mathrm{Na}$ maioria das infecções a $\mathrm{MBL}$ tem um efeito positivo para $\mathrm{O}$ hospedeiro, enquanto contra alguns agentes infecciosos ela pode facilitar a entrada nas células do hospedeiro, como no caso de micobactérias ${ }^{167}$ e Leishmania chagasi ${ }^{168}$.

Garred et al. (2003) ${ }^{155}$ mostraram que a MBL funciona como uma opsonina para $P$. falciparum e o seu ligante putativo nas hemácias infectadas é a glicoproteína gpr78 de $P$. falciparum, homológa a proteína de estresse regulada por glicose de mamíferos. Esta proteína contém dois sítios potenciais para ligação de carboidratos $\mathrm{N}$-ligados compatíveis com sua interação com $\mathrm{MBL}^{169}$. É expressa durante o estágio eritrocítico tanto nos estágios sexuados como assexuados. A expressão aumenta em resposta a choque térmico e é diminuída após privação de glicose in vitro ${ }^{170}$. 
Existem três diferentes polimorfismos no gene da MBL no exon 1 que levam a baixos níveis de MBL: a). no códon 54 (Gly $\rightarrow$ Asp - alelo B), b). no códon $57\left(\right.$ Gly $\rightarrow$ Glu - alelo C) e c). no códon $52(\text { Arg } \rightarrow \text { Cys - alelo D })^{162,171-}$ 173. O alelo tipo selvagem é designado A e as três variantes alélicas são designadas $\mathbf{O}$. Existem outros polimorfismos localizados na região promotora localizados nas posições -550 (variante H/L) e -221 (variante X/Y) (substituição $G \rightarrow C$ ). E outro sítio polimórfico está localizado na posição +4(variante $P / Q)$ (figura 4).

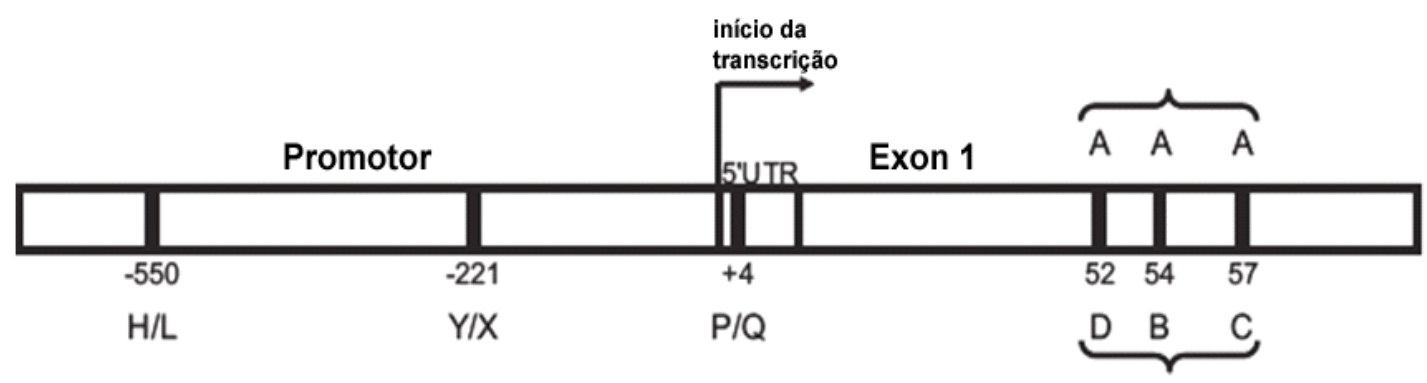

Figura 4. Organização da região promotora e do exon 1 do gene MBL2 (Adaptado de Bouwman et al., 2006) ${ }^{174}$.

Polimorfismos no exon 1 de MBL danificam a formação da hélice tripla ou a oligomerização e interferindo na atividade funcional. Polimorfismos na região promotora estão associados aos níveis séricos de MBL.

Aproximadamente $96 \%$ da variação dos níveis plasmáticos da $\mathrm{MBL}$ podem ser explicados pelos polimorfismos genéticos ${ }^{175}$. Sete haplótipos 
foram definidos pela ocorrência destes polimorfismos entre diferentes grupos étnicos: HYPA, LYQA, LYPA, LXPA, LYPB, LYOC, HYPD. Os haplótipos HYPA e LYQA são altos produtores de MBL sérica, o haplótipo LYPA é um produtor intermediário de MBL e o haplótipo LXPA é definido como baixo produtor de MBL. Os haplótipos LYPB, LYOC, HYPD são considerados deficientes na produção de $M B L^{176,177}$.

$\mathrm{Na}$ tabela 5 sumarizamos alguns estudos da literatura sobre a influência de polimorfismos do gene de MBL na malária. Apesar de contraditórios, a maior parte dos estudos observou alguma associação de polimorfismos da MBL com a evolução clínica da malária. 
Tabela 5. Estudos da literatura sobre a influência de polimorfismos do gene 2 da lectina ligante à manose (MBL) na malária.

\begin{tabular}{|c|c|}
\hline ESTUDO & RESULTADOS \\
\hline $\begin{array}{l}\text { Comparação dos níveis plasmáticos de } \mathrm{MBL} \text { e } \\
\text { da freqüência dos polimorfismos do exon } 1 \text { da } \\
\mathrm{MBL} \text { em crianças com malária grave e } \\
\text { crianças com malária não complicada do } \\
\text { Gabão }{ }^{91} \text {. }\end{array}$ & $\begin{array}{l}\text { - Níveis mais baixos de MBL em crianças com } \\
\text { malária grave do que em crianças com malária } \\
\text { não complicada } \\
\text { - Fraca associação das mutações nos códons } \\
54 \text { e } 57 \text { com malária grave }\end{array}$ \\
\hline $\begin{array}{l}\text { Estudo retrospectivo dos genótipos do exon } 1 \\
\text { da MBL em } 2041 \text { pacientes com malária } \\
\text { (crianças com malária cerebral e/ou anemia } \\
\text { grave, com malária não complicada, com } \\
\text { tuberculose e carreadores persistentes do } \\
\text { vírus da hepatite B no Gâmbia }{ }^{178} \text {. }\end{array}$ & $\begin{array}{l}\text { - } 45 \% \text { dos pacientes carregavam um alelo } \\
\text { variante (códons } 57 \text { ou } 54 \text { ) e } 8,6 \% \text { carregavam } \\
\text { dois alelos variantes (códons } 54 \text { e } 57 \text { ) } \\
\text { - Não foi observada associação de deficiência } \\
\text { de MBL com malária }\end{array}$ \\
\hline $\begin{array}{l}\text { Investigação do exon } 1 \text { e região promotora do } \\
\text { gene MBL e dos níveis séricos de MBL de } 35 \\
\text { indivíduos da Papua Nova Guiné infectados } \\
\text { por } P \text {. falciparum (malária não complicada e } \\
\text { assintomática) }{ }^{154} \text {. }\end{array}$ & $\begin{array}{l}\text { - Variante do códon } 54 \text { foi encontrado em } 3 \% \text { da } \\
\text { população } \\
\text { - Dois novos polimorfismos foram encontrados: } \\
\text { posição }+1(R / S) \text { e }-4(T / U) \text {. } \\
\text { - Níveis séricos de MBL da população com } \\
\text { malária maiores dos que os da população } \\
\text { saudável }\end{array}$ \\
\hline $\begin{array}{l}\text { Investigação de polimorf } \\
\text { crianças de Gana com } \\
\text { anemia grave, com mal } \\
\text { não infectadas e da po } \\
\text { como opsonina para } P . f\end{array}$ & $\begin{array}{l}\text { - Crianças com malária complicada homozigotas } \\
\text { para alelos variantes da MBL apresentaram } \\
\text { parasitemias mais altas e níveis de glicose mais } \\
\text { baixos do que as crianças heterozigotas ou } \\
\text { homozigotas para o alelo selvagem } \\
\text { - Freqüência dos alelos variantes não diferiu } \\
\text { entre crianças infectadas e não infectadas ou } \\
\text { entre crianças com malária cerebral e/ou } \\
\text { anemia grave e com malária não complicada } \\
\text { - Foi caracterizada a proteína gpr78 de } \\
\text { P.falciparum como o ligante de MBL }\end{array}$ \\
\hline $\begin{array}{l}\text { Investigação da potencial relação entre } \\
\text { polimorfismos genéticos da glicose-6-fosfato } \\
\text { desidrogenase (G6PD), MBL, TNF- } \alpha \text { e óxido } \\
\text { nítrico sintase e a prevalência de infecções } \\
\text { assintomáticas por } P \text {. falciparum em } 158 \\
\text { crianças escolares do Gabão }{ }^{86} \text {. }\end{array}$ & $\begin{array}{l}\text { - Meninas heterozigotas para G6PD A- tinham } \\
\text { baixa prevalência de malaria assintomática } \\
(38,9 \% \times 67,3 \% ; P=0,03) \text {. } \\
\text { - Crianças heterozigotas para TNF } \alpha^{-238} \\
\text { carregavam parasitos com alta diversidade } \\
\text { genética } \\
\text { - Nenhuma associação entre polimorfismos de } \\
\text { MBL, TNF } \alpha^{-308, ~ o u ~ N O S 2 ~ e ~ m a l a ́ r i a ~} \\
\text { assintomática }\end{array}$ \\
\hline $\begin{array}{l}\text { Seqüenciamento da região promotora e do } \\
\text { exon } 1 \text { do gene da MBL de crianças do Gabão } \\
\text { ( } 136 \text { com malária não complicada, } 131 \text { com } \\
\text { malária grave e } 39 \text { crianças saudáveis) e } \\
\text { correlação dos resultados com os níveis } \\
\text { séricos de } \mathrm{MBL}^{175} \text {. }\end{array}$ & $\begin{array}{l}\text { - Foram identificados } 14 \text { novos haplótipos } \\
\text { alélicos de MBL2 } \\
\text { - Foi observada associação da nova variante } \\
\text { g.797C>A com suscetibilidade à malária grave } \\
(P=0,010) \\
\text { - Maiores níveis plasmáticos de MBL e os } \\
\text { genótipos de MBL2 correspondentes foram } \\
\text { associados com concentração mais baixa de } \\
\text { diversas citocinas e quimiocinas no plasma de } \\
\text { pacientes com malária }\end{array}$ \\
\hline $\begin{array}{l}\text { Estudo caso-controle em } 870 \text { crianças ( } 290 \\
\text { com malária grave, } 290 \text { assintomáticas e } 290 \\
\text { crianças saudáveis) na influência de } \\
\text { polimorfismos de MBL2 }{ }^{179} \text {. }\end{array}$ & $\begin{array}{l}\text { - Crianças heterozigotas para } M B L 2^{*} C \\
\text { associaram com malária grave e anemia }\end{array}$ \\
\hline
\end{tabular}




\subsection{RECEPTOR DO COMPLEMENTO 1 (CR-1) (CD35)}

CR-1 é uma glicoproteína de aproximadamente 200 kDa expressa por todas células do sangue periférico exceto plaquetas, células NK e linfócitos T ${ }^{180,181}$.Nos tecidos, é expressa por células dendríticas foliculares, linfócitos B, podócitos glomerulares e alguns astrócitos ${ }^{182}$.

O domínio extracelular de CR-1 é composto de 30 consensos curtos repetitivos de proteínas de controle do complemento (complement-controlprotein repeats - CCP) (figura 5). Cada CCP é composto de aproximadamente 60 aminoácidos com quatro cisteínas invariantes. Os 28 CCPs N-terminais podem ser organizados, baseados em um grau de homologia, em quatro regiões longas homólogas (Iong homologous repeats LHRs) A-D, cada uma composta de sete $\mathrm{CCPs}^{183}$.

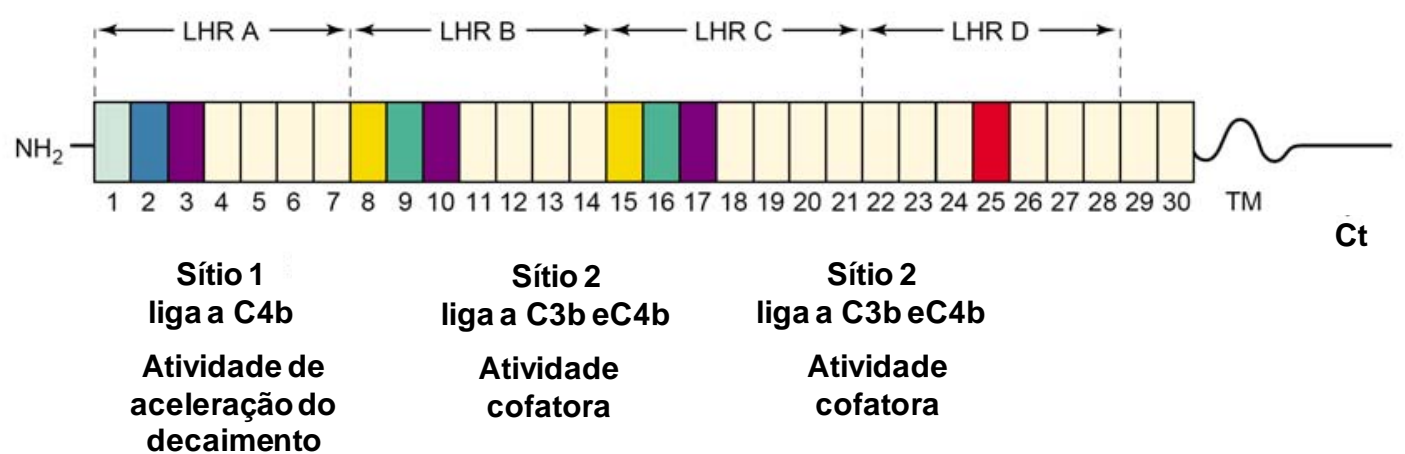

Figura 5. Representação esquemática do gene de CR-1. Cada caixa representa um CCP (complement-control-protein repeats). Sítios 1 e 2 indicados. A identidade entre os sítios é caracterizada pelas cores das caixas (ex. CCP 3,10 e 17 diferem apenas por um aminoácido). Ct: cauda citoplasmática; NH2 região amino terminal; LHR (long homologous repeats); TM domínio transmembrânico (Adaptado de Krych-Goldberg et al., 2002) ${ }^{184}$. 
Existem dois sítios que interagem com C3b e C4b. O sítio 1 que abrange os CCPs 1-3 no LHR A e se liga a C4b e fracamente a C $3 b^{185}$. O sítio 2 abrange os CCPs 8-10 no LHR B e os CCPs 15-17 no LHR C e se liga eficientemente tanto a $\mathrm{C} 3 \mathrm{~b}$ como $\mathrm{C} 4 \mathrm{~b}$, embora com maior afinidade para C $3 b^{186-188}$. Variações na $N$-glicosilação levam a pequenas variações de tamanho do CR1 em humanos ${ }^{182}$.

A habilidade de CR1 de se ligar a imunocomplexos opsonizados por C3b/C4b lhe confere duas funções importantes: 1.) age como receptor de aderência imune ao se ligar aos imunocomplexos opsonizados carrega-os para o fígado e baço aonde são removidos ${ }^{189}$ 2.) retém antígenos opsonizados necessários para manutenção da memória imunológica em DCs foliculares nos centros germinativos ${ }^{182}$. Independente da sua capacidade de ligação a ligantes, CR1 tem 1.) atividade de aceleração do decaimento de C3-convertases (conferida pelo sítio 1) ${ }^{190}$ e C5-convertase (conferida pelo sítio 2$)^{190}$ o que deve regular o tamanho dos complexos imunes e prevenir ativação excessiva do sistema complemento e 2.) atividade cofatora para a limitação da clivagem de C3b e C4b por serina proteases do plasma, produzindo assim substratos para outros receptores de complemento ${ }^{182,186}$. CR1 também se liga a C1q e MBL via região LHR D e estes contribuem para aderência imune mediada por CR-1 ${ }^{191,192}$.

CR1 é uma das moléculas consideradas importantes na patogênese da malária grave. A ligação de CR1 (sítios 1 e/ou 2) ${ }^{193}$ de eritrócitos não infectados aos eritrócitos infectados, especificamente à proteína 1 da membrana de eritrócito infectado por $P$. falciparum ( $P$. falciparum erythrocyte 
membrane protein 1 -PfEMP1) ${ }^{194-196}$. Quanto maior o número de moléculas de CR1 por eritrócito, maior a tendência de formar rosetas ${ }^{196}$. Este fenômeno favorece a aderência de eritrócitos em microvasos do órgão afetado e diminui o fluxo sangüíneo, contribuindo para a patogênese da malária cerebral.

A formação de rosetas é um fenômeno descrito apenas in vitro e os dados sobre a participação de rosetas na malária cerebral são contraditórios $^{197-201}$. A observação que esquizontes de $P$. vivax, um parasita que normalmente não está associado com malária grave, também levanta questões sobre a importância da roseta na patogênese da malária grave por P. falciparum ${ }^{202}$.

\subsubsection{POLIMORFISMOS DE CR1}

A proteína CR-1 apresenta três tipos de polimorfismos genéticos: 1.) variações no tamanho causadas por duplicações e deleções de LHR; 2.) variações na expressão de CR-1 nas hemácias e 3.) grupo sangüíneo $K_{n o p s}{ }^{203}$.

Devido às variações de tamanho, quatro formas alélicas de CR1 foram caracterizadas, contendo de 2 a 6 LHRs. CR1*1 (também conhecido como tipo A ou F) contém quatro LHRs e é o alelo mais comum (82\%) na maioria das populações estudadas.

As variações da expressão de CR1 em hemácias em caucasianos, mas não em africanos, são geneticamente determinados e estão associadas com pelo menos três polimorfismos no gene de CR-1: exon 22 (A3650G), intron 
27 (T520C) e exon 33 (C5507G) ${ }^{204}$. Esses polimorfismos correspondem a haplótipos codominantes de alta e baixa expressão de CR-1 nos eritrócitos, mas não em outros tipos de células, tais como células $B$ e macrófagos ${ }^{181}$. Homozigotos para o alelo L (baixa expressão) expressam menos do que 200 cópias de CR1, homozigotos para o alelo H (alta expressão) expressam diversas vezes este número e os heterozigotos são intermediários ${ }^{204-206}$.

O terceiro tipo de polimorfismo representado pelo sistema sanguíneo Knops inclui os alelos Knops a e b (Kna, Knb), McCoy a e b (McCa e McCb) e Swain-Langley (S/a) e Villien (Vil) 207,208 .

Os fenótipos correspondentes para o primeiro par são $M c C(a+)$ e $M c C(b+)$, e para o segundo par são $S /(a+)$ e $S /(a-)$. Dois fenótipos neste grupo, $M c C\left(b^{+}\right)$e $S /(a-)$ são muito mais freqüentes em populações africanas que são expostas à malária do que em caucasianos, sugerindo que estas duas variantes ajudem na sobrevivência em regiões de malária ${ }^{209}$.

No tabela 6 sumarizamos alguns estudos da literatura sobre a influência de polimorfismos de CR1 na malária. Apesar de contraditórios, a maior parte dos estudos observou alguma associação de polimorfismos da CR1 com a evolução clínica da malária. 
Tabela 6. Estudos da literatura sobre a influência de polimorfismos da molécula CR1.

\begin{tabular}{|c|c|}
\hline ESTUDO & RESULTADOS \\
\hline $\begin{array}{l}\text { Investigação da relação do polimorfismo } L / H \\
\text { HindIII-RFLP em } 1200 \text { crianças com formas } \\
\text { graves de malária cerebral e anemia no } \\
\text { Gambia Polimorfismos de ICAM-1, CR-1 e } \\
\text { IL-1RA }{ }^{210} \text {. }\end{array}$ & $\begin{array}{l}\text { Polimorfismo } L / H \text { HindIII-RFLP } L / H \text { HindIII- } \\
R F L P \text { não foi associado a doença grave. }\end{array}$ \\
\hline $\begin{array}{l}\text { Investigação da relação entre polimorfismo } \\
L / H \text { HindIII-RFLP de CR1 de severidade da } \\
\text { malária em } 185 \text { pacientes com malária } \\
\text { falciparum aguda ( } 55 \text { graves e } 130 \text { não } \\
\text { complicada) e determinaram os níveis de } \\
\text { CR1 nos eritrócitos }^{94} \text {. }\end{array}$ & $\begin{array}{l}\text { Observaram maior freqüência do alelo LL } \\
\text { (baixa expressão de CR1) no grupo de malaria } \\
\text { grave }(P=0,005) \text {. Expressão de CR1 em } \\
\text { pacientes LL foi menor do HH }(P=0,0001) \text { e } \\
\text { heterozigotos }(\mathrm{HL})(P=0,013) \text {. }\end{array}$ \\
\hline $\begin{array}{l}\text { Investigação da relação da quantidade de } \\
\text { CR1 nos eritrócitos com os alelos } L \text { e } H \\
\text { (HindIIII } R F L P \text { ) em população de Mali, Oeste } \\
\text { da África }{ }^{211} \text {. }\end{array}$ & $\begin{array}{l}\text { O nível de expressão de CR1 nos eritrócitos } \\
\text { não se correlacionou com os alelos } \mathrm{H} \text { e L. }\end{array}$ \\
\hline $\begin{array}{l}\text { Investigação da relação dos polimorfismos } \\
\text { de Knops SI1/SI2 e McCa/McCb de CR1 e } \\
\text { malária grave em crianças do Gâmbia, } \\
\text { Oeste da África }{ }^{212} \text {. }\end{array}$ & $\begin{array}{l}\text { Observaram altas freqüências dos alelos } S / 2 \text { e } \\
M c C b \text { distribuídas igualmente entre crianças } \\
\text { com malaria grave e crianças controles não } \\
\text { infectadas. Sugerem que o alelo SI2/McCb } \\
\text { surgiu como resultado de seleção positiva } \\
\text { contra doenças infecciosas e não apenas } \\
\text { malária. }\end{array}$ \\
\hline
\end{tabular}

Investigação dos níveis de expressão de CR1 em eritrócitos de 91 indivíduos saudáveis da Papua Nova Guiné, África e da relação dos polimorfismos do exon 22 (A3650G), do intron 27(T520C) (HindIII RFLP) e do exon 33 (C5507G) do gene de CR1 com a expressão de CR1 $1^{213}$.

Investigação da relação dos alelos $S / L$ e $\mathrm{McCa} / \mathrm{McCb}$ com malária grave (cerebral e anemia) em crianças do Quênia ${ }^{214}$.

Investigação da relação de novos polimorfismos de CR1, nas regiões -873 e 159, em três regiões diferentes (Papua Nova Guiné, Mali e Edinburgo - Reino Unido) com os níveis de expressão de CR1 nos eritrócitos ${ }^{215}$.

Investigação da relação do polimorfismo do intron 27 (HindIII RFLP) de CR1 em 555 crianças assintomáticas de Papua Nova Guiné, com parasitemia e anticorpos antiObservaram deficiência de CR1 nos eritrócitos de mais de $80 \%$ dos indivíduos. Esta deficiência foi associada com o polimorfismo do exon 22 (A3650G) e com a-talassemia. VSA $^{216}$.

Encontraram associação dos alelos S/2/2 e em particular do genótipo S/2/2 McCa/b com proteção de malária cerebral, mas não de anemia grave.

Na Papua Nova Guiné e Mali não foi observada nenhuma correlação nos níveis CR-1 e o polimorfismo -873. Em Edinburgo foi observada uma correlação entre os polimorfismos -873 e -159 e os níveis de CR-1 $(P<0,05)$.

Não observaram nenhuma associação do polimorfismo estudado com parasitemia ou anticorpos anti-VSA (Variant surface antigens). 
JUSTIFICATIVA 
Doenças infecciosas representam os principais problemas de saúde pública no mundo, tanto em termos de morbidade como de mortalidade. Uma combinação complexa de fatores ambientais, do patógeno e do hospedeiro participa na determinação tanto da suscetibilidade aos microrganismos como na evolução da infecção.

Genes relevantes de agentes infecciosos, incluindo bactérias, parasitos e vírus têm sido mapeados e identificados a partir de estudos baseados em população e em famílias. Estudos destes genes ajudam a definir o papel da genética do hospedeiro e sugerem que a suscetibilidade do hospedeiro para a maioria das doenças é altamente poligênica ${ }^{218}$.

Como a malária é uma das principais causas de morte na humanidade há muitos anos, estudos sobre suscetibilidade genética individual à malária são de grande interesse, que além de fornecerem importantes informações evolucionárias, também podem ter, em longo prazo, muitas aplicações práticas. Por exemplo, caso uma vacina para malária esteja sendo investigada em diferentes populações será muito importante saber se uma determinada população apresenta alta freqüência de algum polimorfismo genético que confira mais de $60 \%$ de proteção contra as complicações mais graves da doença, principalmente se o objetivo da vacina for atenuação dos sintomas, mais do que proteção.

Não existem no Brasil muitos estudos de associação de diferentes genes humanos com a suscetibilidade à malária. Nosso estudo propõe a investigação da prevalência de polimorfismos de genes conhecidamente 
importantes na evolução da malária em população naturalmente exposta à doença e a associação destes polimorfismos com a presença ou não de manifestações clínicas e com os níveis de parasitemia.

O impacto destes conhecimentos no controle da malária será considerável, tanto para se identificar alvos de novas terapias como melhorar as estratégias de vacinação e eventualmente a erradicação da doença. Muitos dos polimorfismos a serem estudados são relevantes a múltiplos patógenos e já existem dados que mostram que o papel imunomodulatório de certos polimorfismos se estende a outras doenças. Esperamos que as informações obtidas possam no futuro, agregadas a de outros estudos, ajudar a definir para cada indivíduo um padrão de risco personalizado capaz de prever a suscetibilidade deste indivíduo a vários organismos infecciosos. 
OBJETIVOS 


\section{OBJETIVOS:}

OBJETIVO GERAL: Investigar a influência de polimorfismos genéticos do hospedeiro na suscetibilidade à malária de populações naturalmente expostas da Amazônia Brasileira.

\section{OBJETIVOS ESPECÍFICOS:}

1. Investigar a ocorrência dos seguintes polimorfismos genéticos em indivíduos infectados por plasmódios, residentes em áreas endêmicas de malária:

- Receptores Toll-like (TLR): TLR-1, TLR-4, TLR-6 e TLR-9

- Proteína adaptadora TIRAP(MAL)

- Proteína lectina ligante da manose (MBL)

- Receptor CR1 do complemento (CR-1)

2. Investigar a associação destes polimorfismos com a presença ou não de manifestações clínicas de malária e com os níveis de parasitemia. 
MÉTODOS 


\section{INDIVÍDUOS DA PESQUISA}

\subsection{CARACTERÍSTICAS E PROCEDÊNCIA DA POPULAÇÃo}

Foram estudadas amostras de sangue colhidas de indivíduos residentes em diferentes áreas endêmicas de malária na Amazônia Brasileira e divididos nos seguintes grupos:

Malária sintomática (MS) - indivíduos com sintomas clínicos (febre, dores musculares, dor de cabeça, mal estar) causados pela infecção por $P$. falciparum e/ou P. vivax ou malária mista, confirmada pela gota espessa e por Nested-PCR $(\mathrm{n}=230)$.

- Malária assintomática (AS) - indivíduos com resultado de Nested-PCR positivo para $P$. falciparum elou $P$. vivax sem sintomas clínicos no momento da colheita do sangue e que permaneceram assintomáticos por até 60 dias $(n=74)$.

Estas amostras foram colhidas durante o desenvolvimento de projetos anteriores em malária e estão armazenadas no Laboratório de Malária do Instituto de Medicina Tropical de São Paulo (IMT/SP):

- Município de Peixoto de Azevedo, MT, 1995-1996. Responsável: Dra. Sandra L. Moraes-Avila (IMT/SP)

- Rio Negro, AM, 2005. Responsáveis: Dra. Martha C. Suárez-Mutis e Prof. Dr. José Rodrigues Coura (Laboratório de Doenças Parasitárias, Departamento de Medicina Tropical, Instituto Oswaldo Cruz, FIOCRUZ, Rio de Janeiro, RJ)

- Rio Machado, RO, 1998-1999. Responsáveis: Dra. Fabiana Alves e Prof. Dr. Erney Camargo 


\subsection{DADOS DA POPULAÇÃO}

Na tabela 7 apresentamos os dados demográficos (idade e sexo) e as espécies de Plasmodium detectadas pela gota espessa e/ou "Semi-Nested" PCR da população estudada $(n=304)$.

Tabela 7. Características demográficas e resultado das espécies de Plasmodium encontradas pela gota espessa e/ou "Semi-Nested" PCR.

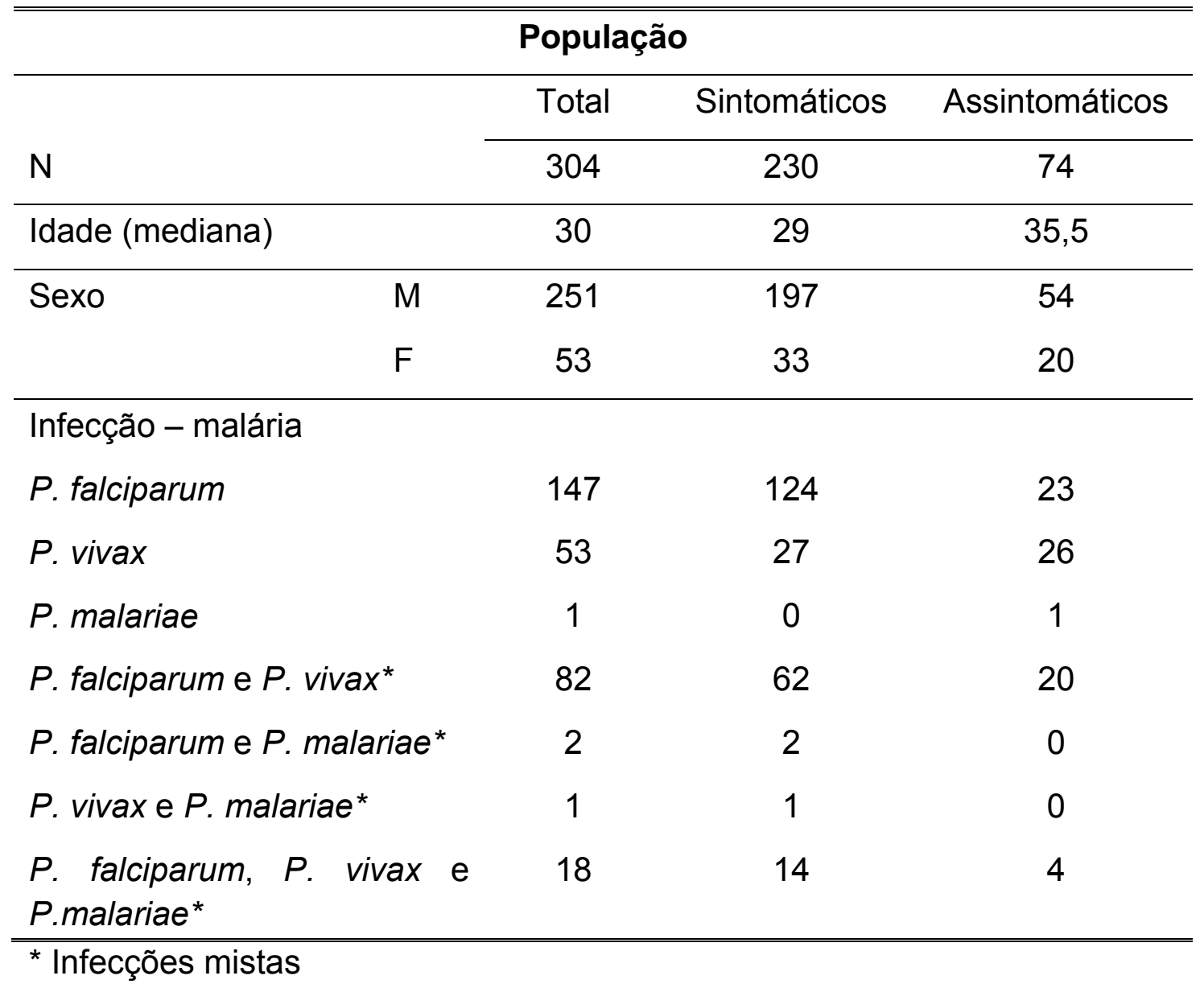

\subsection{AsPECtOS ÉTICOS DA PESQUISA}

O presente trabalho foi aprovado na Comissão de Ética para Análise de Projetos de Pesquisa (CAPPesq) do Hospital das Clínicas da Faculdade de Medicina da Universidade de São Paulo (HCFMUSP). Foram mantidos todos 
os cuidados necessários em relação aos aspectos éticos da conservação e utilização de material biológico estocado, ou seja, foi garantida a preservação rigorosa do anonimato dos indivíduos originariamente envolvidos. Não existe a possibilidade de contato com os indivíduos para obtenção de Termo de Consentimento Livre e Esclarecido (TCLE) para a utilização do material armazenado em nova pesquisa, como determinado pela Resolução n 347 da CONEP, de 13/01/2005.

\section{DETERMINAÇÃo dA PARASITEMIA}

A determinação da parasitemia foi realizada pela gota espessa e a "Semi-Nested" PCR.

\section{EXTRAÇÃo do DNA genÔMICO COM FENOL/CLOROFÓRMIO}

O DNA de cada amostra de sangue foi extraído segundo protocolo descrito por Snounou et al. $(1993)^{219}$ e modificado por Ferreira et al. $(1998)^{220}$. Duzentos microlitros de sangue total foram adicionados a $10 \mu \mathrm{L}$ de saponina (Sigma Chem Co) $1 \%$ e $1 \mathrm{~mL}$ de PBS estéril, e incubados a $37^{\circ} \mathrm{C}$ por 5 min, sendo posteriormente centrifugados a 2000 x g por 15 minutos. $O$ sobrenadante foi desprezado e o sedimento foi lavado com $1 \mathrm{~mL}$ de PBS estéril, centrifugado a 2000 × g por 15 minutos. Esta lavagem foi repetida por mais duas vezes. Após a última lavagem, ao sedimento foram adicionados $200 \mu \mathrm{L}$ de solução de lise [Tris-HCL 1 M pH 8.0, EDTA 500 mM pH 8.0, NaCl $2,5 \mathrm{M}$, SDS $10 \%$, proteinase $\mathrm{K}$ (Invitrogen) $20 \mathrm{mg} / \mathrm{mL}$, qsp $200 \mu \mathrm{L}$ de água 
estéril]. A mistura foi incubada a $56^{\circ} \mathrm{C}$ por 3 horas e em seguida, a proteinase $\mathrm{K}$ foi inativada a $95^{\circ} \mathrm{C}$ por 10 minutos.

Foram adicionados $250 \mu \mathrm{L}$ de fenol equilibrado (USB), misturando gentilmente por 10 minutos. Após centrifugação a 10000 x g por 5 minutos, a fase aquosa foi removida. Posteriormente $250 \mu \mathrm{L}$ de fenol/clorofórmio (1:1) foram adicionados à amostra, centrifugados a $10000 \times g$ por 5 minutos, e a fase aquosa foi novamente removida. Este procedimento foi repetido com $250 \mu \mathrm{L}$ de clorofórmio (Merck). Para precipitar o DNA, a fase aquosa foi retirada e colocada em um novo tubo contendo $25 \mu \mathrm{L}$ de acetato de sódio $3 \mathrm{M} \mathrm{pH} 5.2$ e $600 \mu \mathrm{L}$ de etanol (Merck) gelado (100\%) e incubado a $-20^{\circ} \mathrm{C}$ overnight.

Após incubação, o material foi centrifugado a 14.000 x g por 20 minutos a $4^{\circ} \mathrm{C}$. O sobrenadante foi removido e o sedimento de DNA lavado com 600 $\mu \mathrm{L}$ de etanol $80 \%$ e novamente centrifugado como descrito acima. $\mathrm{O}$ sobrenadante foi descartado e o sedimento foi seco à temperatura ambiente e ressuspenso em $100 \mu \mathrm{L}$ de água estéril. 
4. "Semi-Nested" PCR para a detecçÃo de plasmódios (Kimura et AL. , 1997) 221

\section{1. "PRIMERS"}

“Primer" P1 (5'-ACGATCAGATACCGTCGTAATCTT-3') e o "primer" P2 (5'-GAACCCAAAGACTTTGATTTCTCAT-3') de seqüências do gene SSUrRNA (18S do rRNA) de Plasmodium (gênero-específica).

"Primers" espécie-específicos:

* P. falciparum (F2, 5' - CAATCTAAAAGTCACCTCGAAAGATG -3')

* P. malariae (M1, 5' -GGAAGCTATCTAAAAGAAACACTATAT -3')

* P. vivax (V1, 5' - CAATCTAAGAATAAACTCCGAAGAGAAA - 3')

\subsection{REAÇÃO DA PCR (SNPCR-K)}

Cinco microlitros de DNA foram adicionados à mistura de PCR contendo 0,4 $\mu \mathrm{M}$ de cada "primer" P1e P2, dNTP (Fermentas) $125 \mu \mathrm{M}$, tampão de PCR (Fermentas) 1x e 0,75U de Taq Polimerase (Fermentas). O volume foi completado para $20 \mu \mathrm{L}$ com água destilada estéril. Após uma denaturação inicial a $92^{\circ} \mathrm{C}$ por $2 \mathrm{~min}, 35$ ciclos de $\mathrm{PCR}\left(92^{\circ} \mathrm{C}\right.$ por $30 \mathrm{seg}, 60^{\circ} \mathrm{C}$ por 90 seg) e uma extensão final a $60^{\circ} \mathrm{C}$ por 5 min. O produto da PCR foi diluído em tampão TE 50x (Tris- HCl 10mM, EDTA 1mM, pH 8.0). Uma alíquota de $2 \mu \mathrm{L}$ do produto diluído foi adicionado à mistura da snPCR-K, que contém 0,4 $\mu \mathrm{M}$ do "primer" $\mathrm{P} 1$ e 0,4 $\mu \mathrm{M}$ de cada "primer" espécie-específico, 312,5 $\mu \mathrm{M}$ de cada dNTP e tampão de PCR 1,25x. A Taq polimerase foi diluída a 0,75 unidades em $10 \mu \mathrm{L}$ de tampão de PCR 1x. Após uma denaturação 
inicial a $92^{\circ} \mathrm{C}$ por $2 \mathrm{~min}$, foram realizados 18 ciclos $\left(92^{\circ} \mathrm{C}\right.$ por $30 \mathrm{seg}, 60^{\circ} \mathrm{C}$ por $1 \mathrm{~min}$ ) e uma extensão final a $60^{\circ} \mathrm{C}$ por $5 \mathrm{~min}$. Cinco microlitros do produto da snPCR-K foi separado por eletroforese em gel de agarose $2 \%$, e o fragmento amplificado com aproximadamente 110 pares de base (bp) foi visualizado em luz UV representando sinais positivos.

\subsection{ELETROFORESE EM GEL DE AGAROSE}

Foi utilizado agarose 2\% (Invitrogen) dissolvida em tampão de corrida TAE 1x (Tris acetato $40 \mathrm{mM}$, EDTA $2 \mathrm{mM}$ ) e solubilizada por aquecimento. $\mathrm{O}$ padrão de peso molecular utilizado foi o 100bp DNA Ladder (Fermentas). A todas as amostras foi adicionado tampão de amostra de DNA ( $0,5 \%$ de azul de bromofenol,0,5 de xileno cianol, 100 mM EDTA e 50\% glicerol). Após a corrida, o gel foi corado com brometo de etídio $(0,5 \mu \mathrm{g} / \mathrm{mL})$ durante 15 minutos ao abrigo de luz. O padrão de bandas obtido foi analisado em transluminador sob fonte de luz UV e fotografado em sistema de imagem (Alphalmager-Alpha Innotech). 


\section{GeNOTIPAGEM DOS POLIMORFISMOS}

Todos os polimorfismos estudados são do tipo SNP (Single Nucleotide Polymorphism) e foram identificados pelo método de PCR-RFLP (Polymerase chain reaction - restriction fragment lenght polymorphism). Esse método baseia-se na realização de uma reação de PCR da seqüência genômica com "primer" específico (tabela 8) para cada região polimórfica e em seguida utiliza-se uma enzima de restrição específica para a detecção de cada variante alélica.

$\mathrm{Na}$ tabela 9 sumarizamos as condições da PCR para cada gene estudado. Na tabela 10 apresentamos as condições de amplificação com sua respectiva enzima de restrição.

Foram processados os seguintes polimorfismos: TLR-1(I602S), TLR4(Asp299Gly), TLR-6 (S602P), TLR-9 (-1237, -1486), TIRAP (S180L), MBL (códons 52, 54 e 57 do exon 1 e +4 e -221) e CR-1(C5507G). 
Tabela 8. Polimorfismos genéticos humanos estudados em população de áreas endêmicas de malária no Brasil.

\begin{tabular}{|c|c|c|}
\hline Molécula & Polimorfismos & Primer \\
\hline TIRAP & $\begin{array}{c}\text { L180S } \\
(\mathrm{rs} 8177374)^{*}\end{array}$ & $\begin{array}{l}\text { F :TGCTCATCACGCCGGGCTTCCTT } \\
\mathrm{R}: \text { TAGGCAGCTCTGCTGAGGTCC } \\
\end{array}$ \\
\hline TLR 1 & $\begin{array}{c}\text { lle602Ser } \\
\left(\mathrm{XM} \_001129777\right)^{*}\end{array}$ & $\begin{array}{l}\text { F: GGAAAGTTATAGAGGAACCCT } \\
\text { R: CTTCACCCAGAAAGAATCGTGCC }\end{array}$ \\
\hline TLR 4 & $\begin{array}{c}\text { Códon } 299 \\
\left(\mathrm{NM} \_138554\right)^{*}\end{array}$ & $\begin{array}{l}\text { F: GATTAGCATACTACTTAGACTACCTCCATG } \\
\text { R: GATCAACTTCTGAAAAAGCATTCCCAC }\end{array}$ \\
\hline TLR6 & $\begin{array}{c}\text { S249P } \\
\left(\mathrm{NM} \_006068\right)\end{array}$ & $\begin{array}{l}\text { F: GCATTTCCAAGTCGTTTCTATGT } \\
\text { R: GCAAAAACCCTTCACCTTGTT }\end{array}$ \\
\hline TLR9 & $\begin{array}{l}-1237 \mathrm{~T} \rightarrow \mathrm{C} \\
(\mathrm{AC} 097637)\end{array}$ & $\begin{array}{l}\text { F: CTGCTTGCAGTTGACTGTGT } \\
\text { R: ATGGGAGCAGAGACATAATGGA }\end{array}$ \\
\hline TLR9 & $\begin{array}{l}-1486 \mathrm{~T} \rightarrow \mathrm{C} \\
(\mathrm{AC} 097637)\end{array}$ & $\begin{array}{l}\text { F: TATCGTCTTATTCCCCTGCTGGAATGT } \\
\text { R: TGCCCAGAGCTGACTGCTGG }\end{array}$ \\
\hline $\begin{array}{c}\mathrm{MBL} \\
(\text { Exon 1) } \\
\end{array}$ & $\begin{array}{c}\text { Códon 52, 54, } 57 \\
(\mathrm{DQ} 217939)^{*}\end{array}$ & $\begin{array}{l}\text { F: ATCAACGGCTTCCCAGGCAAAGATGCG } \\
\text { R: CAGGCAGTTTCCTCTGGAAGG } \\
\end{array}$ \\
\hline MBL-221 & $\begin{array}{l}X \rightarrow Y(G \rightarrow C) \\
(D Q 217939)^{*}\end{array}$ & $\begin{array}{l}\text { F: GTTTCCACTCATTCTCATTCCCTAAG } \\
\text { R:CTCAGTTAATGAACACATATTTATC }\end{array}$ \\
\hline $\mathrm{MBL}+4$ & $\begin{array}{l}P \rightarrow Q(C \rightarrow T) \\
(D Q 217939)^{*}\end{array}$ & $\begin{array}{l}\text { F: GTTTCCACTCATTCTCATTCCCTAAG } \\
\text { R:CTCAGTTAATGAACACATATTTATC }\end{array}$ \\
\hline CR-1 & $\begin{array}{c}\text { C5507G } \\
(\text { rs 3811381)* }\end{array}$ & $\begin{array}{l}\text { F: AAGCGCACAGTCACAGGTCAC } \\
\text { R: GAACAGAAAGTTCACAGCGAGG }\end{array}$ \\
\hline
\end{tabular}

*Número de acesso no GeneBank

TLR: Toll like receptor; MBL: Mannose binding lectin; CR-1: Complement receptor-1

Tabela 9. Condições da PCR para cada gene estudado $\left(\mathrm{H}_{2} \mathrm{O}\right.$ qsp $\left.25 \mu \mathrm{L}\right)$.

\begin{tabular}{c|c|c|c|c|c|c}
\hline \hline Molécula & $\begin{array}{c}\text { DNA } \\
\text { genômico } \\
\mu \mathrm{L}\end{array}$ & $\begin{array}{c}\text { Primers [ }]^{*} \\
\mathbf{p m o l}\end{array}$ & $\begin{array}{c}\mathbf{M g C l}_{2}[]^{*} \\
\mathbf{m M}\end{array}$ & $\begin{array}{c}\text { dNTP } \\
(\mathbf{A}, \mathbf{C}, \mathbf{~ T ~ e ~ G ) ~} \\
{[]^{*} \mathbf{~ m M}}\end{array}$ & Tampão & $\begin{array}{c}\text { Taq } \\
\text { polimerase } \\
{[]^{*} \mathbf{~ U}}\end{array}$ \\
\hline $\begin{array}{c}\text { MBL códon 52, } \\
57,54\end{array}$ & $2-4$ & 0,25 & 1,5 & 1 & $1 \times$ & 1 \\
\hline MBL -221/+4 & $2-4$ & 0,25 & 2,5 & 1 & $1 \times$ & 1 \\
\hline $\begin{array}{c}\text { TLR1/ } \\
\text { TLR4/TIRAP }\end{array}$ & $2-4$ & 0,25 & 2 & 1 & $1 \times$ & 1 \\
\hline TNF $\alpha$ & $2-4$ & 0,25 & 2 & 1 & $1 \times$ & 2 \\
\hline TLR9/TLR6/CR-1 & $2-4$ & 0,25 & 1,5 & 1 & $1 \times$ & 1 \\
\hline \hline
\end{tabular}

${ }^{*}[$ ] concentração 
Tabela 10. Condições de amplificação da PCR e enzima de restrição para cada gene estudado. (wt: wild-type; mt: mutante;*localização no cromossomo)

\begin{tabular}{|c|c|c|c|c|}
\hline Molécula & Polimorfismos & $\begin{array}{l}\text { Condições de } \\
\text { amplificação }\end{array}$ & $\begin{array}{l}\text { Enzima de } \\
\text { Restrição }\end{array}$ & Fragmento (pb) \\
\hline $\begin{array}{c}\text { TIRAP } \\
\text { (cromossomo } 11_{11 \mathrm{q} 24.2)^{*}}\end{array}$ & L180S & $\begin{array}{c}95^{\circ} \mathrm{C} 5 \mathrm{~min} \\
35 \times 95^{\circ} \mathrm{C} 30 \mathrm{~s} \\
62^{\circ} \mathrm{C} 30 \mathrm{~s} \\
72^{\circ} \mathrm{C} 30 \mathrm{~s} \\
72^{\circ} \mathrm{C} 7 \mathrm{~min}\end{array}$ & Hру188I & $\begin{array}{c}\mathrm{wt} / \mathrm{wt}-107+20 \\
\mathrm{wt} / \mathrm{mt}-127+107+20 \\
\mathrm{mt}-127\end{array}$ \\
\hline $\begin{array}{c}\text { TLR1 } \\
\text { (cromossomo } 4 \\
4 p 14)^{*}\end{array}$ & $-1602 S$ & $\begin{array}{c}95^{\circ} \mathrm{C} 5 \mathrm{~min} \\
35 \times 95^{\circ} \mathrm{C} 30 \mathrm{~s} \\
55^{\circ} \mathrm{C} 30 \mathrm{~s} \\
72^{\circ} \mathrm{C} 30 \mathrm{~s} \\
72^{\circ} \mathrm{C} 7 \mathrm{~min}\end{array}$ & Alul & $\begin{array}{c}\mathrm{wt} / \mathrm{wt}-280 \\
\mathrm{wt} / \mathrm{mt}-280+151+129 \\
\mathrm{mt}-151+129\end{array}$ \\
\hline $\begin{array}{c}\text { TLR4 } \\
\text { (cromossomo } 9 \\
9 q 32 . q 33)^{*}\end{array}$ & Códon299 & $\begin{array}{c}95^{\circ} \mathrm{C} 5 \mathrm{~min} \\
35 \times 95^{\circ} \mathrm{C} 30 \mathrm{~s} \\
62^{\circ} \mathrm{C} 30 \mathrm{~s} \\
72^{\circ} \mathrm{C} 30 \mathrm{~s} \\
72^{\circ} \mathrm{C} 7 \mathrm{~min}\end{array}$ & Ncol & $\begin{array}{c}\mathrm{wt} / \mathrm{wt}-249 \\
\mathrm{wt} / \mathrm{mt}-249+223+26 \\
\mathrm{mt}-223+26\end{array}$ \\
\hline $\begin{array}{c}\text { TLR6 } \\
\text { (cromossomo } 4 \\
4 \mathrm{p} 14)^{*}\end{array}$ & S249P & $\begin{array}{c}95^{\circ} \mathrm{C} 5 \mathrm{~min} \\
35 \times 95^{\circ} \mathrm{C} 30 \mathrm{~s} \\
63^{\circ} \mathrm{C} 30 \mathrm{~s} \\
72^{\circ} \mathrm{C} 30 \mathrm{~s} \\
72^{\circ} \mathrm{C} 7 \mathrm{~min}\end{array}$ & Avall & $\begin{array}{c}\mathrm{wt} / \mathrm{wt}-160+50 \\
\mathrm{wt} / \mathrm{mt}-210+160+50 \\
\mathrm{mt}-210\end{array}$ \\
\hline $\begin{array}{c}\text { TLR9 } \\
\text { (cromossomo } 3 \\
\text { 3p21.3)* }\end{array}$ & $-\mathrm{T} 1237 \mathrm{C}$ & $\begin{array}{c}95^{\circ} \mathrm{C} 5 \mathrm{~min} \\
35 \times 95^{\circ} \mathrm{C} 30 \mathrm{~s} \\
59^{\circ} \mathrm{C} 30 \mathrm{~s} \\
72^{\circ} \mathrm{C} 30 \mathrm{~s} \\
72^{\circ} \mathrm{C} 7 \mathrm{~min}\end{array}$ & BsTNI & $\begin{array}{c}\mathrm{wt} / \mathrm{wt}-134 \\
\mathrm{wt} / \mathrm{mt}-134+108+26 \\
\mathrm{mt}-108+26\end{array}$ \\
\hline TLR9 & $-\mathrm{T} 1486 \mathrm{C}$ & $\begin{array}{c}95^{\circ} \mathrm{C} 5 \mathrm{~min} \\
35 \times 95^{\circ} \mathrm{C} 30 \mathrm{~s} \\
62^{\circ} \mathrm{C} 30 \mathrm{~s} \\
72^{\circ} \mathrm{C} 30 \mathrm{~s} \\
72^{\circ} \mathrm{C} 7 \mathrm{~min}\end{array}$ & AfIII & $\begin{array}{c}\mathrm{wt} / \mathrm{wt}-111+34 \\
\mathrm{wt} / \mathrm{mt}-145+111+34 \\
\mathrm{mt}-145\end{array}$ \\
\hline MBL & Códon 54 & $\begin{array}{c}95^{\circ} \mathrm{C} 5 \mathrm{~min} \\
35 \times 95^{\circ} \mathrm{C} 20 \mathrm{~s} \\
57^{\circ} \mathrm{C} 20 \mathrm{~s} \\
72^{\circ} \mathrm{C} 30 \mathrm{~s} \\
72^{\circ} \mathrm{C} 7 \mathrm{~min}\end{array}$ & Mboll, & $\begin{array}{c}\mathrm{wt} / \mathrm{wt}-62+56 \\
\mathrm{wt} / \mathrm{mt}-118++62+56 \\
\mathrm{mt}-118\end{array}$ \\
\hline MBL & Códon 57 & $\begin{array}{c}95^{\circ} \mathrm{C} 5 \mathrm{~min} \\
35 \times 95^{\circ} \mathrm{C} 20 \mathrm{~s} \\
57^{\circ} \mathrm{C} 20 \mathrm{~s} \\
72^{\circ} \mathrm{C} 30 \mathrm{~s} \\
72^{\circ} \mathrm{C} 7 \mathrm{~min}\end{array}$ & Hhal, & $\begin{array}{c}\text { wt } / w t-118 \\
\text { wt } / \mathrm{mt}-118+91+27 \\
\text { mt- } 91+27\end{array}$ \\
\hline MBL & -221 & $\begin{array}{c}95^{\circ} \mathrm{C} 5 \mathrm{~min} \\
35 \times 95^{\circ} \mathrm{C} 20 \mathrm{~s} \\
57^{\circ} \mathrm{C} 20 \mathrm{~s} \\
72^{\circ} \mathrm{C} 30 \mathrm{~s} \\
72^{\circ} \mathrm{C} 7 \mathrm{~min}\end{array}$ & BsaJl & $\begin{array}{c}\mathrm{wt} / \mathrm{wt}-243+89 \\
\mathrm{wt} / \mathrm{mt}-332+243+89 \\
\mathrm{mt}-332\end{array}$ \\
\hline MBL & +4 & $\begin{array}{c}95^{\circ} \mathrm{C} 5 \mathrm{~min} \\
35 \times 95^{\circ} \mathrm{C} 20 \mathrm{~s} \\
57^{\circ} \mathrm{C} 20 \mathrm{~s} \\
72^{\circ} \mathrm{C} 30 \mathrm{~s} \\
72^{\circ} \mathrm{C} 7 \mathrm{~min}\end{array}$ & $T a q^{a} I$ & $\begin{array}{c}\mathrm{wt} / \mathrm{wt}-306+26 \\
\mathrm{wt} / \mathrm{mt}-332+306+26 \\
\mathrm{mt}-332\end{array}$ \\
\hline $\begin{array}{c}\text { CR-1 } \\
\text { (cromossomo } 1 \\
1 \mathrm{q} 32)^{*}\end{array}$ & C5507G & $\begin{array}{c}95^{\circ} \mathrm{C} 5 \mathrm{~min} \\
35 \times 95^{\circ} \mathrm{C} 30 \mathrm{~s} \\
64^{\circ} \mathrm{C} 30 \mathrm{~s} \\
72^{\circ} \mathrm{C} 30 \mathrm{~s} \\
72^{\circ} \mathrm{C} 7 \mathrm{~min}\end{array}$ & HруCH4III & $\begin{array}{c}w t / w t-305 \\
w t / m t-305+251+54 \\
m t-251+54\end{array}$ \\
\hline
\end{tabular}




\subsection{ELETROFORESE EM GEL DE AGAROSE}

A detecção dos produtos de PCR em gel de agarose foi realizada conforme o item 4.3 (tabela 11)

\subsection{ELETROFORESE EM GEL DE POLIACRILAMIDA}

Foi utilizado acrilamida/bisacrilamida (29:1), TBE 1x (Tris borato 89 mM, EDTA 2mM), TEMED, perssulfato de amônio e água de milliQ qsp (tabela 11). O padrão de bandas obtido foi analisado em transluminador sob fonte de luz UV e fotografado em sistema de imagem (Alphalmager-Alpha Innotech).

Tabela 11. Gel utilizado para a eletroforese de cada gene estudado.

\begin{tabular}{c|c|c}
\hline \hline Molécula & Tipo de Gel & Concentração \\
\hline TIRAP & poliacrilamida & $3 \%$ \\
\hline TLR-1 & agarose & $4 \%$ \\
\hline TLR-4 & agarose & $3 \%$ \\
\hline TLR-6 & agarose & $10 \%$ \\
\hline TLR-9 -1237 & poliacrilamida & $3 \%$ \\
\hline TLR-9 -1486 & agarose & $4 \%$ \\
\hline MBL códon 52 & agarose & $15 \%$ \\
\hline MBL códon 54 & poliacrilamida & $4 \%$ \\
\hline MBL códon 57 & agarose & $3 \%$ \\
\hline MBL -221 & agarose & $8 \%$ \\
\hline MBL +4 & poliacrilamida & $3 \%$ \\
\hline CR-1 & agarose & \\
\hline \hline
\end{tabular}




\section{AnÁlise Estatística}

Todas as análises estatísticas e os dados descritivos foram realizados no Programa Sigma Stat (Jandel Scientific) e Prysma (GraphPad 4.0). As comparações entre as freqüências e proporções foram feitas pelo teste do Qui-quadrado $\left(\chi^{2}\right)$ ou pelo teste de Fisher (para pequenas casuísticas). Comparações entre dois grupos foram feitas pelo teste não paramétrico de Mann-Whitney e entre múltiplos grupos pelo teste de Kruskal Wallis. As probabilidades dos testes foram feitas para um nível de significância de 95\%. Equilíbrio de Hardy-Weinberg foi determinado pela comparação entre o número dos diferentes genótipos observados com genótipos esperados estimados pela freqüência alélica. Correção de Bonferroni foi aplicada para múltiplas variáveis analisadas. 
RESULTADOS 
1. POLIMORFISMOS DE RECEPTORES PADRÃO DE RECONHECIMENTO DA RESPOSTA IMUNE INATA

\subsection{Distribuição genotípica e ALÉlica de RECEPtores Toll-LiKE E DA MOLÉCULA ADAPTADORA TIRAP}

Foram analisados por PCR-RFLP os polimorfismos dos receptores TLR1 (I602S), TLR-4 (D299G), TLR-6 (P249S), TLR-9 (-T1237C e -C1486T) e da molécula adaptadora TIRAP (S180L) de 298, 304, 290, 290, 298 e 302 indivíduos infectados por Plasmodium, respectivamente com malária (resultados apresentados nas tabelas 12 a 17). Alguns genótipos não foram determinados devido à insuficiência de DNA. Todos os SNPs do grupo AS estavam em HWE enquanto no grupo MS observamos um desequilíbrio ligeiramente significante de TLR1 I602S e TIRAP S180L.

Quando os polimorfismos dos TLRs de todos os indivíduos foram analisados em relação à presença ou não de manifestações clínicas de malária, foram observadas diferenças significantes apenas para os polimorfismos de TLR-1 e TLR-6. A freqüência do genótipo lle/lle de TLR-1 foi maior no grupo AS do que no grupo MS $\left(\chi^{2}=8,251 ; P=0,016\right)$. Esta diferença foi ainda mais significante quando comparamos o genótipo lle/lle com os genótipos Ile/Ser e Ser/Ser agrupados $\left[\chi^{2}=9,521\right.$; $P(P C)=0,001(0,005) ; O R=2,6(1,4-4,9)]$. A freqüência do alelo lle foi maior no grupo AS em relação ao MS $\left[\chi^{2}=7,5 ; P(P C)=0,003(0,015) ; O R=2,2(1,2-3,8)\right]$. A freqüência do alelo variante $P$ de $T L R-6$ foi maior no grupo $A S\left[\chi^{2}=5,3\right.$; $P(P c)=0,01(0,05) ; O R=2,0(1,1-3,7)]$, o que também foi observado quando comparamos o genótipo $P / P$ em relação aos genótipos $S / S$ e $S / P$ agrupados $\left[\chi^{2}=5,2 ; P(P c)=0,01(0,05) ;\right.$ OR=2,1 $\left.(1,1-4,2)\right]$. 
Tabela 12. Freqüência genotípica e alélica de polimorfismos de TLR-1, TLR-4, TLR6 e TLR-9 de indivíduos com (MS) e sem (AS) manifestações clínicas de malária.

\begin{tabular}{|c|c|c|c|c|c|c|c|}
\hline \multicolumn{2}{|c|}{ Polimorfismos } & MS & AS & TOTAL & $x^{2}$ & $\begin{array}{c}\text { Valor } \\
\text { de } \\
P(P c)\end{array}$ & $\begin{array}{c}\text { OR } \\
{[95 \% \mathrm{Cl}]}\end{array}$ \\
\hline \multicolumn{8}{|c|}{ TLR-1 Ile602Ser } \\
\hline & Ile/lle & $134(0,596)$ & $58(0,795)$ & 192 & \multirow{4}{*}{8,2} & \multirow{4}{*}{0,016} & \\
\hline Genótipo & Ile/Ser & $87(0,387)$ & $14(0,192)$ & 101 & & & \\
\hline & Ser/Ser & $4(0,018)$ & $1(0,014)$ & 5 & & & \\
\hline & Total & 225 & 73 & 298 & & & \\
\hline \multirow[t]{2}{*}{ Genótipo } & Ile/lle & $134(0,596)$ & $58(0,795)$ & 192 & \multirow{2}{*}{9,5} & \multirow{2}{*}{$\begin{array}{c}0,001 \\
(0,005)\end{array}$} & \multirow{2}{*}{$\begin{array}{c}2,6 \\
{[1,4-4,9]}\end{array}$} \\
\hline & Ile/Ser+Ser/Ser & $91(0,404)$ & $15(0,205)$ & 106 & & & \\
\hline \multirow[t]{3}{*}{ Alelo } & lle & $355(0,79)$ & $130(0,89)$ & 485 & \multirow{3}{*}{7,5} & \multirow{3}{*}{$\begin{array}{c}0,003 \\
(0,015)\end{array}$} & \multirow{3}{*}{$\begin{array}{c}2,2 \\
{[1,2-3,8]}\end{array}$} \\
\hline & Ser & $95(0,21)$ & $16(0,11)$ & 111 & & & \\
\hline & Total & 450 & 146 & 596 & & & \\
\hline \multicolumn{8}{|c|}{ TLR-4 Asp299Gly } \\
\hline \multirow{4}{*}{ Genótipo } & Asp/Asp & $211(0,917)$ & $67(0,905)$ & 278 & \multirow{4}{*}{0,007} & \multirow{4}{*}{$n s$} & \multirow{4}{*}{$n s$} \\
\hline & Asp/Gly & $17(0,074)$ & $7(0,095)$ & 24 & & & \\
\hline & Gly/Gly & $2(0,009)$ & 0 & 2 & & & \\
\hline & Total & 230 & 74 & 304 & & & \\
\hline Alelo & Asp & $439(0,95)$ & $141(0,95)$ & 580 & \multirow{3}{*}{0,37} & \multirow{3}{*}{ ns } & \multirow{3}{*}{ ns } \\
\hline & Gly & $21(0,05)$ & $7(0,05)$ & 28 & & & \\
\hline & Total & 460 & 148 & 608 & & & \\
\hline \multicolumn{8}{|c|}{ TLR-6 P249S } \\
\hline & $\mathrm{P} / \mathrm{P}$ & $148(0,6758)$ & $58(0,817)$ & 206 & \multirow{4}{*}{5,3} & \multirow{4}{*}{ ns } & \\
\hline Genótipo & S/P & $63(0,2877)$ & $12(0,169)$ & 75 & & & \\
\hline & $\mathrm{S} / \mathrm{S}$ & $8(0,0375)$ & $1(0,014)$ & 9 & & & $n s$ \\
\hline & Total & 219 & 71 & 290 & & & \\
\hline Genótipo & $\mathrm{P} / \mathrm{P}$ & $148(0,68)$ & $58(0,82)$ & 206 & $5 ?$ & 0,01 & 2,1 \\
\hline & $\mathrm{S} / \mathrm{S}+\mathrm{S} / \mathrm{P}$ & $71(0,32)$ & $13(0,18)$ & 84 & 5,2 & $(0,05)$ & {$[1,1-4,2]$} \\
\hline Alelo & $\mathrm{P}$ & $359(0,82)$ & $128(0,90)$ & 487 & & & \\
\hline & $S$ & $79(0,18)$ & $14(0,10)$ & 93 & 5,3 & 0,01 & 2,0 \\
\hline & Total & 438 & 142 & 580 & & $(0,05)$ & \\
\hline TLR9-1237 & & & & & & & \\
\hline & $\mathrm{T} / \mathrm{T}$ & $159(0,726)$ & $56(0,79)$ & 215 & & & \\
\hline Genótipo & $\mathrm{T} / \mathrm{C}$ & $52(0,237)$ & $13(0,18)$ & 65 & & $n s$ & $n s$ \\
\hline & $\mathrm{C} / \mathrm{C}$ & $8(0,037)$ & $2(0,03)$ & 10 & & & \\
\hline & Total & 219 & 71 & 290 & & & \\
\hline Alelo & $\mathrm{T}$ & $370(0,84)$ & $125(0,88)$ & 438 & & & \\
\hline & $\mathrm{C}$ & $68(0,16)$ & $17(0,12)$ & 142 & & $n s$ & $n s$ \\
\hline & Total & 438 & 142 & 580 & & & \\
\hline TLR9-1486 & & & & & & & \\
\hline & $\mathrm{T} / \mathrm{T}$ & $82(0,38)$ & $23(0,324)$ & 105 & & & \\
\hline Genótipo & $\mathrm{T} / \mathrm{C}$ & $107(0,47)$ & $37(0,521)$ & 144 & 051 & $n s$ & ns \\
\hline & $\mathrm{C} / \mathrm{C}$ & $38(0,17)^{\prime}$ & $11(0,155)$ & 49 & 0,54 & & \\
\hline & Total & 227 & 71 & 298 & & & \\
\hline Alelo & $\mathrm{T}$ & $271(0,60)$ & $83(0,58)$ & 354 & & & \\
\hline & C & $183(0,40)$ & $59(0,42)$ & 242 & 0,07 & $n s$ & $n s$ \\
\hline & Total & 454 & 142 & 596 & & & \\
\hline
\end{tabular}

*ns: não significante; OR:odds ratio; $\mathrm{Cl}$ : intervalo de confiança; valor de $P(P$ corrigido de acordo com o número de genes estudados) 
Como referido anteriormente, em função da maior freqüência de casos de $P$. vivax no grupo AS, analisamos também a distribuição dos polimorfismos de TLRs nos indivíduos com infecção por $P$. falciparum separadamente (tabela 13). Os resultados são concordantes com os observados em relação a todos os indivíduos, em que apenas os polimorfismos de TLR-1 apresentaram associação significante.

A distribuição genotípica e alélica de polimorfismos de TLRs foi analisada em relação ao nível de parasitemia dos indivíduos com manifestações clínicas de malária (alta, baixa e muito baixa) (tabela 14). Nenhuma associação estatisticamente significante $(P>0,05)$ foi observada para os polimorfismos de TLR-1, TLR-4 e TLR-6. Foram observadas diferenças significantes para as freqüências dos polimorfismos de TLR-9. Os polimorfismos $T$-1237C e $T$-1486C foram mais freqüentes em indivíduos com altas parasitemias do que nos grupos de indivíduos com baixas e muito baixas parasitemias $\left[\left(\chi^{2}=6,7 ; P=0,035\right)\right.$ e $\left.\left(\chi^{2}=12,6 ; P=0,002\right)\right]$. Da mesma foram diferenças significantes foram observadas para os genótipos carregando os alelos variantes $(T / C$ e $C / C)$ para os dois polimorfismos. 
Tabela 13. Freqüência genotípica e alélica de polimorfismos de TLR-1, TLR-4, TLR6 e TLR-9 em indivíduos com (MS) e sem (AS) manifestações clínicas causadas por $P$. falciparum.

\begin{tabular}{|c|c|c|c|c|c|c|c|}
\hline Polir & lorfismos & MS & AS & TOTAL & $x^{2}$ & $\begin{array}{c}\text { Valor de } \\
P\end{array}$ & $\begin{array}{c}\text { OR } \\
{[95 \% \mathrm{Cl}]}\end{array}$ \\
\hline \multicolumn{8}{|c|}{ TLR-1 Ile602Ser } \\
\hline \multirow{4}{*}{ Genótipo } & lle/lle & $114(0,579)$ & $36(0,783)$ & 150 & \multirow{4}{*}{6,8} & \multirow{4}{*}{0,032} & \\
\hline & Ile/Ser & $79(0,401)$ & $9(0,196)$ & 88 & & & \\
\hline & Ser/Ser & $4(0,02)$ & $1(0,022)$ & 5 & & & \\
\hline & Total & 197 & 46 & 243 & & & \\
\hline Genótipo & $\begin{array}{c}\text { Ile/lle } \\
\text { Ile/Ser+Ser/Ser }\end{array}$ & $\begin{array}{c}114(0,579) \\
83(0,421)\end{array}$ & $\begin{array}{l}36(0,783) \\
10(0,271)\end{array}$ & $\begin{array}{c}150 \\
93\end{array}$ & 6,5 & $\begin{array}{c}0,005 \\
(0,025)\end{array}$ & $\begin{array}{c}2,6 \\
{[1,2-5,6]}\end{array}$ \\
\hline \multirow{2}{*}{ Alelo } & lle & $307(0,78)$ & $81(0,88)$ & 388 & \multirow[b]{2}{*}{4,7} & \multirow[b]{2}{*}{$\begin{array}{c}0,015 \\
(0,075)\end{array}$} & \multirow[b]{2}{*}{$\begin{array}{c}2,1 \\
{[1,1-4,1]}\end{array}$} \\
\hline & $\begin{array}{l}\text { Ser } \\
\text { Total }\end{array}$ & $\begin{array}{c}87(0,22) \\
394\end{array}$ & $\begin{array}{c}11(0,12) \\
92\end{array}$ & $\begin{array}{c}98 \\
486\end{array}$ & & & \\
\hline \multicolumn{8}{|c|}{ TLR-4 Asp299Gly } \\
\hline \multirow{4}{*}{ Genótipo } & Asp/Asp & $184(0,91)$ & $40(0,87)$ & 224 & \multirow{4}{*}{1,6} & \multirow[t]{4}{*}{ ns } & \\
\hline & Asp/Gly & $16(0,08)$ & $6(0,13)$ & 22 & & & \\
\hline & Gly/Gly & $2(0,01)$ & $0(0)$ & 2 & & & \\
\hline & Total & 202 & 46 & 248 & & & \\
\hline \multirow{3}{*}{ Alelo } & Asp & $384(0,95)$ & $86(0,93)$ & 470 & \multirow{3}{*}{0,37} & \multirow{3}{*}{$n s$} & \\
\hline & Gly & $20(0,05)$ & $6(0,07)$ & 26 & & & \\
\hline & Total & 404 & 92 & 496 & & & \\
\hline \multicolumn{8}{|c|}{ TLR-6 P249S } \\
\hline & $\mathrm{P} / \mathrm{P}$ & $130(0,677)$ & $35(0,778)$ & 165 & \multirow{4}{*}{1,8} & \multirow{4}{*}{$n s$} & \\
\hline Genotıpo & $S / P$ & $55(0,286)$ & $9(0,200)$ & 64 & & & \\
\hline & $\mathrm{s} / \mathrm{S}$ & $7(0,036)$ & $1(0,022)$ & 8 & & & \\
\hline & Total & 192 & 45 & 237 & & & \\
\hline \multirow{3}{*}{ Alelo } & $P$ & $315(0,82)$ & $79(0,88)$ & 440 & \multirow{3}{*}{1,7} & \multirow{3}{*}{$n s$} & \\
\hline & $S$ & $69(0,18)$ & $11(0,12)$ & 80 & & & \\
\hline & Total & 384 & 136 & 520 & & & \\
\hline$T L$ & $29-1237$ & & & & & & \\
\hline & $\mathrm{T} / \mathrm{T}$ & $140(0,71)$ & $32(0,70)$ & 172 & & & \\
\hline Genótipo & $\mathrm{T} / \mathrm{C}$ & $50(0,25)$ & $12(0,26)$ & 62 & & $n s$ & \\
\hline & $\mathrm{C} / \mathrm{C}$ & $8(0,04)$ & $2(0,04)$ & 10 & 0,026 & & \\
\hline & Total & 198 & 46 & 244 & & & \\
\hline Alelo & $\mathrm{T}$ & $330(0,83)$ & $76(0,83)$ & 406 & & & \\
\hline & C & $66(0,17)$ & $16(0,17)$ & 82 & 0,028 & $n s$ & \\
\hline & Total & 396 & 92 & 488 & & & \\
\hline$T L$ & $29-1486$ & & & & & & \\
\hline & $\mathrm{T} / \mathrm{T}$ & $70(0,352)$ & $18(0,400)$ & 88 & & & \\
\hline & $\mathrm{T} / \mathrm{C}$ & $98(0,492)$ & $23(0,511)$ & 121 & 1,4 & $n s$ & \\
\hline Genótipo & $\mathrm{C} / \mathrm{C}$ & $31(0,156)$ & $4(0,089)$ & 35 & & & \\
\hline & Total & 199 & 45 & 244 & & & \\
\hline Alolo & $T$ & $238(0,60)$ & $59(0,66)$ & 297 & & & \\
\hline Alelo & C & $160(0,40)$ & $31(0,34)$ & 191 & 1,0 & ns & \\
\hline & Total & 398 & 90 & 488 & & & \\
\hline
\end{tabular}

*ns: não significante; OR:odds ratio; Cl: intervalo de confiança; valor de $P(P$ corrigido de acordo com o número de genes estudados) 
Tabela 14. Freqüências genotípicas e alélicas dos polimorfismos de TLR-1, TLR-4, TLR-6 e TLR-9 em indivíduos com manifestações clínicas de malária (MS) distribuídas pelo grau de parasitemia: alta (> 10.000 parasitas $/ \mathrm{mm}^{3}$ de sangue), baixa (1000-10.000 parasitas $/ \mathrm{mm}^{3}$ de sangue) e muito baixa $\left(<1.000\right.$ parasitas $/ \mathrm{mm}^{3}$ de sangue).

\begin{tabular}{|c|c|c|c|c|c|c|}
\hline \multicolumn{2}{|c|}{ Polimorfismos } & ALTA & BAIXA & $\begin{array}{l}\text { MUITO } \\
\text { BAIXA }\end{array}$ & $x^{2}$ & $\begin{array}{c}\text { Valor de } \\
P \\
\end{array}$ \\
\hline \multicolumn{7}{|c|}{ TLR-1lle602Ser } \\
\hline \multirow{4}{*}{ Genótipo } & Ile/lle & $31(0,66)$ & $49(0,544)$ & $54(0,614)$ & \multirow{4}{*}{4,5} & \multirow{4}{*}{$n s$} \\
\hline & Ile/Ser & $16(0,34)$ & $40(0,444)$ & $31(0,352)$ & & \\
\hline & Ser/Ser & $0(0)$ & $1(0,011)$ & $3(0,034)$ & & \\
\hline & Total & 47 & 90 & 88 & & \\
\hline \multirow{3}{*}{ Alelo } & Ile & $78(0,83)$ & $138(0,77)$ & $139(0,79)$ & \multirow{3}{*}{1,5} & \multirow{3}{*}{ ns } \\
\hline & Ser & $16(0,17)$ & $42(0,23)$ & $37(0,21)$ & & \\
\hline & Total & 94 & 180 & 176 & & \\
\hline \multicolumn{7}{|c|}{ TLR-4Asp299Gly } \\
\hline \multirow{4}{*}{ Genótipo } & Asp/Asp & $44(0,917)$ & $83(0,902)$ & $84(0,933)$ & \multirow{4}{*}{1,3} & \multirow{4}{*}{ ns } \\
\hline & Asp/Gly & $4(0,083)$ & $8(0,087)$ & $5(0,056)$ & & \\
\hline & Gly/Gly & 0 & $1(0,011)$ & $1(0,011)$ & & \\
\hline & Total & 48 & 92 & 90 & & \\
\hline \multirow{3}{*}{ Alelo } & Asp & $92(0,96)$ & $183(0,95)$ & $294(0,961)$ & \multirow{3}{*}{0,6} & \multirow{3}{*}{$n s$} \\
\hline & Gly & $4(0,04)$ & $11(0,05)$ & $13(0,039)$ & & \\
\hline & Total & 96 & 194 & 307 & & \\
\hline \multicolumn{7}{|c|}{ TLR-6P249S } \\
\hline \multirow{4}{*}{ Genótipo } & $\mathrm{P} / \mathrm{P}$ & $35(0,795)$ & $59(0,68)$ & $54(0,614)$ & \multirow{4}{*}{4,9} & \multirow{4}{*}{ ns } \\
\hline & $\mathrm{S} / \mathrm{P}$ & $8(0,182)$ & $24(0,28)$ & $31(0,352)$ & & \\
\hline & $\mathrm{s} / \mathrm{S}$ & $1(0,023)$ & $4(0,05)$ & $3(0,034)$ & & \\
\hline & Total & 48 & 92 & 90 & & \\
\hline \multirow{3}{*}{ Alelo } & $\mathrm{P}$ & $78(0,886)$ & $142(0,816)$ & $139(0,789)$ & \multirow{3}{*}{3,7} & \multirow{3}{*}{ ns } \\
\hline & s & $10(0,114))$ & $32(0,184)$ & $37(0,21)$ & & \\
\hline & Total & 88 & 174 & 176 & & \\
\hline \multicolumn{7}{|c|}{ TLR-9-1237 } \\
\hline & $T / T$ & $26(0,565)$ & $67(0,74)$ & $69(0,775)$ & & \\
\hline & $\mathrm{T} / \mathrm{C}$ & $17(0,370)$ & $22(0,24)$ & $16(0,180)$ & & \\
\hline Genotıpo & $\mathrm{C} / \mathrm{C}$ & $3(0,065)$ & $2(0,02)$ & $4(0,045)$ & 1,9 & $n s$ \\
\hline & Total & 46 & 91 & 89 & & \\
\hline & $T / T$ & $26(0,565)$ & $67(0,74)$ & $69(0,775)$ & & \\
\hline Genótipo & $\mathrm{T} / \mathrm{C}+\mathrm{C} / \mathrm{C}$ & $20(0,435)$ & $24(0,26)$ & $20(0,225)$ & 6,8 & 0,032 \\
\hline & $T$ & $69(0,75)$ & $156(0,86)$ & $154(0,87)$ & & \\
\hline Alelo & C & $23(0,25)$ & $26(0,14)$ & $24(0,13)$ & 6,7 & 0,035 \\
\hline & Total & 92 & 182 & 178 & & \\
\hline$T L R-S$ & 1486 & & & & & \\
\hline & $T / T$ & $9(0,19)$ & $41(0,46)$ & $32(0,36)$ & & \\
\hline & $\mathrm{T} / \mathrm{C}$ & $26(0,54)$ & $40(0,44)$ & $41(0,46)$ & & \\
\hline Genótipo & $\mathrm{C} / \mathrm{C}$ & $13(0,27)$ & $9(0,1)$ & $16(0,18)$ & 12,5 & 0,014 \\
\hline & Total & 48 & 90 & 89 & & \\
\hline Genótipo & $\mathrm{T} / \mathrm{T}+\mathrm{T} / \mathrm{C}$ & $35(0,73)$ & $81(0,86)$ & $73(0,82)$ & 62 & 0035 \\
\hline & $\mathrm{C} / \mathrm{C}$ & $13(0,27)$ & $9(0,14)$ & $16(0,18)$ & 6,2 & 0,035 \\
\hline & $\mathrm{T}$ & $44(0,46)$ & $122(0,68)$ & $105(0,59)$ & & \\
\hline A & C & $52(0,54)$ & $58(0,32)$ & $73(0,41)$ & 12,6 & 0,002 \\
\hline & Total & 96 & 180 & 178 & & \\
\hline
\end{tabular}

*ns: não significante 
Analisamos também a distribuição dos polimorfismos de TLRs nos indivíduos com baixa parasitemia e indivíduos com muito baixa parasitemia agrupados comparando com o grupo de indivíduos com alta parasitemia. Foram observadas diferenças significantes para os polimorfismos de TLR-9 (tabela 15). Os polimorfismos $T-1237 C$ e $T-1486 C$ e os genótipos carregando o polimorfismo $(T / C$ e $C / C)$ de TLR-9 foram mais freqüentes nos indivíduos com altas parasitemias.

Tabela 15. Freqüências genotípicas e alélicas dos polimorfismos de TLR-9 em indivíduos com manifestações clínicas de malária (MS) distribuídas pelo grau de parasitemia: alta (> 10.000 parasitas $/ \mathrm{mm}^{3}$ de sangue), baixa $(\leq 10.000$ parasitas $/ \mathrm{mm}^{3}$ de sangue).

\begin{tabular}{|c|c|c|c|c|c|c|}
\hline & & ALTA & BAIXA & $x^{2}$ & $\begin{array}{c}\text { Valor de } \\
P\end{array}$ & OR [95\% Cl] \\
\hline \multicolumn{7}{|c|}{ TLR-9-1237 } \\
\hline \multirow{4}{*}{ Genótipo } & $T / T$ & $26(0,565)$ & $136(0,76)$ & \multirow{4}{*}{6,6} & \multirow{4}{*}{0,038} & \\
\hline & $\mathrm{T} / \mathrm{C}$ & $17(0,370)$ & $38(0,21)$ & & & \\
\hline & $\mathrm{C} / \mathrm{C}$ & $3(0,065)$ & $6(0,03)$ & & & \\
\hline & Total & 46 & 180 & & & \\
\hline \multirow{2}{*}{ Genótipo } & $T / T$ & $26(0,565)$ & $136(0,76)$ & \multirow{2}{*}{6,5} & \multirow{2}{*}{0,005} & \multirow{2}{*}{$2,4[1,2-4,7]$} \\
\hline & $\mathrm{T} / \mathrm{C}+\mathrm{C} / \mathrm{C}$ & $20(0,435)$ & $44(0,24)$ & & & \\
\hline \multirow[t]{3}{*}{ Alelo } & $T$ & $69(0,75)$ & $310(0,86)$ & \multirow{3}{*}{6,7} & \multirow{3}{*}{0,005} & \multirow{3}{*}{$2,1[1,2-3,6]$} \\
\hline & C & $23(0,25)$ & $50(0,14)$ & & & \\
\hline & Total & 92 & 360 & & & \\
\hline \multicolumn{7}{|c|}{ TLR-9-1486 } \\
\hline \multirow{4}{*}{ Genótipo } & $T / T$ & $9(0,19)$ & $73(0,41)$ & \multirow{4}{*}{9,6} & \multirow{4}{*}{0,008} & \\
\hline & $\mathrm{T} / \mathrm{C}$ & $26(0,54)$ & $81(0,45)$ & & & \\
\hline & $\mathrm{C} / \mathrm{C}$ & $13(0,27)$ & $25(0,14)$ & & & \\
\hline & Total & 48 & 179 & & & \\
\hline \multirow{2}{*}{ Genótipo } & $\mathrm{T} / \mathrm{T}$ & $9(0,19)$ & $73(0,41)$ & \multirow{2}{*}{4.7} & \multirow{2}{*}{0,0024} & \multirow{2}{*}{$3,0[1,4-6,5]$} \\
\hline & $\mathrm{T} / \mathrm{C}+\mathrm{C} / \mathrm{C}$ & $38(0,81)$ & $106(0,59)$ & & & \\
\hline \multirow{3}{*}{ Alelo } & $T$ & $44(0,46)$ & $227(0,63)$ & \multirow{3}{*}{9,7} & \multirow{3}{*}{0,0009} & \multirow{3}{*}{$2,0[1,3-3,2]$} \\
\hline & C & $52(0,54)$ & $131(0,37)$ & & & \\
\hline & Total & 96 & 358 & & & \\
\hline
\end{tabular}

*ns: não significante; OR:odds ratio; Cl: intervalo de confiança

Investigamos também o polimorfismo S180L da molécula adaptadora MAL/TIRAP pelo fato desta já ter sido relacionada à proteção na malária.

Ao analisarmos a distribuição genotípica e alélica do polimorfismo S180L da MAL/TIRAP em todos os indivíduos (tabela 16) foi observada fraca 
associação do alelo polimórfico com ausência de manifestações clínicas $\left[\chi^{2}=2,9 ; P=0,043 ; \mathrm{OR}=1,53[0,94-2,51)\right]$. Nenhuma diferença foi observada quando analisamos apenas os pacientes infectados por $P$. falciparum (dados não apresentados).

Tabela 16. Freqüência genotípica e alélica de polimorfismo S180L da molécula adaptadora MAL/TIRAP em indivíduos com (MS) e sem (AS) manifestações clínicas de malária.

\begin{tabular}{|c|c|c|c|c|c|c|c|}
\hline \multicolumn{2}{|c|}{ TIRAP } & MS & AS & TOTAL & $\chi^{2}$ & $\begin{array}{c}\text { Valor de } \\
P\end{array}$ & OR [95\% Cl] \\
\hline \multicolumn{2}{|c|}{ S180L } & & & & & & \\
\hline \multirow{4}{*}{ Genótipo } & Ser/Ser & $177(0,776)$ & $49(0,681)$ & 226 & & & \\
\hline & Se/Leu & $40(0,175)$ & $18(0,250)$ & 58 & & & \\
\hline & Leu/leu & $11(0,048)$ & $5(0,069)$ & 16 & 2,7 & $n s$ & \\
\hline & Total & 228 & 72 & 300 & & & \\
\hline \multirow{3}{*}{ Alelo } & Ser & $394(0,86)$ & $116(0,81)$ & 510 & & & \\
\hline & Leu & $62(0.14)$ & $28(0.19)$ & 90 & 2.9 & 0,043 & $1.53[0.94-2.51]$ \\
\hline & Total & 456 & 144 & 600 & & & \\
\hline
\end{tabular}

${ }^{*} n s$ : não significante;OR:odds ratio; $\mathrm{Cl}$ : intervalo de confiança; valor de $P(P$ corrigido de acordo com o número de genes estudados)

Também não foi observada associação do polimorfismo S180L com os níveis de parasitemia dos indivíduos com manifestações clínicas de malária (tabela 17).

Tabela 17. Freqüência genotípica e alélica do polimorfismo $S 180 L$ da molécula adaptadora MAL/TIRAP em indivíduos com manifestações clínicas de malária (MS) distribuídas pelo grau de parasitemia: alta $\left(>10.000\right.$ parasitas $/ \mathrm{mm}^{3}$ de sangue), baixa (1000-10.000 parasitas $/ \mathrm{mm}^{3}$ de sangue) e muito baixa $\left(<1.000\right.$ parasitas $/ \mathrm{mm}^{3}$ de sangue).

\begin{tabular}{|c|c|c|c|c|c|c|}
\hline \multicolumn{2}{|c|}{ TIRAP } & ALTA & BAIXA & $\begin{array}{l}\text { MUITO } \\
\text { BAIXA }\end{array}$ & $\chi^{2}$ & $\begin{array}{c}\text { Valor de } \\
P\end{array}$ \\
\hline \multicolumn{2}{|c|}{ S180L } & & & & & \\
\hline \multirow{4}{*}{ Genótipo } & Ser/Ser & $36(0,77)$ & $76(0,83)$ & $65(0,73)$ & & \\
\hline & Ser/Leu & $8(0,17)$ & $13(0,14)$ & $19(0,21)$ & & \\
\hline & Leu/Leu & $3(0,06)$ & $3(0,03)$ & $5(0,06)$ & 2,7 & ns \\
\hline & Total & 47 & 92 & 89 & & \\
\hline \multirow{3}{*}{ Alelo } & Ser & $80(0,85)$ & $165(0,90)$ & $149(0,84)$ & & \\
\hline & Leu & $14(0,15)$ & $19(0,10)$ & $29(0,16)$ & 2,9 & $n s$ \\
\hline & Total & 94 & 184 & 178 & & \\
\hline
\end{tabular}

*ns: não significante 
Nenhuma associação significante foi observada com idade para os SNPs de TLRs estudados. Na tabela 18 apresentamos apenas os dados de TLR9 e TLR1.

Tabela 18. Idade dos pacientes (valores medianos em anos e os percentis de $25 \%$ e $75 \%$ entre parêntesis) com manifestações clínicas de malária (sintomáticos) de acordo com os genótipos TLR-1 e de TLR-9 estratificados de acordo com os níveis de parasitemia.

\begin{tabular}{|c|c|c|c|}
\hline & \multicolumn{3}{|c|}{ TLR-1 I602S } \\
\hline & Ile/lle & Ile/Ser & Ser/Ser \\
\hline Sintomáticos & $29,0(23,0-36,2)$ & $29,0(23,0-36,0)$ & $43,5(37,0-58,5)$ \\
\hline \multicolumn{4}{|l|}{ Comparação } \\
\hline \multicolumn{2}{|l|}{ Teste Kruskall-Wallis } & \multicolumn{2}{|l|}{$P=0,05$} \\
\hline \multicolumn{2}{|c|}{ Teste Mann-Whitney (Ile/lle vs. Ile/Ser) } & \multicolumn{2}{|l|}{$P=0,90$} \\
\hline & \multicolumn{3}{|c|}{ TLR9 $-1237 C / T$} \\
\hline & TT & CT & $\mathrm{CC}$ \\
\hline Alta parasitemia: idade & $23,0(19,0-29)$ & $24,0(21,3-26,0)$ & $26(23,0-26,0)$ \\
\hline Baixa parasitemia: idade & $30,0(23,3-37,0)$ & $30,0(25,0-36,0)$ & $33,5(29,0-37,0)$ \\
\hline \multicolumn{2}{|l|}{ Comparação } & Alta parasitemia & Baixa parasitemia \\
\hline \multirow[t]{3}{*}{ Teste Kruskall-Wallis } & & $P=0,892$ & $P=0,696$ \\
\hline & \multicolumn{3}{|c|}{ TLR9 -1486C/T } \\
\hline & TT & TC & $\mathrm{CC}$ \\
\hline Alta parasitemia: idade & $27,0(21,3-34,8)$ & $23,0(19,0-28,0)$ & $26,0(19,0-30,3)$ \\
\hline Baixa parasitemia: idade & $32,0(23,0-36,3)$ & $29,5(25,0-39,5)$ & $30,0(24,5-37,0)$ \\
\hline \multicolumn{2}{|l|}{ Comparação } & Alta parasitemia & Baixa parasitemia \\
\hline \multicolumn{2}{|l|}{ Teste Kruskall-Wallis } & $P=0,575$ & $P=0,779$ \\
\hline
\end{tabular}




\subsection{DISTRIBUIÇÃO GENOTíPICA E ALÉLICA DE POLIMORFISMOS DA MBL}

Foram analisados por PCR-RFLP os polimorfismos dos códons 52,54 e 57 do exon 1, -221 da região promotora e +4 da região não traduzida do gene 2 da $M B L$ de todos indivíduos infectados com malária (resultados apresentados na (tabela 19). Todos os SNPs do grupo AS e MS estavam em HWE (Equilíbrio de Hardy-Weinberg).

Nenhuma associação estatisticamente significante foi observada para os polimorfismos dos códons 52, 54 e 57 do exon $1(B, C$ e $D)$ e -221 da região promotora e a presença ou não de manifestações clínicas de malária na população estudada $(P>0,05)$. A ausência do polimorfismo $P / Q$ da região promotora de MBL foi associada com malária assintomática (grupo AS) quando comparamos os genótipos $P / P$ com $P / Q$ e $Q / Q\left[\chi^{2}=5,1 ; P=0,012\right.$; $\mathrm{OR}=1,9(1,1-3,2)]$. A freqüência do alelo $P$ foi maior no grupo AS em relação ao grupo MS, mas sem diferença significante $(P>0,05)$. 
Tabela 19. Freqüência genotípica e alélica dos polimorfismos dos códons 52,54 e 57 do exon $1(B, C$ e $D),-221$ da região promotora e +4 da região não traduzida do gene 2 da MBL de todos indivíduos com (MS) e sem (AS) manifestações clínicas de malária.

\begin{tabular}{|c|c|c|c|c|c|c|c|}
\hline \multicolumn{2}{|c|}{ Polimorfismos } & MS & AS & Total & $x^{2}$ & $\underset{P}{\text { Valor do }}$ & $\begin{array}{c}\text { OR } \\
{[95 \% \mathrm{Cl}}\end{array}$ \\
\hline \multicolumn{8}{|c|}{$\operatorname{Arg52Cys}(A / D)$} \\
\hline \multirow{4}{*}{ Genótipo } & $\mathrm{A} / \mathrm{A}$ & $207(0,91)$ & $70(0,96)$ & 277 & \multirow{4}{*}{1,96} & \multirow{4}{*}{ ns } & \\
\hline & $A / D$ & $21(0,09)$ & $3(0,04)$ & 24 & & & \\
\hline & $D / D$ & 0 & 0 & 0 & & & \\
\hline & Total & 228 & 73 & 301 & & & \\
\hline \multirow{3}{*}{ Alelo } & $A$ & $435(0,95)$ & $143(0,98)$ & 578 & \multirow{3}{*}{1,9} & \multirow{3}{*}{ ns } & \\
\hline & $\mathrm{D}$ & $21(0,05)$ & $3(0,02)$ & 24 & & & \\
\hline & Total & 456 & 146 & 602 & & & \\
\hline \multicolumn{8}{|c|}{$\operatorname{Arg} 54 C y s(A / B)$} \\
\hline & $\mathrm{A} / \mathrm{A}$ & $181(0,80)$ & $55(0,75)$ & 236 & \multirow{4}{*}{2,3} & \multirow{4}{*}{ ns } & \\
\hline \multirow[t]{4}{*}{ Genótipo } & $A / B$ & $43(0,19)$ & $15(0,21)$ & 58 & & & \\
\hline & $\mathrm{B} / \mathrm{B}$ & $3(0,01)$ & $3(0,04)$ & 6 & & & \\
\hline & Total & 227 & 73 & 300 & & & \\
\hline & $A$ & $405(0,89)$ & $125(0,86)$ & 530 & \multirow{3}{*}{1,4} & \multirow{3}{*}{$n s$} & \\
\hline \multirow[t]{2}{*}{ Alelo } & B & $49(0,11)$ & $21(0,24)$ & 70 & & & \\
\hline & Total & 454 & 146 & 600 & & & \\
\hline \multicolumn{8}{|c|}{$\operatorname{Arg} 57 C y s(A / C)$} \\
\hline \multirow{4}{*}{ Genótipo } & $\mathrm{A} / \mathrm{A}$ & $219(0,952)$ & $74(0,100)$ & 293 & \multirow{4}{*}{3,7} & \multirow{4}{*}{ ns } & \\
\hline & $\mathrm{A} / \mathrm{C}$ & $11(0,048)$ & $0(0)$ & 11 & & & \\
\hline & $\mathrm{C} / \mathrm{C}$ & 0 & 0 & 0 & & & \\
\hline & Total & 230 & 74 & 304 & & & \\
\hline \multirow{3}{*}{ Alelo } & A & $449(0,98)$ & $148(0,100)$ & 597 & \multirow{3}{*}{3,6} & \multirow{3}{*}{ ns } & \\
\hline & C & $11(0,02)$ & $0(0)$ & 11 & & & \\
\hline & Total & 460 & 148 & 608 & & & \\
\hline \multicolumn{8}{|c|}{$A / O$} \\
\hline \multirow[t]{4}{*}{ Genótipo } & $\mathrm{A} / \mathrm{A}$ & $156(0,69)$ & $53(0,73)$ & 209 & \multirow{4}{*}{1,0} & \multirow{4}{*}{ ns } & \\
\hline & $\mathrm{A} / \mathrm{O}$ & $62(0,27)$ & $16(0,22)$ & 78 & & & \\
\hline & $\mathrm{O} / \mathrm{O}$ & $9(0,04)$ & $4(0,05)$ & 13 & & & \\
\hline & Total & 227 & 73 & 300 & & & \\
\hline \multirow[t]{3}{*}{ Alelo } & $A$ & $374(0,82)$ & $122(0,84)$ & 496 & \multirow{3}{*}{0,11} & \multirow{3}{*}{ ns } & \\
\hline & $\mathrm{O}$ & $80(0,18)$ & $24(0,16)$ & 104 & & & \\
\hline & Total & 454 & 146 & 600 & & & \\
\hline
\end{tabular}

*ns: não significante;OR: odds ratio; Cl: intervalo de confiança

A: alelo normal ; O: alelo mutante ( $D, B$ e $C$ ); presença de 1 mutação (A/O); presença em 2 ou 3 mutações $(\mathrm{O} / \mathrm{O})$ 
Continuação da tabela 19.

\begin{tabular}{|c|c|c|c|c|c|c|c|}
\hline \multicolumn{8}{|c|}{$-221 C / G(X / Y)$} \\
\hline & $X / X$ & $3(0,014)$ & $1(0,014)$ & 4 & \multirow{4}{*}{0,94} & \multirow{4}{*}{ ns } & \\
\hline \multirow[t]{3}{*}{ Genótipo } & $X / Y$ & $72(0,333)$ & $19(0,271)$ & 91 & & & \\
\hline & $\mathrm{Y} / \mathrm{Y}$ & $141(0,653)$ & $50(0,714)$ & 191 & & & \\
\hline & Total & 216 & 70 & 286 & & & \\
\hline \multirow[t]{3}{*}{ Alelo } & $\mathrm{X}$ & $78(0,18)$ & $21(0,15)$ & 99 & \multirow{3}{*}{0.085} & \multirow{3}{*}{$n s$} & \\
\hline & $\mathrm{Y}$ & $354(0,82)$ & $88(0,85)$ & 442 & & & \\
\hline & Total & 432 & 109 & 541 & & & \\
\hline \multicolumn{8}{|c|}{$+4 C / T(P / Q)$} \\
\hline Genótipo & $\mathrm{P} / \mathrm{P}$ & $114(0,511)$ & $49(0,662)$ & 163 & \multirow{4}{*}{5,1} & & \\
\hline & $P / Q$ & $97(0,435)$ & $23(0,311)$ & 120 & & & \\
\hline & $Q / Q$ & $12(0,054)$ & $2(0,027)$ & 14 & & $0,012^{a}$ & $1,1,9$ \\
\hline & Total & 223 & 74 & 297 & & & \\
\hline \multirow[t]{3}{*}{ Alelo } & $P$ & $325(0,73)$ & $95(0,82)$ & 420 & \multirow{3}{*}{1,2} & \multirow{3}{*}{$n s$} & \\
\hline & $\mathrm{Q}$ & $121(0,27)$ & $27(0,18)$ & 148 & & & \\
\hline & Total & 446 & 122 & 568 & & & \\
\hline
\end{tabular}

*ns: não significante;OR: odds ratio; Cl: intervalo de confiança

${ }^{a} \mathrm{PP}$ vs $\mathrm{P} / \mathrm{Q}+\mathrm{Q} / \mathrm{Q}$

Baseados nas freqüências dos polimorfismos do exon $1(A / A$ ou $A / O)$ e do promotor -221 $(X / Y)$, ambos relacionados à produção de $M B L$, calculamos a freqüência de genótipos de produção suficiente de MBL $(Y A / Y A+Y A / X A+Y A / O+X A / X A)$ e comparamos com a freqüência de genótipos de produção insuficiente de $\mathrm{MBL}(X A / X A / O+O / O)$. Estas freqüências não diferiram em relação à presença ou não de manifestações clínicas $(P>0,05)$ (tabela 20). 
Tabela 20. Freqüência dos diplótipos do exon 1 e da posição -221 da região promotora do gene 2 da MBL de todos os indivíduos com (MS) e sem (AS) manifestações clínicas de malária.

\begin{tabular}{ccccc}
\hline \hline Genótipo & MS & AS & Total & Valor do $P$ \\
YA/YA & $86(0,404)$ & $36(0,52)$ & $122(0,43)$ & \\
YA/XA & $56(0,263)$ & $13(0,19)$ & $69(0,24)$ & \\
YA/O & $45(0,211)$ & $12(0,17)$ & $57(0,20)$ & \\
XA/XA & $3(0,014)$ & $1(0,01)$ & $4(0,01)$ & \\
XA/O & $14(0,066)$ & $4(0,06)$ & $18(0,06)$ & \\
O/O & $9(0,042)$ & $3(0,04)$ & $12(0,04)$ & \\
\multicolumn{5}{c}{} \\
Suficiente & $190(0,89)$ & $62(0,90)$ & $252(0,89)$ & $n s$ \\
Insuficiente & $23(0,11)$ & $7(0,10)$ & $30(0,11)$ & $n$ \\
\hline "MBL suficiente (YA/YA+YA/XA+YA/O+XA/XA) X MBL insuficiente (XA/O+O/O)
\end{tabular}

Como a prevalência de indivíduos infectados por $P$. vivax foi significantemente maior no grupo AS (35\%) do que no grupo MS (12\%) $(P<$ 0,0001), analisamos a genotipagem da MBL apenas dos indivíduos com infecção por $P$. falciparum (incluindo as mistas) em relação à presença ou não de manifestações clínicas (tabela 21). Assim, considerando apenas a infecção por $P$. falciparum, não foi observada associação para os polimorfismos dos códons 52, 54 e $57(B, C$ e $D)$ do exon 1 com presença ou não de sinais e manifestações clínicas clínicos de malária na população estudada $(P>0,05)$. Fraca associação foi observada entre os genótipos $X / X$ e $X / Y$ e presença de manifestações clínicas de malária $\left[\chi^{2}=2,9 ; P=0,043\right.$; OR=1,9 $(0,90-4,1)]$. A ausência do polimorfismo $P / Q$ da região promotora de MBL foi associada com malária assintomática (grupo AS) quando comparamos os genótipos $P / P$ com $P / Q$ e $Q / Q \quad\left[\chi^{2}=4,6 ; \quad P=0,016\right.$; $\mathrm{OR}=2,1(1,0-4,0)]$. A freqüência do alelo $P$ também foi maior no grupo $A S$ em relação ao grupo MS $\left[\chi^{2}=4,4 ; P=0,017 ; \mathrm{OR}=1,8(1,0-3,2)\right]$. 
Também quando analisamos apenas os pacientes infectados por $P$. falciparum, não observamos associação dos diplótipos de produção insuficiente $(X A / X A / O+O / O)$ e presença de manifestações clínicas de malária $(P>0,05)$ (tabela 22).

Tabela 21. Freqüência genotípica e alélica dos polimorfismos dos códons $52,54 \mathrm{e}$ 57 do exon 1 ( $D, B$ e $C$ ), -221 da região promotora e +4 da região não traduzida do gene da MBL de indivíduos com (MS) e sem (AS) manifestações clínicas causadas por $P$. falciparum.

\begin{tabular}{|c|c|c|c|c|c|c|c|}
\hline \multicolumn{2}{|c|}{ Polimorfismos } & MS & AS & Total & $x^{2}$ & $\begin{array}{c}\text { Valor do } \\
P\end{array}$ & $\begin{array}{c}\text { OR } \\
{[95 \% \mathrm{Cl}]}\end{array}$ \\
\hline \multicolumn{8}{|c|}{$\operatorname{Arg52Cys}(A / D)$} \\
\hline \multirow{4}{*}{ Genótipo } & $\mathrm{A} / \mathrm{A}$ & $180(0,9)$ & $43(0,935)$ & 223 & \multirow{4}{*}{0,53} & \multirow{4}{*}{$n s$} & \\
\hline & $A / D$ & $20(0,01)$ & $3(0,065)$ & 23 & & & \\
\hline & $\mathrm{D} / \mathrm{D}$ & 0 & 0 & 0 & & & \\
\hline & Total & 200 & 46 & 246 & & & \\
\hline \multirow{3}{*}{ Alelo } & $A$ & $380(0,95)$ & $89(0,97)$ & 469 & \multirow{3}{*}{0,51} & \multirow{3}{*}{$n s$} & \\
\hline & D & $20(0,05)$ & $3(0,03)$ & 23 & & & \\
\hline & Total & 400 & 92 & 492 & & & \\
\hline \multicolumn{8}{|c|}{ Arg54Cys(A/B) } \\
\hline \multirow{4}{*}{ Genótipo } & $\mathrm{A} / \mathrm{A}$ & $160(0,8)$ & $36(0,78)$ & 196 & \multirow{4}{*}{0,014} & \multirow{4}{*}{ ns } & \\
\hline & $A / B$ & $37(0,185)$ & $9(0,2)$ & 46 & & & \\
\hline & $\mathrm{B} / \mathrm{B}$ & $3(0,015)$ & $1(0,02)$ & 4 & & & \\
\hline & Total & 200 & 46 & 246 & & & \\
\hline \multirow{3}{*}{ Alelo } & $A$ & $357(0,89)$ & $81(0,88)$ & 438 & \multirow{3}{*}{0,011} & \multirow{3}{*}{ ns } & \\
\hline & B & $43(0,11)$ & $11(0,12)$ & 54 & & & \\
\hline & Total & 400 & 92 & 492 & & & \\
\hline \multicolumn{8}{|c|}{$\operatorname{Arg57Cys}(A / C)$} \\
\hline \multirow{4}{*}{ Genótipo } & $\mathrm{A} / \mathrm{A}$ & $192(0,95)$ & $47(0,100)$ & 239 & \multirow{4}{*}{2,4} & \multirow{4}{*}{$n s$} & \\
\hline & $A / C$ & $10(0,05)$ & 0 & 10 & & & \\
\hline & $\mathrm{C} / \mathrm{C}$ & 0 & 0 & 0 & & & \\
\hline & Total & 202 & 47 & 249 & & & \\
\hline \multirow{3}{*}{ Alelo } & $A$ & $394(0,98)$ & $94(0,100)$ & 488 & \multirow{3}{*}{2,4} & & \\
\hline & C & $10(0,02)$ & $0(0)$ & 10 & & & \\
\hline & Total & 404 & 94 & 498 & & & \\
\hline \multicolumn{8}{|l|}{$A / O$} \\
\hline \multirow{4}{*}{ Genótipo } & $\mathrm{A} / \mathrm{A}$ & $135(0,68)$ & $34(0,74)$ & 169 & \multirow{4}{*}{0,78} & \multirow{4}{*}{$n s$} & \\
\hline & $\mathrm{A} / \mathrm{O}$ & $56(0,28)$ & $10(0,22)$ & 66 & & & \\
\hline & $\mathrm{O} / \mathrm{O}$ & $8(0,04)$ & $2(0,04)$ & 10 & & & \\
\hline & Total & 199 & 46 & 245 & & & \\
\hline \multirow{3}{*}{ Alelo } & A & $326(0,82)$ & $78(0,85)$ & 404 & \multirow{3}{*}{0,43} & \multirow{3}{*}{$n s$} & \\
\hline & 0 & $72(0,18)$ & $14(0,15)$ & 86 & & & \\
\hline & Total & 398 & 92 & 490 & & & \\
\hline
\end{tabular}

${ }^{*} n s:$ não significante; OR: odds ratio; Cl: intervalo de confiança

A: alelo normal ; $O$ :alelo mutante $(\mathrm{D}, \mathrm{B}$ e $\mathrm{C})$ presença de 1 mutação $(\mathrm{A} / \mathrm{O})$; presença em 2 ou 3 mutações $(\mathrm{O} / \mathrm{O})$ 
Continuação da tabela 21.

\begin{tabular}{|c|c|c|c|c|c|c|c|}
\hline \multicolumn{8}{|c|}{$-221 C / G(X / Y)$} \\
\hline \multirow{4}{*}{ Genótipo } & $X / X$ & $3(0,016)$ & $1(0,022)$ & 4 & \multirow{4}{*}{3,35} & \multirow{4}{*}{$n s$} & \\
\hline & $X / Y$ & $65(0,340)$ & $9(0,200)$ & 74 & & & \\
\hline & $Y / Y$ & $123(0,644)$ & $35(0,778)$ & 158 & & & \\
\hline & Total & 191 & 45 & 236 & & & \\
\hline \multirow[t]{2}{*}{ Genótipo } & $X / X+X / Y$ & $68(0,356)$ & $10(0,222)$ & 78 & \multirow{2}{*}{2,95} & \multirow{2}{*}{0,043} & \\
\hline & $Y / Y$ & $123(0,644)$ & $35(0,778)$ & 158 & & & {$[0,90-4,1]$} \\
\hline \multirow[t]{3}{*}{ Alelo } & $x$ & $71(0,19)$ & $11(0,12)$ & 82 & \multirow{3}{*}{2,1} & \multirow{3}{*}{$n s$} & \\
\hline & Y & $311(0,81)$ & $79(0,88)$ & 390 & & & \\
\hline & Total & 382 & 90 & 472 & & & \\
\hline \multicolumn{8}{|c|}{ +4 C/T (P/Q) } \\
\hline \multirow[t]{4}{*}{ Genótipo } & P/P & $95(0,485)$ & $31(0,660)$ & 126 & \multirow{4}{*}{4,98} & \multirow{4}{*}{ ns } & \\
\hline & $P / Q$ & $89(0,454)$ & $15(0,319)$ & 104 & & & \\
\hline & $\mathrm{Q} / \mathrm{Q}$ & $12(0,061)$ & $1(0,021)$ & 13 & & & \\
\hline & Total & 196 & 47 & 243 & & & \\
\hline \multirow[t]{2}{*}{ Genótipo } & $\mathrm{P} / \mathrm{P}$ & $95(0,485)$ & $31(0,66)$ & 126 & \multirow{2}{*}{4,6} & \multirow{2}{*}{0,016} & 2,1 \\
\hline & $P / Q+Q / Q$ & $101(0,515)$ & $16(0,34)$ & 117 & & & {$[1,0-4,0]$} \\
\hline \multirow[t]{3}{*}{ Alelo } & $\mathrm{P}$ & $279(0,71)$ & $77(0,82)$ & 356 & \multirow{3}{*}{4,4} & \multirow{3}{*}{0,017} & \multirow{3}{*}{$\begin{array}{c}1,8 \\
{[1,0-3,2]}\end{array}$} \\
\hline & $Q$ & $113(0,29)$ & $17(0,18)$ & 130 & & & \\
\hline & Total & 392 & 94 & 486 & & & \\
\hline
\end{tabular}

*ns: não significante; OR: odds ratio; Cl: intervalo de confiança

Tabela 22. Freqüência dos diplótipos do exon 1 e -221 da região promotora do gene de indivíduos com (MS) e sem (AS) manifestações clínicas causadas por $P$. falciparum.

\begin{tabular}{ccccc}
\hline \hline Genótipo & MS & AS & Total & Valor do $\boldsymbol{P}$ \\
YA/YA & $75(0,40)$ & $24(0,56)$ & $99(0,43)$ & \\
YA/XA & $49(0,26)$ & $7(0,16)$ & $56(0,24)$ & \\
YA/O & $39(0,21)$ & $8(0,19)$ & $47(0,20)$ & \\
XA/XA & $3(0,02)$ & $1(0,02)$ & $4(0,02)$ & \\
XA/O & $14(0,07)$ & $2(0,05)$ & $16(0,07)$ & \\
O/O & $8(0,04)$ & $1(0,02)$ & $8(0,04)$ & \\
& & & \\
Suficiente & $166(0,88)$ & $40(0,93)$ & $206(0,89)$ & \\
Insuficiente & $22(0,0,12)$ & $3(0,07)$ & $25(0,11)$ & \\
\hline \hline
\end{tabular}


A distribuição genotípica e alélica de $\mathrm{MBL}$ foi analisada em relação ao nível de parasitemia dos indivíduos com manifestações clínicas de malária (tabela 23). Nenhuma associação estatisticamente significante $(P>0,05)$ foi observada para todos os polimorfismos do gene da MBL estudados distribuídos em três níveis de parasitemia: alta $\left(>10.000\right.$ parasitas $/ \mathrm{mm}^{3}$ de sangue), baixa (1.000-10.000 parasitas $/ \mathrm{mm}^{3}$ de sangue) e muito baixa $\left(<1.000\right.$ parasitas $/ \mathrm{mm}^{3}$ de sangue). Ao analisarmos a distribuição dos genótipos considerando juntos os indivíduos com altas e baixas parasitemias ( $\geq 1.000$ parasitas $/ \mathrm{mm}^{3}$ de sangue) em relação aos indivíduos com parasitemias muito baixas ( $<1.000$ parasitas $/ \mathrm{mm}^{3}$ de sangue), observamos maior freqüência do alelo $D\left[\chi^{2}=3,7 ; P=0,021 ; O R=2,55(1,0-6,2)\right]$ e do genótipo $A / D\left[\chi^{2}=4,3 ; P=0,018 ; O R=2,7(1,0-6,8)\right]$ nos indivíduos com parasitemias maiores que 1.000 parasitas $/ \mathrm{mm}^{3}$ de sangue. Observamos associação entre níveis mais baixos de parasitemia e a produção suficiente de $M B L(Y A / Y A+Y A / X A+Y A / O+X A / X A)\left[\chi^{2}=5,7 ; \quad P=0,009 ; O R=0,27(0,09-\right.$ 0,84)] (tabela 24). 
Tabela 23. Freqüências genotípicas e alélicas dos polimorfismos dos códons 52,54 e 57 do exon 1, -221 da região promotora e +4 da região não traduzida do gene 2 da MBL de indivíduos com manifestações clínicas de malária (MS) distribuídas pelo grau de parasitemia: alta (> 10.000 parasitas $/ \mathrm{mm}^{3}$ de sangue), baixa (1000-10.000 parasitas $/ \mathrm{mm}^{3}$ de sangue) e muito baixa $\left(<1.000\right.$ parasitas $/ \mathrm{mm}^{3}$ de sangue).

\begin{tabular}{|c|c|c|c|c|c|c|}
\hline \multicolumn{2}{|c|}{ Polimorfismos } & ALTA & BAIXA & MUITO BAIXA & $x^{2}$ & $\begin{array}{c}\text { Valor de } \\
P \\
\end{array}$ \\
\hline \multicolumn{7}{|c|}{$\operatorname{Arg52Cys(A/D)}$} \\
\hline \multirow{4}{*}{ Genótipo } & A/A & $39(0,83)$ & $83(0,902)$ & $85(0,955)$ & \multirow{4}{*}{5,8} & \multirow{4}{*}{$n s$} \\
\hline & $A / D$ & $8(0,16)$ & $9(0,098)$ & $4(0,045)$ & & \\
\hline & $\mathrm{D} / \mathrm{D}$ & $0(0)$ & $0(0)$ & $0(0)$ & & \\
\hline & Total & 47 & 92 & 89 & & \\
\hline \multirow{3}{*}{ Alelo } & A & $86(0,91)$ & $175(0,95)$ & $174(0,98)$ & \multirow{3}{*}{5,5} & \multirow{3}{*}{ ns } \\
\hline & D & $8(0,09)$ & $9(0,05)$ & $4(0,02)$ & & \\
\hline & Total & 94 & 184 & 178 & & \\
\hline \multicolumn{7}{|c|}{$\operatorname{Arg} 54 C y s(A / B)$} \\
\hline \multirow{4}{*}{ Genótipo } & $\mathrm{A} / \mathrm{A}$ & $41(0,87)$ & $71(0,780)$ & $69(0,775)$ & \multirow{4}{*}{2,8} & \multirow{4}{*}{ ns } \\
\hline & $A / B$ & $6(0,13)$ & $18(0,198)$ & $19(0,213)$ & & \\
\hline & $\mathrm{B} / \mathrm{B}$ & $0(0)$ & $2(0,022)$ & $1(0,011)$ & & \\
\hline & Total & 47 & 91 & 89 & & \\
\hline \multirow{3}{*}{ Alelo } & $A$ & $88(0,94)$ & $160(0,88)$ & $157(0,88)$ & \multirow{3}{*}{2,4} & \multirow[b]{3}{*}{$n s$} \\
\hline & B & $6(0,06)$ & $22(0,12)$ & $21(0,12)$ & & \\
\hline & Total & 94 & 182 & 178 & & \\
\hline \multicolumn{7}{|c|}{$\operatorname{Arg} 57 C y s(A / C)$} \\
\hline \multirow{4}{*}{ Genótipo } & A/A & $44(0,917)$ & $90(0,978)$ & $85(0,944)$ & \multirow{4}{*}{2,8} & \multirow{4}{*}{ ns } \\
\hline & $\mathrm{A} / \mathrm{C}$ & $4(0,083)$ & $2(0,022)$ & $5(0,056)$ & & \\
\hline & $\mathrm{C} / \mathrm{C}$ & $0(0)$ & $0(0)$ & $0(0)$ & & \\
\hline & Total & 48 & 92 & 90 & & \\
\hline \multirow{3}{*}{ Alelo } & $A$ & $92(0,96)$ & $182(0,99)$ & $175(0,97)$ & \multirow{3}{*}{2,7} & \multirow{3}{*}{ ns } \\
\hline & C & $4(0,04)$ & $2(0,01)$ & $5(0,03)$ & & \\
\hline & Total & 96 & 182 & 180 & & \\
\hline \multicolumn{7}{|c|}{$A / O$} \\
\hline & $\mathrm{A} / \mathrm{A}$ & $31(0,66)$ & $64(0,703)$ & $61(0,685)$ & \multirow{4}{*}{0,28} & \multirow{4}{*}{ ns } \\
\hline Genótipo & $\mathrm{A} / \mathrm{O}$ & $14(0,30)$ & $22(0,242)$ & $26(0,292)$ & & \\
\hline & $\mathrm{O} / \mathrm{O}$ & $2(0,04)$ & $5(0,055)$ & $2(0,022)$ & & \\
\hline & Total & 47 & 91 & 89 & & \\
\hline \multirow{3}{*}{ Alelo } & $A$ & $76(0,81)$ & $150(0,82)$ & $148(0,83)$ & \multirow{3}{*}{0,22} & \multirow{3}{*}{ ns } \\
\hline & $\mathrm{O}$ & $18(0,19)$ & $32(0,18)$ & $30(0,17)$ & & \\
\hline & Total & 94 & 182 & 178 & & \\
\hline
\end{tabular}

${ }^{*} n s:$ não significante

A: alelo normal ; $O$ :alelo mutante (D, B e C); presença de 1 mutação (A/O); presença em 2 ou 3 mutações $(\mathrm{O} / \mathrm{O})$ 
Continuação da tabela 23.

\begin{tabular}{|c|c|c|c|c|c|c|}
\hline \multicolumn{7}{|c|}{$-221 C / G(X / Y)$} \\
\hline \multirow{4}{*}{ Genótipo } & $X / X$ & $1(0,02)$ & $0(0)$ & $2(0,02)$ & \multirow{4}{*}{4,0} & \multirow{4}{*}{$n s$} \\
\hline & $X / Y$ & $17(0,39)$ & $31(0,36)$ & $24(0,28)$ & & \\
\hline & $Y / Y$ & $26(0,59)$ & $54(0,64)$ & $61(0,70)$ & & \\
\hline & Total & 44 & 85 & 87 & & \\
\hline \multirow[t]{3}{*}{ Alelo } & $\mathrm{X}$ & $19(0,22)$ & $31(0,18)$ & $28(0,16)$ & \multirow{3}{*}{1,2} & \multirow{3}{*}{ ns } \\
\hline & $\mathrm{Y}$ & $69(0,78)$ & $139(0,82)$ & $146(0,84)$ & & \\
\hline & Total & 88 & 170 & 174 & & \\
\hline \multicolumn{7}{|c|}{ +4 C/T (P/Q) } \\
\hline \multirow{4}{*}{ Genótipo } & $\mathrm{P} / \mathrm{P}$ & $23(0,51)$ & $49(0,55)$ & $42(0,47)$ & \multirow{4}{*}{1,6} & \multirow{4}{*}{$n s$} \\
\hline & $P / Q$ & $19(0,42)$ & $35(0,39)$ & $43(0,48)$ & & \\
\hline & $\mathrm{Q} / \mathrm{Q}$ & $3(0,07)$ & $5(0,06)$ & $4(0,04)$ & & \\
\hline & Total & 45 & 89 & 89 & & \\
\hline \multirow[t]{3}{*}{ Alelo } & $P$ & $65(0,72)$ & $133(0,75)$ & $127(0,71)$ & \multirow{3}{*}{0,53} & \multirow{3}{*}{ ns } \\
\hline & Q & $25(0,28)$ & $45(0,25)$ & $51(0,29)$ & & \\
\hline & Total & 90 & 178 & 178 & & \\
\hline
\end{tabular}

${ }^{*} n s:$ não significante

Tabela 24. Freqüência do diplótipo do exon 1 e da posição -221 da região promotora do gene 2 da MBL de indivíduos com manifestações clínicas de malária (MS) distribuídas pelo grau de parasitemia: alta (> 10.000 parasitas $/ \mathrm{mm}^{3}$ de sangue), baixa (1000-10.000 parasitas $/ \mathrm{mm}^{3}$ de sangue) e muito baixa $(<1.000$ parasitas $/ \mathrm{mm}^{3}$ de sangue).

\begin{tabular}{|c|c|c|c|c|c|c|c|}
\hline Genótipo & Alta & Baixa & $\begin{array}{l}\text { Muito } \\
\text { baixa }\end{array}$ & Total & $x^{2}$ & $\begin{array}{c}\text { Valor de } \\
P\end{array}$ & OR \\
\hline YA/YA & $15(0,35)$ & $37(0,44)$ & $34(0,40)$ & $86(0,41)$ & & & \\
\hline YA/XA & $12(0,28)$ & $22(0,26)$ & $22(0,26)$ & $56(0,26)$ & & & \\
\hline YA/O & $9(0,21)$ & $12(0,14)$ & $24(0,28)$ & $45(0,21)$ & & & \\
\hline$X A / X A$ & $1(0,02)$ & $0(0)$ & $2(0,02)$ & $3(0,01)$ & & & \\
\hline $\mathrm{XA} / \mathrm{O}$ & $4(0,09)$ & $8(0,10)$ & $2(0,02)$ & $14(0,07)$ & & & \\
\hline $\mathrm{O} / \mathrm{O}$ & $2(0,05)$ & $5(0,06)$ & $2(0,02)$ & $9(0,04)$ & & & \\
\hline $\begin{array}{l}\text { Suficiente } \\
\text { Insuficiente }\end{array}$ & $\begin{array}{c}37(0,86) \\
6(0,14)\end{array}$ & $\begin{array}{l}71(0,84) \\
13(0,16)\end{array}$ & $\begin{array}{c}82(0,95) \\
4(0,05)\end{array}$ & $\begin{array}{c}190(0,89) \\
23(0,11)\end{array}$ & 5,7 & 0,009 & $\begin{array}{c}0,27 \\
{[0,09-0,84]}\end{array}$ \\
\hline
\end{tabular}

Analisamos a associação entre TLR1 e MBL e a presença ou não de manifestações clínicas. Observamos uma diferença significante entre os indivíduos com produção suficiente de $M B L(Y A / Y A+Y A / X A+Y A / O+X A / X A)$ e 
não carreadores do polimorfismo TLR1 I602S (Ile/lle) e ausência de manifestações clínicas de malária $\left[\chi^{2}=4,8 ; P=0,014 ; \mathrm{OR}=0,095[0,005-1,6)\right]$ (tabela 25).

Tabela 25. Freqüência do diplótipo do exon 1 e da posição -221 da região promotora de gene de MBL e do gene TLR1 com (MS) e sem (AS) manifestações clínicas de malária.

\begin{tabular}{|c|c|c|c|c|c|c|}
\hline & $\bar{S}$ & AS & Total & $\overline{x^{2}}$ & Valor de $P$ & OR \\
\hline Suficiente +lle/lle & $102(0,90)$ & $46(1)$ & $148(0,93)$ & \multirow{2}{*}{4,8} & \multirow{2}{*}{0,014} & 0,095 \\
\hline Insuficiente + Ile/Ser e Ser/Ser & $11(0,10)$ & 0 & $11(0,17)$ & & & {$[0,005-1,6]$} \\
\hline
\end{tabular}

Analisamos também a associação entre TLR9-1486 e MBL e os níveis de parasitemia. Observamos uma diferença significante entre os indivíduos com produção suficiente de $\mathrm{MBL}(\mathrm{YA} / \mathrm{YA}+\mathrm{YA} / \mathrm{XA}+\mathrm{YA} / \mathrm{O}+\mathrm{XA} / \mathrm{XA})$ e não carreadores do polimorfismo TLR1 I602S (Ile/lle) com parasitemias mais baixas $\left[\chi^{2}=7,6 ; P=0,0031 ; O R=0,16[0,04-0,67)\right]$ (tabela 26$)$.

Tabela 26. Freqüência do diplótipo do exon 1 e da posição -221 da região promotora de gene 2 de MBL e da região promotora -1486 do gene TLR9 em indivíduos com manifestações clínicas de malária (MS) distribuídas pelo grau de parasitemia: alta (> 10.000 parasitas $/ \mathrm{mm}^{3}$ de sangue), baixa $(\leq 10.000$ parasitas $/ \mathrm{mm}^{3}$ de sangue).

\begin{tabular}{ccccccc}
\hline & Alta & $\begin{array}{c}\text { Baixa } \\
\text { +muito } \\
\text { baixa }\end{array}$ & Total & $\chi^{2}$ & $\begin{array}{c}\text { Valor de } \\
\boldsymbol{P}\end{array}$ & OR \\
\hline Suficiente $+\mathrm{T} / \mathrm{T}$ & $8(0,61)$ & $58(0,91)$ & $66(0,86)$ & 7,6 & 0,0031 & $\begin{array}{c}0,16 \\
{[0,04-0,67]}\end{array}$ \\
\hline Insuficiente $+\mathrm{T} / \mathrm{C} / \mathrm{C} / \mathrm{C}$ & $5(0,39)$ & $6(0,09)$ & $11(0,14)$ & & & \\
\hline \hline
\end{tabular}

*suficiente (YA/YA+YA/XA+YA/O+XA/XA); insuficiente (XA/O+O/O); lle (selvagem); Ser (mutante) 
1.3. Distribuição genotípica E ALÉLica do GENE do RECEPTOR DE COMPLEMENTO CR-1

Foi analisado por PCR-RFLP o polimorfismo C5507G do receptor de complemento $\mathrm{CR}-1$ de todos os indivíduos infectados com malária (tabela 27) e apenas nos indivíduos infectados por $P$. falciparum (tabela 28). O SNP do grupo AS e MS estavam em HWE (Equilíbrio de Hardy-Weinberg). Nenhuma diferença significante foi observada entre a freqüência do polimorfismo nos indivíduos com manifestações clínicas de malária e a freqüência nos indivíduos assintomáticos, tanto considerando todos os indivíduos como quando consideramos apenas os indivíduos infectados por $P$. falciparum $(P>0,05)$.

Tabela 27. Freqüência genotípica e alélica do polimorfismo C5507G do receptor de complemento CR-1 em indivíduos com (MS) e sem (AS) manifestações clínicas.

\begin{tabular}{|c|c|c|c|c|c|c|}
\hline \multicolumn{2}{|c|}{$\begin{array}{c}\text { CR-1 } \\
\text { C5507G }\end{array}$} & MS & AS & TOTAL & $x^{2}$ & Valor de $P$ \\
\hline Genótipo & $\begin{array}{l}\mathrm{C} / \mathrm{C} \\
\mathrm{C} / \mathrm{G} \\
\mathrm{G} / \mathrm{G} \\
\text { Total }\end{array}$ & $\begin{array}{c}142(0,631) \\
78(0,347) \\
5(0,022) \\
225\end{array}$ & $\begin{array}{c}46(0,639) \\
23(0,319) \\
3(0,042) \\
72\end{array}$ & $\begin{array}{c}188 \\
101 \\
8 \\
297\end{array}$ & 0,89 & $n s$ \\
\hline Alelo & $\begin{array}{c}\mathrm{C} \\
\mathrm{G} \\
\text { Total }\end{array}$ & $\begin{array}{c}362(0,80) \\
88(0,20) \\
450\end{array}$ & $\begin{array}{c}115(0,80) \\
29(0,20) \\
144\end{array}$ & $\begin{array}{l}477 \\
117 \\
594\end{array}$ & 0,023 & $n s$ \\
\hline
\end{tabular}

${ }^{*} n s:$ não significante 
Tabela 28. Freqüência genotípica e alélica do polimorfismo C5507G do receptor de complemento CR-1 em indivíduos com (MS) e sem (AS) manifestações clínicas causadas por $P$. falciparum.

\begin{tabular}{|c|c|c|c|c|c|c|}
\hline \multicolumn{2}{|c|}{ CR-1 } & MS & AS & $\overline{\text { TOTAL }}$ & $x^{2}$ & $\begin{array}{c}\text { Valor de } \\
P\end{array}$ \\
\hline \multicolumn{7}{|c|}{ C5507G } \\
\hline \multirow{4}{*}{ Genótipo } & $\mathrm{C} / \mathrm{C}$ & $125(0,635)$ & $33(0,702)$ & 158 & \multirow{4}{*}{0,81} & \multirow{4}{*}{$n s$} \\
\hline & $C / G$ & $68(0,345)$ & $13(0,277)$ & 81 & & \\
\hline & $\mathrm{G} / \mathrm{G}$ & $4(0,020)$ & $1(0,021)$ & 5 & & \\
\hline & Total & 197 & 47 & 244 & & \\
\hline \multirow[t]{3}{*}{ Alelo } & C & $318(0,81)$ & $79(0,84)$ & 397 & \multirow{3}{*}{0,55} & \multirow{3}{*}{ ns } \\
\hline & G & $76(0,19)$ & $15(0,16)$ & 91 & & \\
\hline & Total & 394 & 94 & 488 & & \\
\hline
\end{tabular}

${ }^{*}$ ns: não significante

Nenhuma diferença foi observada também quando analisamos a distribuição dos polimorfismos C5507G nos grupos de indivíduos com diferentes níveis de parasitemia (tabela 29) $(P>0,05)$.

Tabela 29. Freqüência genotípica e alélicas do polimorfismo C5507G do receptor de complemento CR-1 em indivíduos com manifestações clínicas de malária (MS) distribuídas pelo grau de parasitemia: alta ( $>10.000$ parasitas $/ \mathrm{mm}^{3}$ de sangue), baixa (1000-10.000 parasitas $/ \mathrm{mm}^{3}$ de sangue) e muito baixa $\left(<1.000\right.$ parasitas $/ \mathrm{mm}^{3}$ de sangue).

\begin{tabular}{|c|c|c|c|c|c|c|}
\hline \multicolumn{2}{|c|}{$\overline{\text { CR-1 }}$} & ALTA & BAIXA & MUITO BAIXA & $x^{2}$ & $\begin{array}{c}\text { Valor de } \\
P\end{array}$ \\
\hline \multicolumn{2}{|c|}{ C5507G } & & & & & \\
\hline \multirow{4}{*}{ Genótipo } & $\mathrm{C} / \mathrm{C}$ & $30(0,64)$ & $56(0,615)$ & $56(0,644)$ & & \\
\hline & $C / G$ & $17(0,36)$ & $33(0,363)$ & $28(0,322)$ & & \\
\hline & $\mathrm{G} / \mathrm{G}$ & $0(0)$ & $2(0,022)$ & $3(0,034)$ & 1,9 & $n s$ \\
\hline & Total & 47 & 91 & 87 & & \\
\hline \multirow{3}{*}{ Alelo } & $\mathrm{C}$ & $77(0,82)$ & $145(0,80)$ & $140(0,80)$ & & \\
\hline & G & $17(0,18)$ & $37(0,20)$ & $34(0,20)$ & 0,19 & $n s$ \\
\hline & Total & 94 & 182 & 174 & & \\
\hline
\end{tabular}

*ns: não significante 
A malária é uma das doenças mais importantes do mundo que causa altas taxas de morbidade e mortalidade, principalmente de crianças com menos de cinco anos de idade, e para a qual não existe uma vacina eficaz. Entre os esforços para o desenvolvimento de uma vacina está a busca de maiores conhecimentos da resposta imune na malária e de como fatores genéticos do hospedeiro podem influenciar esta resposta.

O espectro de manifestações clínicas da malária é amplo, indo de infecções assintomáticas a manifestações graves, sendo que as graves são apresentadas apenas por pequena proporção dos indivíduos infectados. Além do ambiente e do próprio parasito, a genética do hospedeiro deve desempenhar um papel fundamental nas diferenças individuais de manifestações clínicas.

A relevância de fatores genéticos do hospedeiro na malária foi proposta há mais de 50 anos atrás por Haldane, quando este observou que a presença de talassemia protegia contra malária e que esta havia sido selecionada em áreas de alta endemicidade de malária ${ }^{71}$. Além de diversar desordens genéticas que são associadas com a suscetibilidade à malária, vários polimorfismos de mediadores da resposta imune, tanto inata como adquirida, têm sido descritos e estudados quanto à sua associação com a malária, como MBL, TLRs, CR1, iNOS, receptores de IFN, TNF- $\alpha$, CD36, LT$\alpha, \mathrm{IL}-12, \mathrm{IL}-4, \mathrm{IL}-10$.

A capacidade inata do hospedeiro de reconhecer patógenos invasores e montar uma resposta defensiva contra estes é essencial para a sobrevivência. Na malária, uma rápida produção de citocinas pró- 
inflamatórias pela resposta inata ajuda no controle da parasitemia até que a imunidade adaptativa seja gerada para eliminar completamente o parasito. Mas, ao mesmo tempo em que a imunidade inata desencadeia a ativação de células e produção de citocinas que são importantes contra o plasmódio, a exacerbação desta resposta pode acarretar dano ao hospedeiro. Portanto, é muito importante o equilíbrio dos mecanismos efetores da resposta imune.

A resposta imune inata depende de vários PRRs expressos em uma grande variedade de células para desempenhar seu papel. Os PRRs desencadeiam um processo de ativação e sinalização nas células do hospedeiro para que as mesmas produzam citocinas e daí ocorra ativação da imunidade adaptativa para ampliação dos mecanismos imunológicos. PRRs como TLRs, MBL, CR1 e CD36 têm sido envolvidos no reconhecimento do parasito na malária.

No presente trabalho nós investigamos a ocorrência de SNPs dos PRRs MBL, CR-1, TLR1, TLR4, TLR6 e TLR9 e da molécula adaptadora TIRAP em população com malária de área endêmica na Amazônia Brasileira. A freqüência dos SNPS foi analisada em relação à expressão clínica de malária e aos níveis de parasitemia dos indivíduos.

Muitos dados sugerem que a família dos TLRs desempenham um papel importante na imunidade inata e na interligação desta com a imunidade adaptativa $^{222}$. TLRs dirigem a resposta imune após o reconhecimento de patógenos invasores através da indução de quimiocinas e citocinas inflamatórias. Diversas variações genéticas na via de sinalização estão 
associadas com suscetibilidade ou com resistência a diversas doenças infecciosas $^{87,144}$.

GPI de $P$. falciparum são reconhecidos por TLR2/TLR1, TLR2/TLR6 e TLR4, cuja sinalização resulta na produção de citocinas próinflamatórias ${ }^{134,135}$ e induz sintomas de malária grave em camundongos ${ }^{223}$, enquanto o pigmento malárico, hemozoína, pode ativar a resposta imune inata via TLR9 ${ }^{129}$.

Neste estudo, investigamos SNPs nos genes de TLR1 (I602S), TLR4 (D229G), TLR6 (S249P) e TLR9 (T-1237C/-1486C), pois estes são os TLRs mais prováveis de estarem envolvidos no reconhecimento de plasmódios. Também investigamos um SNP na molécula MAL/TIRAP (S180L) que é a proteína adaptadora comum para TLR2 e TLR4. Nós mostramos pela primeira vez uma associação entre presença de sintomas não graves de malária e variantes em TLR1 e TLR6. Ainda, observamos que polimorfismos do promotor de TLR9 estão associados com altas parasitemias.

Estudos funcionais da variante TLR1 I602S sugerem que este alelo causa diminuição da expressão de TLR1 na superfície celular, produção de

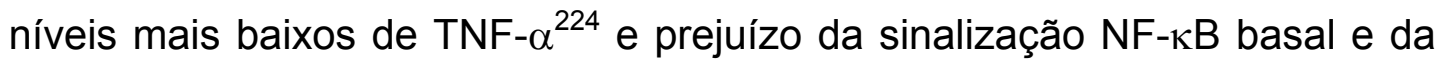
induzida por lipopeptídeo de Mycobacterium tuberculosis ${ }^{225}$. Existem relatos que na infecção por Mycobacterium leprae, a sinalização via TLR2/TLR1 seja prejudicial para o hospedeiro e que o alelo TLR1 $602 S$ esteja associado com menor incidência de hanseníase ${ }^{224}$. Já os nossos dados sugerem que o alelo TLR1 602S é um fator de risco para malária. Uma possível explicação de nossos dados é que em doenças infecciosas como a malária, é 
necessário que o hospedeiro mantenha o plasmódio sob controle e elimine-o tão rápido quanto possível para evitar sua multiplicação no fígado ao contrário de doenças crônicas, como a hanseníase. Nós também observamos uma associação marginal com presença de sintomas de malária e a variante TLR6 S249P. A função deste polimorfismo não é conhecida. Entretanto o que é interessante, é que ambos TLR1 e TLR6 funcionam como heterodímeros com TLR2 para ter especificidade ao ligante e TLR2 é o principal receptor para GPI. Nós não investigamos o polimorfismo TLR2 Arg753GIn, pois a sua freqüência é muito baixa na população brasileira (Ramasawmy et al. dados não publicados). Pode-se presumir que um defeito nestes receptores possa prejudicar o reconhecimento de GPI e levar a um clareamento ineficiente do parasito.

TLR1, 6 e 10 evoluíram sob forte seleção "purificadora" ${ }^{226}$, e é interessante observar que a freqüência do alelo TLR1 $602 S$ difere entre as populações, sendo de $75 \%$ em Caucasianos, $26 \%$ em descendentes africanos, $0 \%$ no Sudeste Asiático ${ }^{224}$ e $10 \%$ na população do Amazonas que é formada principalmente de uma mistura de Ameríndios, Caucasianos e Africanos. É interessante especular porque estes polimorfismos de TLR teriam sido seletivamente mantidos. Uma possibilidade deve ser o importante papel de sinalização de TLR que leva a uma cascata de amplificação de respostas inflamatórias efetivas a patógenos, mesmo quando estes estão presentes em baixas quantidades, mas que podem se multiplicar rapidamente e matar o hospedeiro. Por outro lado, uma resposta exagerada hiperreativa poderia ser igualmente danosa, levando a 
imunopatologia potencialmente fatal. Olhando por uma perspectiva evolucionária, é difícil para o hospedeiro desenvolver um equilíbrio da cascata de amplificação que permita uma resposta calibrada para todos patógenos ou mesmo para todas doses potenciais de patógenos. Assim, a variação permanente nas vias de TLR deve refletir balanceamento da seleção por diferentes patógenos e epidemias seqüenciais, levando à manutenção de alelos que tenham diferentes eficácias contra diferentes alvos infecciosos. $^{224}$

O alelo TLR4 D229G não mostrou nenhuma associação com presença de sintomas de malária no nosso estudo. Indivíduos carreadores deste alelo apresentaram baixa produção de IL-6 e diminuição dos níveis de IL-1 $\beta$ após administração oral de LPS, o que sugere que este polimorfismo prejudica a ativação da resposta imune inata via TLR4 ${ }^{227}$. Recentemente, foi visto uma associação do polimorfismo TLR4 D229G com malária grave em crianças africanas $^{92}$. A ausência de associação que observamos não exclui TLR4 como um gene importante na malária. Nosso estudo não tem força bastante para detectar uma associação, pois a freqüência do alelo TLR4 299G foi muito baixa ( $5 \%$ ) e também pelo fato de nossos pacientes não apresentarem sintomas graves da doença. Estudos populacionais mostraram uma distribuição geográfica específica dos haplótipos de $T L R 4^{228}$. Na África, a freqüência do alelo TLR4 299G é de 10 a $18 \%$, cerca de 10 a 20 vezes maior do que as freqüências encontradas em outros continentes, sendo praticamente ausente em população caucasiana e ausente na população 
asiática $^{229}$. O background genético das populações pode explicar a ausência de concordância entre os estudos de polimorfismos de TLR4.

Os polimorfismos do promotor de TLR9 não mostraram nenhuma associação com presença de sintomas, o que está de acordo com um estudo recente com malária grave ${ }^{93}$. Entretanto, nós observamos uma associação de TLR9 T-1486C e T-1237 com altas parasitemias. Recentemente, foi relatado que TLR9 $T$-1486C está associado com malária placentária $^{93}$, que é caracterizada por acúmulo excessivo de hemozoína. Também foi observada alta expressão de TNF $\alpha$ em macrófagos isolados de placenta de mulheres com malária ${ }^{230}$. Mas, os mecanismos pelos quais TLR9 deva contribuir na patogênese de malária ainda precisa ser esclarecido. Provavelmente estes polimorfismos levem a uma disfunção de TLR9. Estudos em murinos mostram que o contínuo acúmulo de hemozoína em DCs acarreta uma disfunção destas células via TLR9 e induz menor produção de citocinas pró-inflamatórias e aumento na produção de IL$10^{231,232}$. Estes resultados sugerem uma inibição da resposta imune mediada por TLR durante estágios mais tardios da infecção. Recentemente e corroborando com os dados anteriores, foi mostrado que $P$. yoelii escapa da resposta imune do hospedeiro ao ativar $\mathrm{T}_{\text {regs }}$ via $\mathrm{TLR}^{140}$. Embora a função deste SNP não seja clara, pode estar em desequilíbrio de ligação com um algum alelo causal ainda não identificado, que poderia influenciar o nível de transcrição.

A proteína adaptadora MAL codificada pelo gene TIRAP está envolvida na sinalização de TLR2 e TLR4. Recentemente, foi observado que 
indivíduos heterozigotos para a variante TIRAP S180L são protegidos de doenças infecciosas e esta variante atenua a sinalização via TLR2 ${ }^{150}$. Nós não observamos diferença na distribuição genotípica desta variante entre indivíduos com sintomas de malária e assintomáticos. Entretanto, heterozigotos foram mais comuns entre assintomáticos do que em indivíduos com sintomas de malária ( $25 \%$ vs. $18 \%)$, apesar da diferença não ter alcançado significância estatística. Esta observação pode sugerir que indivíduos assintomáticos reconhecem os parasitas eficientemente no contexto dos polimorfismos de TLR1 e TLR6 e modulam a resposta imune apropriadamente em relação à variante TIRAP.

Juntos, nossos dados indicam que os polimorfismos do promotor de TLR9 devem de alguma forma controlar o nível da parasitemia por Plasmodium enquanto a deficiência de $T L R 1$ parece predispor à presença de sintomas de malária. Da mesma forma que com outros fatores genéticos $^{233}$, o papel dos polimorfismos de TLR deve variar com a endemicidade de malária, como acontece com a manifestação da doença. Estes achados genéticos podem contribuir para o entendimento da patogênese da malária e levantar uma questão interessante que deve ser investigada em outra população a fim de validar a contribuição genética destes loci na patogênese da malária.

Investigamos também polimorfismos do gene da MBL. A MBL é uma proteína sérica importante na resposta imune inata, pois é capaz de eliminar vários microorganismos através da ativação da cascata do complemento e por opsonização. Enquanto em muitas infecções a MBL tem um efeito 
protetor da doença ${ }^{91}$ em outras, os agentes infecciosos se utilizam da MBL para facilitar a entrada nas células do hospedeiro como é o caso de micobactérias ${ }^{167}$ e Leishmania chagasi ${ }^{168}$. Isto poderia explicar porque altas freqüências de polimorfismos que causam deficiência da $\mathrm{MBL}$ podem ser encontradas mesmo em populações expostas constantemente a vários microrganismos infecciosos ${ }^{234-236}$.

MBL auxilia na fagocitose independente do sistema complemento e desta maneira induz a produção de citocinas pró-inflamatórias em monócitos, principalmente IL-6 e IL-1 $\beta^{237}$, mas em altas concentrações (>400 mg/L), a MBL multimérica pode ter um efeito supressor da produção destas citocinas, como observado na infecção por Neisseria meningitidis ${ }^{238}$ e na malária ${ }^{175}$. Os níveis de MBL multimérica e os genótipos MBL2 podem modular a liberação de citocinas e quimiocinas em resposta a infecção por P. falciparum ${ }^{175}$.

Experimentalmente MBL se liga a GPI de $P$. falciparum e via complexo MBL-MASP inibe a invasão do parasito nos eritrócitos e sua multiplicação ${ }^{155,160}$.

Variantes do gene MBL2 que diminuem os níveis séricos da proteína ou que codificam proteínas disfuncionais têm sido associadas com proteção a várias infecções e doenças autoimunes ${ }^{239-241}$ ou com predisposição ou aumento da gravidade de outras doenças, como lepra, tuberculose ${ }^{242}$, HIVV $^{243,244}$, leishmaniose visceral ${ }^{168}$, colite ulcerativa esporádica ${ }^{245}$ e doença cardíaca reumática ${ }^{246,247}$. 
Em nosso estudo, não observamos nenhuma associação das variantes do exon 1 de $M B L 2(B, C$ e $D)$ com expressão clínica da malária. Dados semelhantes foram observados em populações do Gâmbia ${ }^{178}$, de Gana $^{155}$ e do Gabão ${ }^{86}$. Já em outros estudos foi observada fraca associação entre variantes $B$ e $C$ (que causam produção mais baixa de $M B L$ ) e malária grave ${ }^{91}$ e associação do alelo $C$ com malária grave e anemia ${ }^{179}$. O resultado de uma meta-análise destes cinco estudos mostrou aumento de $30 \%$ no risco de malária em indivíduos com uma mutação missense, ou seja, alteração em um ou mais códons do gene $M B L 2^{179}$. Nesta meta-análise não foi incluído o trabalho de Boldt et al. $(2006)^{175}$, que também não observaram associação de variantes do exon 1 de $M B L 2$ e gravidade de sintomas na malária.

Nossos resultados mostraram associação do polimorfismo $P / Q$ da posição +4 da região não traduzida do gene MBL2 (P/Q) com presença de sintomas de malária $(P=0,012)$. Um efeito deste polimorfismo nos níveis séricos de $\mathrm{MBL}$ in vivo foi observado apenas quando se compararam os haplótipos LYQA e LYPA, sendo que indivíduos carregando à variante $Q$ (LYQA) apresentavam maiores níveis séricos de MBL do que os indivíduos que não carregavam este alelo (LYPA). Estes haplótipos são construídos considerando-se todas as variantes do gene MBL2 [-550 (H/L) e $-221(X / Y)$ da região promotora, posição +4 da região não traduzida $(P / Q)$ e do exon 1 $(A / O)]^{177}$. Esses dados associados aos nossos podem sugerir que os indivíduos carreadores do alelo $Q$, por expressarem níveis séricos mais altos de MBL tenham maior probabilidade de desenvolver os sintomas da doença. 
Também observamos fraca associação do polimorfismo -221 (X/Y) com a presença de sintomas de malária. Diversos estudos em populações com diferentes origens mostraram que os diplótipos XA, YA e YO (construídos a partir da distribuição dos alelos do exon 1 e da posição +221 do promotor do gene de $M B L)$ têm impacto na regulação dos níveis séricos de $M B L^{177}$. $O$ papel regulatório desses diplótipos de MBL2 pode ser modulado por citocinas pró-inflamatórias liberadas durante a resposta imune inata ${ }^{175,236}$.

Observamos associação de maiores parasitemias com a presença do alelo $D$ do exon $1(P=0,021)$ e com o haplótipo de produção insuficiente de MBL $(X A / O+O / O)(P=0,009)$. Níveis baixos de MBL podem ser prejudiciais na infecção por $P$. falciparum, com redução da ativação do sistema complemento e de opsonização, mecanismos que auxiliam no controle da parasitemia. Garred et al. (2003) ${ }^{155}$ observaram associação de altos níveis da parasitemia e baixos níveis de glicose com os haplótipos O/O vs A/A e A/O. Provavelmente, a deficiência de MBL não seja associada com a presença de sintomas de malária, mas seja um fator de risco para gravidade da doença principalmente em crianças ainda sem imunidade adaptativa bem desenvolvida.

Os dados da literatura são contraditórios sobre a associação de polimorfismo de CR1 e malária. O polimorfismo do intron 27 de CR1 ( $L / H-$ Hind III RFLP) foi o mais estudado até o momento e em apenas um estudo foi encontrada associação deste com menor expressão de CR1 nos eritrócitos e malária grave ${ }^{94}$. Outros estudos não mostraram associação do polimorfismo $L / H$ - Hind III RFLP com malária grave ${ }^{210}$, ou com níveis de 
expressão de $\mathrm{CR} 1^{211}$, ou com parasitemia ${ }^{216}$. O polimorfismo do exon 22 (A3650G) de CR1 foi associado à deficiência de CR1 nos eritrócitos de indivíduos da Papua Nova Guiné, mas não foi estudado em relação às manifestações clínicas de malária ${ }^{213}$. O alelo de Knop S/2/2 e em particular o genótipo S/2/2 McCa/b foi associado com proteção de malária cerebral, mas não de anemia grave..$^{214}$

Nenhum dado existe na literatura sobre a associação do polimorfismo CR1 C5507G com malária, que está em desequilíbrio de ligação com os polimorfismos do intron 27 (Hind III RFLP) e do exon 22 (A3650G) $)^{248,249}$ e que foi o polimorfismo de CR1 incluído em nosso estudo. Não observamos associação deste com a expressão clínica de malária nem com parasitemia. Provavelmente, nosso estudo não tenha força suficiente para detectar uma associação, pois não estudamos indivíduos com sintomas graves de malária e CR1 tem sido implicado na patogênese da malária grave, principalmente malária cerebral, pela sua participação na formação de rosetas. Entretanto, a importância da formação de rosetas na patogênese da malária cerebral tem sido questionada, pelo fato desta ser observada também na malária por $P$. vivax $^{202,250}$, uma infecção que não causa malária cerebral e nem se observa citoaderência do parasito ao endotélio vascular. Infelizmente não foi possível determinarmos os níveis de expressão de CR1 em nossa população para relacionarmos com a ocorrência do polimorfismo CR1 C5507G, como observado em outras populações ${ }^{204,205,209}$.

Os PRRs podem interagir com uma célula ou com várias células e obviamente múltiplos receptores podem aumentar a função efetora da célula 
e induzir diferentes respostas que medeiam um controle eficiente contra o patógeno. Recentemente, foi demonstrado que MBL e TLR2/TLR6 cooperam mutuamente no reconhecimento de Staphylococcus aureus o que mostra um sinergismo de mecanismos imunológicos na defesa contra o patógeno ${ }^{239}$. Nossos resultados também sugerem uma cooperação entre TLR1 e TLR9 e MBL na resposta imune contra a malária, pois os indivíduos com haplótipo de produção suficiente de $M B L(Y A / Y A+Y A / X A+Y A / O+X A / X A)$ e não carreadores do polimorfismo TLR1 I602S tiveram menor risco da presença de manifestações clínicas de malária e os indivíduos com haplótipo de produção suficiente de $M B L$ (YA/YA+YA/XA+YA/O+XA/XA) e não carreadores do polimorfismo TLR9 -1486 apresentaram menores níveis de parasitemia.

É importante termos em mente que existem razões biológicas potenciais para que um mesmo polimorfismo de gene relacionado à resposta imune tenha diferentes conseqüências em diferentes regiões malarígenas. A associação pode variar de acordo com a prevalência local de polimorfismos críticos dos antígenos do parasito e diferenças regionais na intensidade de transmissão de malária, que podem ter conseqüências complexas para o desenvolvimento da imunidade adquirida e o padrão de manifestações clínicas da malária ${ }^{251}$. Estas são questões que tornam importantes os estudos de epidemiologia genética em diferentes regiões endêmicas de malária no mundo e os conhecimentos adquiridos provavelmente facilitarão o desenvolvimento futuro de vacinas eficazes e terapias que reduzam o impacto global da malária. 
CONCLUSÕES 
1. Foram observadas associações dos polimorfismos TLR1 I602S, TLR6 TLR6 S249P e da posição +4 da região não traduzida $(P / Q)$ de $M B L 2$ com manifestações clínicas de malária.

2. Foram observadas associações dos polimorfismos TLR9 T1486C, TLR9 T1237C, MBL ${ }^{*} D$ (códon 52) e do diplótipo de produção insuficiente de $\mathrm{MBL}(X A+O / O)$ com parasitemias mais altas.

3. Nenhuma associação foi observada entre o polimorfismo CR-1 C5507G e manifestações clínicas de malária ou com parasitemia.

4. Considerando juntos os polimorfismos de MBL e TLR, observamos que indivíduos com diplótipo de produção suficiente de MBL $(Y A / Y A+Y A / X A+Y A / O+X A / X A)$ e carreadores do polimorfismo TLR1 I602S tinham menos manifestações clínicas de malária e indivíduos com diplótipo de produção suficiente de $\mathrm{MBL}$ e não carreadores do alelo TLR9 -1486C tinham parasitemias mais baixas do que os indivíduos com diplótipo de produção insuficiente de MBL e carreadores dos alelos variantes de TLR1 I602S e TLR9 -1486C, respectivamente.

5. Nossos dados indicam que polimorfismos do promotor de TLR-9 e os diplótipos de produção insuficiente de $\mathrm{MBL}(X A+O / O)$ devem de algum modo controlar o nível de parasitemia por plasmódios enquanto a deficiência de TLR1 parece predispor para a presença de manifestações clínicas de malária. 
Variants in the Toll-like receptor pathway signaling are associated with clinical outcomes of malaria.

Fabiana MS LEORATTI ${ }^{1}$, Lilian FARIAS ${ }^{1}$, Fabiana P ALVES ${ }^{5}$, Martha C SUAREZ-MÚTIS ${ }^{6}$, José R COURA ${ }^{6}$, Jorge KALIL ${ }^{2,3,4}$, Erney P CAMARGO ${ }^{5}$, Sandra L MORAES ${ }^{1,2}$ and Rajendranath RAMASAWMY ${ }^{2,4,7}$.

${ }^{1}$ Instituto de Medicina Tropical de São Paulo, ${ }^{5}$ Instituto de Ciências Biomédicas, University of São Paulo, São Paulo, Brazil

${ }^{2}$ Heart Institue (InCor) and ${ }^{3}$ Division of Clinical Immunology and Allergy, Department of Clinical Medicine, University of São Paulo School of Medicine, São Paulo, Brazil.

${ }^{4}$ Institute of Immunology Investigation, São Paulo, Brazil.

${ }^{5}$ Fundação Instituto Oswaldo Cruz (FIOCRUZ), Rio de Janeiro, Brazil.

${ }^{7}$ Servico de Imunologia, Hospital Universitário Professor Edgar Santos, Universidade Federal da Bahia, Salvador, Brazil.

Running head: Malaria and toll-like receptors

Corresponding author:

Rajendranath RAMASAWMY

Laboratorio de Imunologia

InCor-FMUSP

Av. Eneas Carvalho Aguiar,44

Bloco II- 9 andar

Sao Paulo, SP

Brazil

CEP. 05403-000

e-mail: ramasawm@usp.br 
Abstract

Background. Malaria is one of the most significant infectious diseases in the world, and causes a heavy toll in infant mortality. Toll-like receptors (TLRs), a key component of innate immunity, are central to counter-infection. Variants in the TLRs-pathway signaling are associated with susceptibility to infectious diseases.

Methods. We genotyped single nucleotide polymorphisms of the TLRspathway signaling genes in patients with mild malaria and Plasmodiuminfected asymptomatic individuals (ASY) by polymerase chain reaction.

Results. Genotype distributions for the TLR-1 I602S differed significantly between patients with mild malaria and ASY. The TLR-1 $602 S$ allele revealed an OR of $2.2(\mathrm{P}(\mathrm{Pc})=0.003(0.015)$ associated with malaria among patients with Plasmodium (Pspp)-mild malaria and $2.1 \quad(P(P c)=0.015(0.75)$ ) among patients with Plasmodium falciparum (Pf)-mild malaria respectively. The TLR6 S249P SNP showed an excess of homozygotes for the TLR-6 249P allele in ASY compared to patients with Pspp-mild malaria $(P(P c)=0.01(0.05)$; $\mathrm{OR}=2.1[95 \% \mathrm{Cl} 1.1-4.2])$ suggesting that the TLR-6 249S allele may be a risk factor for malaria $(P(P c)=0.01(0.05) ; 2.0[1.1-3.7]$. The $T L R-9-1486 C$ allele showed a strong association with high parasitemia $(P=0.0009)$.

Conclusions. Our findings indicate that TLR-1 and TLR-6 variants are significantly associated with mild malaria while $T L R-9 T-1486 \mathrm{C}$ variants with parasitemia. This may bring additional understanding to the pathogenesis of malaria. 


\section{Introduction}

Malaria, a vector-borne disease, is caused by the protozoan parasite Plasmodium, which is transmitted by the mosquito Anopheles. Plasmodium falciparum (Pf) malaria affects $300-500$ million people annually and is the leading cause of death among young children in sub-Saharan Africa. It is estimated that one million children die from malaria infection each year [1] and nearly 2.5 and 2.6 billion people are at possible risk of transmission of Pf and Plasmodium vivax $(P v)$ respectively [2].

$P f$-infected individuals show a wide spectrum of clinical manifestations, which range from asymptomatic (ASY) infection to severe life-threatening forms such as hyperparasitemia, hypoglycemia, cerebral malaria, respiratory distress or vital organ dysfunction. Elevated levels of circulating TNF $\alpha, \mathrm{IL}-6, \mathrm{IL}-12, \mathrm{IL}-\beta$, and IL-10 seemed to correlate with the severity of the disease and with fatal outcomes [3]. Autopsy studies of human brain tissue from patients with cerebral malaria showed increased expression of TNF $\alpha$ and IL-1 $\beta[4-6]$.

The interaction of the host with the pathogen has several layers of complexity: 1) genetic make-up of the host; 2) the genetics of the parasite; 3 ) the malaria vector mosquito Anopheles and 4) favorable environment for the development of the disease. However, not all individuals infected by Plasmodium develop severe and complicated disease. Only a very small subset of Plasmodium-infected individuals (1-2\%) progresses to the life threatening forms of malaria [1]. This has led to the pertinent question of why only a very small subset of Plasmodium-infected individuals develops severe and complicated symptoms while others remain asymptomatic (ASY) or have mild malaria. The development of severe and complicated disease in only 1$2 \%$ of $P f$-infected children is probably a reflex of differential susceptibility. Indeed, numerous studies reported that host genetics are strong determinants in differential susceptibility to human infection [7]. Furthermore, inter-individuals variations in the expression of cytokines appeared to be under the influence of genetic factors, and individuals may be classified as high or low inflammatory responders $[8,9]$. Better control of Plasmodium 
infection in the host implies that a fine balance must be achieved between the generation of a host immune response sufficient to contain the parasite, but tightly controlled at the same time so as to avoid collateral damage to the host.

Severe malaria is characterized by marked changes in cytokine expression, which results from the immune response of the individual to infection. A robust innate immune response by a susceptible host either to the parasite Plasmodium itself or to the metabolites released from ruptured red blood cells may lead to high proinflammatory cytokines production, which in turn trigger the major symptoms such as high fever [10]. Innate immunity is the first line of host defense in response to invading pathogen. Over the last decade, a new family of pathogen recognition receptors has been identified under the name toll-like receptors (TLRs) [11]. TLRs recognize invading pathogens through distinct pathogen associated molecular patterns and play a key role in innate immunity of the host. In human, ten functional TLRs are described. Upon recognizing their respective ligands, the TLRs trigger the production of proinflammatory cytokines through the NFKB-dependent or interferon regulatory factor-dependent signaling pathways. The intracellular signaling of TLRs is mediated by at least five adaptor proteins, MyD88, MAL/TIRAP, TRIF, TICAM and SARM [12]. TLR1, 2, 4, 5, 6 and 10 are found on the extracellular surface of cells while TLR3 and 7-9 known as nucleic acids sensors are located intracellular within the endoplasmic reticulum and cytoplasmic vesicles such as endosomes. TLR2 functions as a heterodimer with TLR1 or TLR6 and recognizes a wide variety of ligands and glycosylphosphatidylinositol (GPI) of $P f$ is one of them [13]. TLR4 among its different ligands also recognized GPI of Pf [13]. TLR9, a receptor for double stranded DNA (CpG DNA), is activated by Plasmodium DNA [14]. Mice immunized with synthesized GPI and challenged with Plasmodium berghi are protected against malaria-related acidosis, pulmonary edema compared to non-immunized mice suggesting that GPI may contribute to fatalities and pathogenesis of malaria [15]. In vitro GPI influences the expression of 
adhesion molecules and proinflammatory cytokines IL-1 and TNF $\alpha$ [16], all of which are known to cause severe malaria [17,18].

Myeloid differentiation factor (MyD88) is the central mediator of TLRs and IL-1 signaling. In mice deficient for MyD88 and infected with Plasmodium berghei, a decrease in IL-12 production with no sign of liver damage is observed compared to wild type mice [19]. Several SNPs in the TLR family influence the inflammatory pathways and are associated with susceptibility to infection [20,21], Two variants in the TLR4 gene, TLR-4 Asp299Gly (rs4986790) and TLR-4 Thr399lle (rs4986791), have been reported [22]. The TLR4 Asp299Gly variant is associated with susceptibility to bacterial infections [23]. TLR-2 Arg753GIn variant (rs5743708) is suggested as a predisposable factor to staphylococcal infection [24]. The promoter polymorphisms of TLR-9; TLR-9 -1237C/T (rs5743836) is cited to confer susceptibility to asthma [25], while $T L R-9-1486 C / T r s 1870884)$ is associated with placental malaria [26]. TLR-1 I602S variant is associated with susceptibility to inflammatory bowel disease confined to the ileum [27] and protection against leprosy [28]. TLR-6 S249P ( $r s 5743810)$ is associated with asthma [29]. The adaptor protein MAL encoded by TIRAP on chromosome 11q24.2, contained a variant TIRAP S180L (rs8177374) that is associated with protection to several infectious diseases including malaria [30]. Noteworthy, TLR-1 and TLR-6 are situated on chromosome 4p14, TLR-2 on chromosome 4q31.3, TLR-4 on chromosome 9q32-q33 and TLR-9 on chromosome $3 p 21.3$.

Here, we investigated whether SNPs in the TLRs gene and the adaptor protein MAL/TIRAP gene may be associated with clinical outcomes of malaria in Plasmodium-infected individuals as Plasmodium displayed a variety of ligands for the TLRs. To this end, we conducted a case-control study by comparing patients with mild malaria to ASY Plasmodium-infected individuals. We report that TLR-1-I602S and TLR-6-S249P are associated with mild malaria while the promoter SNPs of TLR-9 with high Plasmodium parasitemia. 


\section{Material and Methods}

Study area and population: The study population was from three endemic areas of the Amazonian region of Brazil and consisted of 304 unrelated Plasmodium-infected individuals. 265 were from Peixoto de Azevedo, a city of Matto Grosso state (PA); 23 from Machado River community, a tributary of the Madeira River $180 \mathrm{~km}$ downstream from Porto Velho, Rondonian State [31] and 16 from the Padauiri River community, a left margin affluent of Negro river, Amazon state [32]. This studied population is mostly of descendent of Amerindian origins mixed with Caucasians and Africans. The climate of the three areas is similar, with a rainy season from October to April and a dry season from May to September. The temperature ranges from 15 to $38 \mathrm{C}$ with a high humidity $>90 \%$. All individuals participating in this study provided informed consent, which was approved by the Ethical Committee of the Hospital das Clinicas da Faculdade de Medicina da Universidade de São Paulo.

All the individuals in the study are Plasmodium-infected as confirmed by thick blood smear film or polymerase chain reaction specific for detection of Plasmodium from blood samples drawn at admission as described below. Plasmodium-infected individuals who presented malaise, fever, or muscular pain and headache were considered symptomatic and henceforth designed as patients with mild malaria while those without any symptoms for sixty days consecutively as asymptomatic (ASY).

Thick blood smear film test. From each individual, thick blood films were prepared and stained with Giemsa for microscopic identification of Plasmodium. Well-trained microscopists examined 200 fields of Giemsastained thick blood smears at $\times 1,000$ magnification under immersion oil. Parasite density was determined by counting the number of asexual forms per 200 leukocytes, assuming a leukocyte number of 6,000 per milliliter.

Detection of Plasmodium circulating DNA: Genomic DNA was isolated from blood cells collected in EDTA tubes by the phenol-chloroform method. Detection of Plasmodium species was performed as described elsewhere [33,34]. Briefly, the method is based on a nested-polymerase 
chain reaction (PCR) with genus-specific primers for the target $18 \mathrm{~S}$ rRNA gene followed by a second round of PCR with primer-specific for the species $(P f, P \vee$ and $P m)$.

Single nucleotide polymorphisms genotyping: The following nonsynonymous SNPs (TLR-1 T1805G (I602S), TLR-4 896A/G (D229G), TLR-6 745C/T (S249P), TIRAP 975C/T (S180L) and the two promoter SNPs of $T L R-9$ at position $T-1237 C$ and $T-1486 C$ were studied. The different SNPs were identified by PCR-restriction fragment length polymorphisms. The primers and PCR cycling conditions are shown in Table 1. The PCR reaction for each SNP was one microliter $(\mu \mathrm{L})$ of genomic DNA (50ng) added to $24 \mu \mathrm{L}$ of amplification mix containing containing $2 \mathrm{U}$ of Taq polymerase in buffer that contained100 mmol/L Tris- $\mathrm{HCl}(\mathrm{pH}, 8.3)$ and $500 \mathrm{mmol} / \mathrm{L} \mathrm{KCL}, 1.5$ $\mathrm{mmol} / \mathrm{L} \mathrm{MgCl}$, $40 \mathrm{mmol} / \mathrm{L} \mathrm{dNTPs}$, and $0.25 \mathrm{pmol} / \mathrm{L}$ each of forward and reverse primer. The PCR was performed under their respective PCR cycling conditions for 35 cycles. Ten $\mu \mathrm{L}$ of PCR product was digested with $5 \mathrm{U}$ of respective restriction endonuclease from New England biolabs in a final volume of $20 \mu \mathrm{L}$ that contained $2 \mu \mathrm{L}$ of $10 \mathrm{X}$ enzyme buffer according to the manufacturer instructions. The resulting fragments were separated by electrophoresis in either a $3 \%$ agarose gel or $12 \%$ polyacylamide gel and were visualized under UV light by staining with ethidium bromide. To insure the validity of our genotyping methods, known genotype for each SNP was used as control.

Statistical analysis: Statistical analysis was performed using Prism software, version 4.0 (GraphPad). Allele and genotype frequencies were calculated by direct counting. Associations between disease groups and a specific allele, as well as between disease groups and genotypes, were analyzed using the $\chi^{2}$ test along with the OR and $95 \% \mathrm{Cl}$. The HardyWeinberg expectation (HWE) was determined by comparing the observed number of different genotypes with those expected under the HWE for the estimated allele frequency. Statistical comparison also was performed using Fisher's exact test whenever a variable in the contingency table was below 5 . 
Bonferroni corrections were applied by multiplying the $P$ values to the number of gene studied.

\section{Results}

The baseline characteristics of the 304 Plasmodium-infected individuals are shown in Table 2. Of the 304 Plasmodium-infected individuals, 230 had mild malaria symptoms and 74 were asymptomatic (ASY). The median age was 29 years and 35.5 years for patients with mild malaria and ASY respectively $(P=0.0001)$. Among the patients with malaria, 202 had Pf infection in contrast to 47 individuals among the ASY. However, only 124 patients with mild malaria and 27 ASY had single Pf infection. For clarity of comparison between patients with mild malaria and ASY, the individuals were stratified as Pf infection irrespective of other plasmodium species co-infection and Plasmodium species (Pspp)-infection that included Pf-infection and other species infection.

Overall, we investigated 298, 304, 290, 290, 298 and 302 Plasmodium-infected individuals for the TLR-1 I602S, TLR-4 D229G, TLR-6 S249P, TLR-9 T-1237C, TLR-9 T-1486C and TIRAP S180L SNPS respectively. The multiple missing genotypes were due to lack of DNA. All the SNPs were in HWE in the ASY group while the TLR1 I602S and TIRAP S180L deviated slightly and significantly in patients with mild malaria respectively. To ensure that there was no error in genotyping for both polymorphisms, the typing was repeated with the inclusion of control DNA of known genotype for both SNPs. No discordance was observed. The genotype distributions and allele frequencies for all the SNPs are shown in Table 3. For determining whether there was any difference in the genotype distribution for each SNP, comparison of the patient with mild malaria group with the ASY group was first carried out with Pf-infected individuals and secondly with the total number of individuals i.e. Pspp-infected individuals. Only the TLR-1 I602S genotype distribution was significantly different between the patient with mild malaria group and ASY $\left(2 \times 3 \chi^{2}=9.6\right.$; $\mathrm{P}=$ 0.008 among Pspp-infected) and $\left(2 \times 3 \chi^{2}=6.9 ; \mathrm{P}=0.032\right.$ among $P f-$ infected) respectively. Homozygosity for the allele TLR-1 602I was 
predominant among the ASY group (lle/lle vs. Ile/Ser + Ser/Ser; $2 \times 2 \chi^{2}=$ 9.5; $\mathrm{P}(\mathrm{Pc})=0.001(0.005) ; \mathrm{OR}=2.6[95 \% \mathrm{Cl} 1.4-4.9]$ among Psppinfected). Similar trend was also observed in the Pf-infected group $\left(2 \times 2 \chi^{2}=\right.$ 6.6; $\mathrm{P}(\mathrm{PC})=0.005(0.025) ; \mathrm{OR}=2.6[95 \% \mathrm{Cl} 1.2$ - 5.6]). Heterozygotes were more prevalent in patients with mild malaria than in the ASY (39\% vs. $19 \%$ among Pspp-infected and $40 \%$ vs. $20 \%$ among Pf-infected with a statistical difference of $\left(2 \times 2 \chi^{2}=9.5 ; \mathrm{P}(\mathrm{Pc})=0.001(0.005)\right.$; $\mathrm{OR}=2.7[95 \% \mathrm{Cl} 1.4-$ 5.1]) and $\left(2 \times 2 \chi^{2}=6.9 ; \mathrm{P}(\mathrm{PC})=0.004(0.020) ; \mathrm{OR}=2.7[95 \% \mathrm{Cl} 1.3-6.1]\right)$ respectively when heterozygous individuals were compared with homozygous individuals for the TLR-1 602I allele. The frequency for homozygosity of the TLR-1 602S allele was similar in both groups. Altogether, the TLR-1 $602 S$ allele seems to be a risk allele for the development of malaria, and a comparison of allele frequency in the 2 groups yields an OR associated with the TLR-1 602S allele of $2.2(\mathrm{P}(\mathrm{Pc})=$ 0.003(0.015) among Pspp-infected and $2.1(P(P c)=0.015(0.75))$ among Pfinfected.

Comparison of the TLR-6 S249P between patients with mild malaria and ASY showed a higher proportion of individuals homozygous for the TLR$6249 P$ allele in the ASY group. Significant difference is revealed only when comparison was restricted to Pspp-infected (P/P vs. P/S + S/S, $2 \times 2 \chi^{2}=5.2$; $\mathrm{P}(\mathrm{Pc})=0.01(0.05) ; \mathrm{OR}=2.1[95 \% \mathrm{Cl} 1.1-4.2])$.

We then examined whether the studied SNPs genotypes could be associated with age and parasitemia. Patients with mild malaria symptoms were stratified into high ( $\geq 10,000$ parasites/ $\mu \mathrm{L}$ of blood) and low $(<10,000$ parasites $/ \mu \mathrm{L}$ of blood) parasitemia load. Only the TLR-9 promoter polymorphisms showed a difference in the distribution of genotypes between both groups as shown in Table 4 (data are shown only for TLR-9 T-1237C and TLR-9 T-1486C). An association between the homozygous TLR-9 $1237 T$ allele and low parasitemia was observed (TT vs. T/C + CC, $2 \times 2 \chi^{2}=$ $6.5 ; P=0.005)$. Similar observation was revealed with the TLR-9 T-1486C polymorphism (TT vs. C/T + CC, $2 \times 2 \chi^{2}=7.9 ; \mathrm{P}=0.0014$ ) with the TLR9 $1486 T$ allele associated with low parasitemia while the TLR-9 $-1486 \mathrm{C}$ allele is 
strongly associated with high parasitemia $\left(\chi^{2}=9.7 ; P=0.0009\right)$. No significant association was found with age for any of the SNP studied. Data are shown only for TLR9 and TLR1 in Table 5.

\section{Discussion}

Malaria cause the heaviest toll on infant mortality and to date there is no efficient vaccine against this disease. The mechanisms highlighting the disease is far from understood as to why only some Plasmodium-infected infant die while others remain ASY or develop uncomplicated disease. However, the fact that only a small subset of Plasmodium-infected individuals develops life-threatening complications strongly suggests that genetic makeup of the host plays a fundamental role in addition to environment and the parasite itself. The identification of these genes may pave the way for a better understanding of the disease and designing efficient vaccine. Increasing evidence suggests that the TLR family plays an important role in innate immunity and in bridging innate and adaptive immunity [11]. TLRs orchestrate innate immune responses upon recognition of invading pathogens through the induction of chemokines and inflammatory cytokines. Several genetic variations in the TLR-pathway signaling are associated with either susceptibility or resistance to several infectious diseases [20,21].

GPI from Pf are recognized by TLR2/TLR1, TLR2/TLR6 and TLR4 [13] and induces severe malaria symptoms in mice [15]. In this study, we looked for SNPs in the TLR1, TLR4, TLR6, TLR9 as these TLRs are more likely to mediate recognition of the invading pathogen Plasmodium. We also looked for the SNP in TIRAP as it is a common adaptor protein for TLR2 and TLR4. Here, we show for the first time to our knowledge an association to mild malaria and variants in TLR1 and TLR6. Furthermore, we observed that the TLR9 promoter polymorphisms are associated with high parasitemia.

Functional studies of the TLR-1 I602S variant suggested that the TLR$1602 S$ allele is associated with aberrant trafficking of the receptor to the cell surface, lower levels of TNF- $\alpha$ [28] and to impaired basal and lipopeptideinduced NF- $\mathrm{BB}$ signaling compared to the 602I allele [35]. TLR2 is the major 
receptor for GPI and functions as a heterodimer either with TLR1 or TLR6 to attribute ligand specificity. We did not searched for the polymorphism TLR-2 $\operatorname{Arg} 753 \mathrm{G} / \mathrm{n}$, as its frequency is very low in the Brazilian population (Ramasawmy et al. unpublished data). In leprosy caused by the intracellular bacteria Mycobacterium leprae, it is reported that signaling through TLR2/TLR1 may be detrimental to the host since TLR-1 602S allele is associated with a decreased incidence of leprosy [28]. Our data suggest that the TLR-1 $602 S$ allele is a risk factor for malaria. A possible explanation of our data is that in acute infectious disease such as malaria, it is probably necessary that the host keeps the Plasmodium parasite in check and eliminates it as fast as possible to avoid its multiplication and migration to the liver in contrast to chronic infectious disease as leprosy. We also observed borderline association with mild malaria and TLR-6 S249P variant. The function of this polymorphism is not known. However, interestingly both TLR1 and TLR6 functions as heterodimers with TLR2. It can be assumed that a defect in these receptors may impair the recognition of GPI, which in turn may lead to inefficient clearance of the parasite.

TLR-1, 6 and 10 are believed to have been evolved under strong purifying selection [36] and it is interesting to observe that the frequency of the TLR-1 602 S allele differs worldwide with $75 \%$ in Caucasian, $26 \%$ in African descent, $0 \%$ in East Asian [28] and 10\% in the population of the Amazons that is mainly an admixture of Amerindians, Caucasians and Africans. It is probably as Johnson et al. [28] pointed out that purifying allele for the TLR-1 $1602 S$ may be restricted by either additional genetic or environmental factors with regard to specific pathogens since one study reported that African Americans with similar environment and social status are twice more likely to develop tuberculosis than their Caucasians counterpart [37].

The TLR-4 D229G did not reveal any association with mild malaria in our study. Recently, it has been shown that the TLR-4 Asp299Gly is associated with severe malaria in African children [38]. The absence of association in this study does not exclude TLR-4 as important gene in 
malaria-involvement. Our study is not powered enough to detect an association as the frequency of the minor allele TLR-4 299G is very low (5\%) and also the fact that our patients are with uncomplicated illness of malaria.

The promoter polymorphisms of TLR-9 did not show any association with mild malaria, which is in line with a recent study with severe malaria [38]. However, we observed an association of the TLR-9 T-1486C with high parasitemia. Recently, it was reported that the TLR-9 T-1486C is associated with placental malaria [26] that is characterized by excessive accumulation of hemozoin. High expression of TNF $\alpha$ is observed in hemozoin-laden macrophages from placenta of malaria-infected women [39]. However, the mechanisms by which TLR9 may contribute in the pathogenesis of malaria remain to be demonstrated. Interestingly, mice deficient for TLR9 gene are partially resistant to Plasmodium yoelii and it is suggested that malaria parasite may require TLR9 to activate regulatory $T$ cells for immune escape [40]. Although the function of this SNP is not clear, it may be in linkage disequilibrium with an as-yet-unidentified causal allele, which might influence transcriptional level.

The adaptor protein MAL encoded by TIRAP is involved in the downward signaling of TLR2 and TLR4. Recently, it was observed that bearers of the TIRAP S180L variants in the heterozygous state are protected from infectious diseases and this variant attenuates TLR2 signaling [30]. We did not observe a difference in the genotype distribution of this variant between patients with mild malaria and ASY. However, heterozygotes were more common among the ASY than patients with mild malaria ( $25 \%$ vs. $18 \%)$ but failed to reach statistical significance. It may suggest that ASY individuals may recognize the parasites efficiently in light of the TLR-1 and TLR-6 polymorphisms and modulate the immune response appropriately with reference to the TIRAP variant.

Altogether, our data indicate that TLR-9 promoter polymorphisms to some extent may control the level of Plasmodium parasitemia while TLR1 deficiency seems to predispose to mild malaria. These genetic findings may contribute to the understanding of the pathogenesis of malaria and raise a 
potentially interesting issue that is worthy of further investigation in other population in order to validate the genetics contribution of these loci to the pathogenesis of malaria.

Acknowledgement: Financial support. Sao Paulo State Research Foundation (FAPESP) and the Brazilian Council for Scientific and Technological Development (CNPq).

Potential conflict of interest: none 


\section{REFERENCES}

1. Greenwood B, Mutabingwa T. Malaria in 2002. Nature 2002; 415:670-2.

2. Guerra CA, Snow RW, Hay SI. Defining the global spatial limits of malaria transmission in 2005. Adv Parasitol. 2006; 62:157-79.

3. Lyke KE, Burges R, Cissoko Y, et al. Serum levels of the proinflammatory cytokines interleukin-1 beta (IL-1beta), IL-6, IL-8, IL-10, tumor necrosis factor alpha, and IL-12(p70) in Malian children with severe Plasmodium falciparum malaria and matched uncomplicated malaria or healthy controls. Infect Immun. 2004; 72:5630-7.

2. Porta J, Carota A, Pizzolato GP, Wildi E, Widmer MC, Margairaz C, Grau GE. Immunopathological changes in human cerebral malaria. Clin Neuropathol. 1993;12:142-6.

5. Udomsangpetch R, Chivapat S, Viriyavejakul P, Riganti M, Wilairatana P, Pongponratin E, Looareesuwan S. Involvement of cytokines in the histopathology of cerebral malaria. Am J Trop Med Hyg. 1997; 57:501-6.

6. Brown H, Turner G, Rogerson S, Tembo M, Mwenechanya J, Molyneux $\mathrm{M}$, Taylor T. Cytokine expression in the brain in human cerebral malaria. $\mathrm{J}$ Infect Dis. 1999;180:1742-6.

7. Cooke GS, Hill AV. Genetics of susceptibility to human infectious disease. Nat Rev Genet. 2001;2:967-77.

8. Westendorp RG, Langermans JA, Huizinga TW, Elouali AH, Verweij CL, Boomsma DI, Vandenbroucke JP. Genetic influence on cytokine production and fatal meningococcal disease. Lancet. 1997;349:170-3.

9. Wurfel MM, Park WY, Radella F, et al. Identification of high and low responders to lipopolysaccharide in normal subjects: an unbiased approach to identify modulators of innate immunity. J Immunol. 2005;175:2570-8.

10. Kwiatkowski D, Bate CA, Scragg IG, Beattie P, Udalova I, Knight JC. The malarial fever response--pathogenesis, polymorphism and prospects for intervention. Ann Trop Med Parasitol. 1997; 91:533-42. 
11. Akira S, Uematsu S, Takeuchi O. Pathogen recognition and innate immunity. Cell. 2006;124:783-801.

12. O'Neill LA, Bowie AG. The family of five: TIR-domain-containing adaptors in Toll-like receptor signalling. Nat Rev Immunol. 2007;7:353-64.

13. Krishnegowda G, Hajjar AM, Zhu J, et al. Induction of proinflammatory responses in macrophages by the glycosylphosphatidylinositols of Plasmodium falciparum: cell signaling receptors, glycosylphosphatidylinositol (GPI) structural requirement, and regulation of GPI activity. J Biol Chem. 2005; 280:8606-16.

14. Parroche P, Lauw FN, Goutagny $N$, et al. Malaria hemozoin is immunologically inert but radically enhances innate responses by presenting malaria DNA to Toll-like receptor 9. Proc Natl Acad Sci U S A. 2007;104:1919-24

15. Schofield L, Hewitt MC, Evans K, Siomos MA, Seeberger PH. Synthetic GPI as a candidate anti-toxic vaccine in a model of malaria. Nature. 2002; 418:785-9.

16. Schofield L, Novakovic S, Gerold P, Schwarz RT, McConville MJ, Tachado SD. Glycosylphosphatidylinositol toxin of Plasmodium upregulates intercellular adhesion molecule-1, vascular cell adhesion molecule-1, and E-selectin expression in vascular endothelial cells and increases leukocyte and parasite cytoadherence via tyrosine kinasedependent signal transduction. J Immunol. 1996;156:1886-96.

17. Grau GE, Taylor TE, Molyneux ME, Wirima JJ, Vassalli P, Hommel M, Lambert $\mathrm{PH}$. Tumor necrosis factor and disease severity in children with falciparum malaria. N Engl J Med. 1989;320:1586-91.

18. Turner GD, Morrison $\mathrm{H}$, Jones $\mathrm{M}$, et al. An immunohistochemical study of the pathology of fatal malaria. Evidence for widespread endothelial activation and a potential role for intercellular adhesion molecule-1 in cerebral sequestration. Am J Pathol. 1994;145:1057-69.

19. Adachi K, Tsutsui H, Kashiwamura S, et al. Plasmodium berghei infection in mice induces liver injury by an IL-12- and toll-like receptor/myeloid 
differentiation factor 88-dependent mechanism. J Immunol. 2001; 167:5928-34.

20. Schröder NW, Schumann RR. Single nucleotide polymorphisms of Tolllike receptors and susceptibility to infectious disease. Lancet Infect Dis. 2005;5:156-64.

21. Turvey SE, Hawn TR. Towards subtlety: understanding the role of Tolllike receptor signaling in susceptibility to human infections. Clin Immunol. 2006;120:1-9.

22. Arbour NC, Lorenz E, Schutte BC, et al. TLR4 mutations are associated with endotoxin hyporesponsiveness in humans. Nat Genet. 2000;25:18791.

23. Kiechl S, Lorenz E, Reindl M, et al. Toll-like receptor 4 polymorphisms and atherogenesis. N Engl J Med. 2002;347:185-92.

24. Lorenz E, Mira JP, Cornish KL, Arbour NC, Schwartz DA. A novel polymorphism in the Toll-like receptor 2 gene and its potential association with staphylococcal infection. Infect Immun 2000;68:63986401.

25. Lazarus R, Klimecki WT, Raby BA, et al. Single-nucleotide polymorphisms in the Toll-like receptor 9 gene (TLR9): frequencies, pairwise linkage disequilibrium, and haplotypes in three U.S. ethnic groups and exploratory case-control disease association studies. Genomics. 2003; 81:85-91.

26. Mockenhaupt FP, Hamann L, von Gaertner C, Bedu-Addo G, von Kleinsorgen C, Schumann RR, Bienzle U. Common polymorphisms of toll-like receptors 4 and 9 are associated with the clinical manifestation of malaria during pregnancy. J Infect Dis. 2006;194(2):184-8.

27. Pierik M, Joossens S, Van Steen K, Van Schuerbeek N, Vlietinck R, Rutgeerts $\mathrm{P}$, Vermeire $\mathrm{S}$. Toll-like receptor- $1,-2$, and -6 polymorphisms influence disease extension in inflammatory bowel diseases. Inflamm Bowel Dis. 2006;12(1):1-8. 
28. Johnson CM, Lyle EA, Omueti KO, et al. Cutting edge: A common polymorphism impairs cell surface trafficking and functional responses of TLR1 but protects against leprosy. J Immunol. 2007;178:7520-4.

29. Tantisira K, Klimecki WT, Lazarus R, et al. Toll-like receptor 6 gene (TLR6): single-nucleotide polymorphism frequencies and preliminary association with the diagnosis of asthma. Genes Immun. 2004;5(5):3436.

30. Khor CC, Chapman SJ, Vannberg FO, et al. A Mal functional variant is associated with protection against invasive pneumococcal disease, bacteremia, malaria and tuberculosis. Nat Genet. 2007;39:523-8.

31. Alves FP, Durlacher RR, Menezes MJ, Krieger H, Pereira da Silva LH, Camargo EP. High prevalence of asymptomatic Plasmodium vivax and Plasmodium falciparum infections in native Amazonian populations. Am. J. Trop. Med. Hyg. 2002; 66: 641-648.

32. Suárez-Mutis MC, Cuervo $P$, Leoratti FM, et al. Cross sectional study reveals a high percentage of asymptomatic Plasmodium vivax infection in the Amazon Rio Negro area, Brazil. Rev Inst Med Trop Sao Paulo. 2007; 49:159-64

33. Kimura M, Kaneko O, Liu Q, et al. Identification of the four species of human malaria parasites by nested PCR that targets variant sequences in the small subunit rRNA gene. Parasitol. Int. 46: 91-5, 1997.

34. Snounou G, Viriyakosol S, Jarra W, Thaithong S, Brown KN. Identification of the four human malaria parasite species in field samples by the polymerase chain reaction and detection of a high prevalence of mixed infections. Mol. Biochem. Parasitol. 58: 283-92, 1993.

35. Hawn TR, Misch EA, Dunstan SJ, et al. A common human TLR1 polymorphism regulates the innate immune response to lipopeptides. Eur J Immunol. 2007;37:2280-9.

36. Roach JC, Glusman G, Rowen L, et al. The evolution of vertebrate Tolllike receptors. Proc Natl Acad Sci U S A. 2005;102:9577-82. 
37. Stead WW, Senner JW, Reddick WT, Lofgren JP. Racial differences in susceptibility to infection by Mycobacterium tuberculosis. $\mathrm{N}$ Engl $\mathrm{J}$ Med. 1990;322:422-7.

38. Mockenhaupt FP, Cramer JP, Hamann L, et al. Toll-like receptor (TLR) polymorphisms in African children: Common TLR-4 variants predispose to severe malaria. Proc Natl Acad Sci U S A. 2006;103:177-82.

39. Moormann AM, Sullivan AD, Rochford RA, Chensue SW, Bock PJ, Nyirenda T, Meshnick SR. Malaria and pregnancy: placental cytokine expression and its relationship to intrauterine growth retardation. J Infect Dis. 1999; 180: 1987-93.

40. Hisaeda H, Tetsutani K, Imai T, et al. Malaria Parasites Require TLR9 Signaling for Immune Evasion by Activating Regulatory T Cells. J Immunol. 2008; 180:2496-503. 
Table 1. Primers and PCR conditions for the different polymorphisms studied.

\begin{tabular}{|c|c|c|c|c|}
\hline Primer sequence $5^{\prime}$ to $3^{\prime}$ & PCR program & RE & \multicolumn{2}{|c|}{ Allele length in bp } \\
\hline TLR1(I602S)F: GGAAAGTTATAGAGGAACCCT & \multirow{2}{*}{$\begin{array}{l}95^{\circ} \mathrm{C} 5 \mathrm{~min} ; 35 \times\left(95^{\circ} \mathrm{C} 30 \mathrm{~s} ;\right. \\
\left.55^{\circ} \mathrm{C} 30 \mathrm{~s} ; 72^{\circ} \mathrm{C} 30 \mathrm{~s}\right) 72^{\circ} \mathrm{C} 7 \mathrm{~min}\end{array}$} & Alu I & TLR-1 602S & $129+151$ \\
\hline TLR1(I602S)R: CTTCACCCAGAAAGAATCGTGCC & & & TLR-1 602I & 280 \\
\hline TLR4A299GF:GATTAGCATACTTAGACTACTACCTCCATG & \multirow{2}{*}{$\begin{array}{l}95^{\circ} \mathrm{C} 5 \mathrm{~min} ; 35 \times\left(95^{\circ} \mathrm{C} 30 \mathrm{~s} ;\right. \\
\left.62^{\circ} \mathrm{C} 30 \mathrm{~s} ; 72^{\circ} \mathrm{C} 30 \mathrm{~s}\right) 72^{\circ} \mathrm{C} 7 \mathrm{~min}\end{array}$} & Nco I & $T L R-4229 G$ & $30+219$ \\
\hline TLR4A299GR: GATCAACTTCTGAAAAAGCATTCCCAC & & & TLR-4 299D & 249 \\
\hline TLR6S249PF: GCATTTCCAAGTCGTTTCTATGT & \multirow{2}{*}{$\begin{array}{l}95^{\circ} \mathrm{C} 5 \mathrm{~min} ; 35 \times\left(95^{\circ} \mathrm{C} 30 \mathrm{~s} ;\right. \\
\left.63^{\circ} \mathrm{C} 30 \mathrm{~s} ; 72^{\circ} \mathrm{C} 30 \mathrm{~s}\right) 72^{\circ} \mathrm{C} 7 \mathrm{~min}\end{array}$} & Ava II & $T L R-6249 P$ & $50+160$ \\
\hline TLR6S249PR: GCAAAAACCCTTCACCTTGTT & & & TLR-6 249S & 210 \\
\hline TLR9-1237F:CTGCTTGCAGTTGACTGTGT & \multirow{2}{*}{$\begin{array}{l}95^{\circ} \mathrm{C} 5 \mathrm{~min} ; 35 \times\left(95^{\circ} \mathrm{C} 30 \mathrm{~s} ;\right. \\
\left.59^{\circ} \mathrm{C} 30 \mathrm{~s} ; 72^{\circ} \mathrm{C} 30 \mathrm{~s}\right) 72^{\circ} \mathrm{C} 7 \mathrm{~min}\end{array}$} & Bst NI & $T L R-9-1237 C$ & $27+48+60$ \\
\hline TLR9-1237R:ATGGGAGCAGAGACATAATGGA & & & $T L R-9-1237 T$ & $27+108$ \\
\hline TLR9-1486F: TATCGTCTTATTCCCCTGCTGGAATGT & \multirow{2}{*}{$\begin{array}{l}95^{\circ} \mathrm{C} 5 \mathrm{~min} ; 35 \times\left(95^{\circ} \mathrm{C} 30 \mathrm{~s} ;\right. \\
\left.62^{\circ} \mathrm{C} 30 \mathrm{~s} ; 72^{\circ} \mathrm{C} 30 \mathrm{~s}\right) 72^{\circ} \mathrm{C} 7 \mathrm{~min}\end{array}$} & AfI II & $T L R-9-1486 T$ & $34+111$ \\
\hline TLR9-1486R: TGCCCAGAGCTGACTGCTGG & & & $T L R-9-1486 C$ & 145 \\
\hline TIRAPS180LF: TGCTCATCACGCCGGGCTTCCTT & \multirow{2}{*}{$\begin{array}{l}95^{\circ} \mathrm{C} 5 \mathrm{~min} ; 35 \times\left(95^{\circ} \mathrm{C} 30 \mathrm{~s} ;\right. \\
\left.62^{\circ} \mathrm{C} 30 \mathrm{~s} ; 72^{\circ} \mathrm{C} 30 \mathrm{~s}\right) 72^{\circ} \mathrm{C} 7 \mathrm{~min}\end{array}$} & Hpy188I & TIRAP 180S & $21+106$ \\
\hline TIRAPS180LR: TAGGCAGCTCTGCTGAGGTCC & & & TIRAP $180 L$ & 127 \\
\hline
\end{tabular}


Table 2. Baseline characteristics of the Plasmodium-infected individuals.

\begin{tabular}{|l|l|l|l|l|}
\hline & & \multicolumn{3}{|c|}{ Plasmodium-infected individuals } \\
\hline & Total & Mild malaria cases & Asymptomatic & P value \\
\hline N & 304 & 230 & 74 & \\
\hline Age : median & 30 & 29 & 35.5 & 0.0001 \\
\hline Sex: Male & 251 & $197(86)$ & $54(73)$ & 0.02 \\
\hline \multicolumn{1}{|c|}{ Female } & 53 & $33(14)$ & $20(27)$ & 0.02 \\
\hline P. sp. infection & & & & 0.001 \\
\hline P. falciparum (Pf) & 147 & $124(54)$ & $23(31)$ & 0.0001 \\
\hline P. vivax (Pv) & 53 & $27(12)$ & $26(35)$ & \\
\hline P. malariae (Pm) & 1 & $0(0)$ & $1(1)$ & \\
\hline Pf and Pv & 82 & $62(27)$ & $20(27)$ & 0.88 \\
\hline Pf + Pm & 2 & $2(1)$ & $1(0)$ & \\
\hline Pv + Pm & 1 & $18(6)$ & $10)$ & \\
\hline Pf + Pv + Pm & 18 & & & \\
\hline
\end{tabular}

Data are no. and (\%) of individuals. 
Table 3. Frequencies of genotypes and alleles of polymorphisms studied in patients with malaria and asymptomatic individuals, and further stratified by Plasmodium falciparum infection only and mixed infection.

\begin{tabular}{|c|c|c|c|c|c|c|c|}
\hline & & & & & & \multicolumn{2}{|c|}{ Comparisons } \\
\hline \multirow{2}{*}{\multicolumn{2}{|c|}{ Genotypes }} & \multicolumn{2}{|c|}{ Malaria symptoms } & \multicolumn{2}{|c|}{ ASY cases } & p.f. vs. p.f. & Total vs. total \\
\hline & & P. falciparum & Total & P. falciparum & Total & & \\
\hline \multirow[t]{3}{*}{ TLR1 } & lle/lle & $114(0.58)$ & $134(0.59)$ & $36(0.78)$ & $58(0.80)$ & & \\
\hline & Ile/Ser & $79(0.40)$ & $87(0.39)$ & $9(0.20)$ & $14(0.19)$ & & \\
\hline & Ser/Ser & $4(0.02)$ & $4(0.02)$ & $1(0.02)$ & $1(0.01)$ & & \\
\hline & Ille & $307(0.78)$ & $355(0.79)$ & $81(0.88)$ & $130(0.89)$ & & \\
\hline & Ser & $87(0.22)$ & $95(0.21)$ & $11(0.12)$ & $16(0.11)$ & & \\
\hline \multicolumn{6}{|c|}{ Statistical comparisons } & $\mathrm{P}(\mathrm{Pc}) ; \mathrm{OR}[95 \% \mathrm{Cl}]$ & $\mathrm{P}(\mathrm{Pc}) ; \mathrm{OR}[95 \% \mathrm{Cl}]$ \\
\hline \multicolumn{6}{|c|}{ TLR1-I602S: I/I vs. I/S + S/S genotypes } & $0.005(0.025) ; 2.6[1.2-5.6]$ & $0.001(0.005) ; 2.6[1.4-4.9]$ \\
\hline \multicolumn{6}{|c|}{ TLR1-I602S: I/I vs. I/S genotypes } & $0.004(0.02) ; 2.8[1.3-6.1]$ & $0.002(0.01) ; 2.7[1.4-5.1]$ \\
\hline \multicolumn{6}{|c|}{ TLR1-I602S: I vs. S alleles } & $0.015(0.75) ; 2.1[1.1-4.1]$ & $0.003(0.015) ; 2.2[1.2-3.8]$ \\
\hline \multirow[t]{5}{*}{ TLR4 } & A299A & $184(0.91)$ & $211(0.92)$ & $40(0.87)$ & $67(0.91)$ & & \\
\hline & A229G & $16(0.08)$ & $17(0.07)$ & $6(0.13)$ & $7(0.09)$ & & \\
\hline & G299G & $2(0.01)$ & $2(0.01)$ & $0(0.00)$ & $0(0.00)$ & & \\
\hline & Asp & $384(0.95)$ & $439(0.95)$ & $86(0.93)$ & $141(0.95)$ & & \\
\hline & Gly & $20(0.05)$ & $21(0.05)$ & $6(0.07)$ & $7(0.05)$ & & \\
\hline \multirow[t]{5}{*}{ TLR6 } & P249P & $130(0.68)$ & $148(0.67)$ & $35(0.78)$ & $58(0.82)$ & ns & \\
\hline & P249S & $55(0.28)$ & $63(0.29)$ & $9(0.20)$ & $12(0.17)$ & ns & \\
\hline & S249S & $7(0.04)$ & $8(0.04)$ & $1(0.02)$ & $1(0.01)$ & & \\
\hline & $249 \mathrm{P}$ & $315(0.82)$ & $359(0.82)$ & $79(0.88)$ & $128(0.90)$ & & \\
\hline & $249 S$ & $69(0.18)$ & $79(0.18)$ & $11(0.12)$ & $14(0.10)$ & & \\
\hline \multicolumn{8}{|c|}{ Statistical comparisons } \\
\hline \multicolumn{6}{|c|}{ TLR6-S249P: P/P vs. P/S + S/S genotypes } & ns & $0.01(0.05) ; 2.1[1.1-4.2]$ \\
\hline \multicolumn{6}{|c|}{ TLR6-S249P: P/P vs. P/S genotypes } & ns & $0.02(0.10) ; 2.2[1.0-4.1]$ \\
\hline \multicolumn{6}{|c|}{ TLR6-S249P: P vs. S allele } & $0.10(0.5) ; 1.6[0.8-3.1]$ & $0.01(0.05) ; 2.0[1.1-3.7]$ \\
\hline
\end{tabular}




\begin{tabular}{|c|c|c|c|c|c|c|}
\hline \multirow[t]{5}{*}{ TLR9 } & $1237 \mathrm{~T} / \mathrm{T}$ & $140(0.71)$ & $159(0.73)$ & $32(0.70)$ & $56(0.79)$ & \\
\hline & 1237T/C & $50(0.25)$ & $52(0.24)$ & $12(0.26)$ & $13(0.18)$ & \\
\hline & $1237 \mathrm{C} / \mathrm{C}$ & $8(0.04)$ & $8(0.04)$ & $2(0.04)$ & $2(0.03)$ & \\
\hline & $1237 \mathrm{~T}$ & $330(0.83)$ & $370(0.84)$ & $76(0.83)$ & $125(0.88)$ & \\
\hline & $1237 \mathrm{C}$ & $66(0.17)$ & $68(0.16)$ & $16(0.17)$ & $17(0.12)$ & \\
\hline \multirow[t]{5}{*}{ TLR9 } & $1486 \mathrm{~T} / \mathrm{T}$ & $70(0.35)$ & $82(0.36)$ & $18(0.40)$ & $23(0.32)$ & \\
\hline & $1486 \mathrm{~T} / \mathrm{C}$ & $98(0.49)$ & $107(0.47)$ & $23(0.51)$ & $37(0.52)$ & \\
\hline & $1486 \mathrm{C} / \mathrm{C}$ & $31(0.16)$ & $38(0.17)$ & $4(0.09)$ & $11(0.16)$ & \\
\hline & 1486T & $238(0.60)$ & $271(0.60)$ & $59(0.66)$ & $83(0.58)$ & \\
\hline & $1486 \mathrm{C}$ & $160(0.40)$ & $183(0.40)$ & $31(0.34)$ & $59(0.42)$ & \\
\hline \multirow[t]{5}{*}{ TIRAP } & S180S & $156(0.78)$ & $177(0.78)$ & $32(0.69)$ & $49(0.68)$ & \\
\hline & S180L & $34(0.17)$ & $40(0.18)$ & $10(0.22)$ & $18(0.25)$ & \\
\hline & L180L & $10(0.05)$ & $11(0.05$ & $4(0.09)$ & $5(0.07)$ & \\
\hline & $180 \mathrm{~S}$ & $346(0.87)$ & $394(0.86)$ & $74(0.80)$ & $116(0.81)$ & \\
\hline & $180 \mathrm{~L}$ & $54(0.13)$ & $62(0.14)$ & $18(0.20)$ & $28(0.19)$ & \\
\hline \multicolumn{6}{|c|}{ TIRAP S180L: S vs. L allele } & $0.043(0.25) ; 1.5[0.94-2.5]$ \\
\hline
\end{tabular}

Data are no. (\%) of individuals. $\chi 2$ test was used to determine differences between genotype and allele frequencies.

$\mathrm{P}(\mathrm{Pc})$; $\mathrm{P}$ value( $\mathrm{P}$ value corrected according to number of genes studied; $\mathrm{Cl}$ : confidence interval, OR: odds ratio 
Table 4. Genotype and allele frequencies for the $T L R 9-1237 C / T$ and $T L R 9-1486 C / T$ polymorphisms in patients with malaria stratified according to parasitemia load.

\begin{tabular}{|c|c|c|c|c|c|}
\hline & \multicolumn{2}{|c|}{ Parasitemia load } & \multicolumn{3}{|c|}{ Comparison } \\
\hline TLR9 $-1237 \mathrm{C} / \mathrm{T}$ & High & Low & $\chi^{2}$ & $\mathrm{P}$ value & OR $[95 \% \mathrm{Cl}]$ \\
\hline \multicolumn{6}{|l|}{ Genotype } \\
\hline TT & $26(0.57)$ & $136(0.76)$ & & & \\
\hline TC & $17(0.37)$ & $38(0.21)$ & & & \\
\hline $\mathrm{CC}$ & $3(0.06)$ & $6(0.03)$ & & & \\
\hline \multicolumn{6}{|c|}{ Genotype comparison } \\
\hline TT vs. TC + CC & & & 6.54 & 0.005 & $2.4[1.2-4.7]$ \\
\hline TC vs. TT & & & 5.7 & 0.008 & $2.3[1.2-4.8]$ \\
\hline \multicolumn{6}{|l|}{ Allele } \\
\hline $\mathrm{T}$ & $69(0.75)$ & $310(0.86)$ & & & \\
\hline $\mathrm{C}$ & $23(0.25)$ & $50(0.14)$ & & & \\
\hline \multicolumn{2}{|c|}{ Allele comparison C vs. T } & & 6.7 & 0.005 & $2.1[1.2-3.6]$ \\
\hline \multicolumn{6}{|l|}{ TLR9-1486 C/T } \\
\hline $\mathrm{CC}$ & $9(0.19)$ & $73(0.41)$ & & & \\
\hline CT & $26(0.54)$ & $81(0.45)$ & & & \\
\hline TT & $13(0.27)$ & $25(0.14)$ & & & \\
\hline \multicolumn{6}{|c|}{ Genotype Comparison } \\
\hline \multicolumn{2}{|l|}{ CC vs. TT } & & 9.4 & 0.001 & $4.2[1.6-11.1]$ \\
\hline \multicolumn{2}{|l|}{ CT vs. TT } & & 5.5 & 0.009 & $2.6[1.1-5.9]$ \\
\hline \multicolumn{2}{|l|}{$\mathrm{CC}+\mathrm{CT}$ vs. TT } & & 7.96 & 0.0024 & $3.0[1.3-6.5]$ \\
\hline \multicolumn{6}{|l|}{ Allele } \\
\hline C & $44(0.46)$ & $227(0.63)$ & & & \\
\hline $\mathrm{T}$ & $52(0.54)$ & $131(0.37)$ & & & \\
\hline \multicolumn{2}{|c|}{ Allele comparison C vs. T } & & 9.7 & 0.0009 & $2.0[1.3-3.2]$ \\
\hline
\end{tabular}

Data are no. (\%) of individuals. $\chi^{2}$ test was used to determine differences between genotype and allele frequencies. $\mathrm{Cl}$ : confidence interval, OR: odds ratio 
Table 5. Demographic of patients with mild malaria according to TLR1 genotypes and to TLR-9 genotypes stratified according to parasitemia load.

\begin{tabular}{|c|c|c|c|}
\hline & \multicolumn{3}{|l|}{ TLR-1 I602S } \\
\hline & Ile/lle & Ile/Ser & Ser/Ser \\
\hline Symptomatics & $29.0(23.0-36.2)$ & $29.0(23.0-36.0)$ & $43.5(37.0-58.5)$ \\
\hline \multicolumn{4}{|l|}{ Comparison } \\
\hline \multicolumn{2}{|l|}{ Kruskall-Wallis test } & $P=0.05$ & \\
\hline \multicolumn{2}{|c|}{ Mann-Whitney test (lle/lle vs. Ile/Ser) } & $P=0.90$ & \\
\hline & \multicolumn{2}{|l|}{ TLR9 $-1237 \mathrm{C} / \mathrm{T}$} & \\
\hline & TT & CT & $\mathrm{CC}$ \\
\hline High parasitemia: age & $23.0(19.0-29)$ & $24.0(21.3-26.0)$ & $26(23.0-26.0)$ \\
\hline Low parasitemia: age & $30.0(23.3-37.0)$ & $30.0(25.0-36.0)$ & $33.5(29.0-37.0)$ \\
\hline Comparison & & High & Low \\
\hline \multirow[t]{3}{*}{ Kruskall-Wallis } & & $P=0.892$ & $P=0.696$ \\
\hline & \multicolumn{2}{|l|}{ TLR9 -1486C/T } & \\
\hline & TT & $\mathrm{TC}$ & $\mathrm{CC}$ \\
\hline High parasitemia; age & $27.0(21.3-34.8)$ & $23.0(19.0-28.0)$ & $26.0(19.0-30.3)$ \\
\hline Low parasitemia; age & $32.0(23.0-36.3)$ & $29.5(25.0-39.5)$ & $30.0(24.5-37.0)$ \\
\hline Comparisons & & High parasitemia & Low parasitemia \\
\hline Kruskall-Wallis & & $P=0.575$ & $P=0.779$ \\
\hline
\end{tabular}

Age: median values in years are indicated with $25 \%$ and $75 \%$ in brackets 
Mensagem encaminhada de jid@press.uchicago.edu -----

Data: 18 Mar 2008 18:00:18 -0400

De: The Journal of Infectious Diseases<jid@press.uchicago.edu>

Endereço para Resposta (Reply-To): The Journal of Infectious Diseases

<jid@press.uchicago.edu>

Assunto: Re: MS \#40948R1, Variants in the Toll-like receptor pathway

signaling are associated with clinical outcomes of malaria

Para: ramasawm@usp.br

Cc: pweller@bidmc.harvard.edu

Dear Dr. Ramasawmy,

We are pleased to inform you that your revised manuscript has been accepted for publication in The Journal of Infectious Diseases.

You will receive an e-mail from our publisher the University of Chicago Press (UCP), when your proofs are ready to be downloaded from the Internet. On return of your proofs to $U C P$, your paper will be scheduled for publication.

The page charges are $\$ 55$ per printed page for up to six pages and $\$ 85$ for each additional page. Charges for color use may also apply: a minimum of $\$ 500$ for the first page of color and $\$ 400$ for additional page of color. Written assurance of payment for these charges is required. A request for payment of the appropriate charges will be sent with the proofs.

If you prefer, you can avoid color charges by having color figures published in black and white; to do so, please send electronic files of all new black and white figures to the JID office e-mail address below.

Note that IDSA now grants $\mathrm{NIH}$-funded authors permission to deposit their accepted manuscripts with PubMed central and to publish it there twelve (12 months) after publication in the Journal.

A publication agreement is attached below. Please review and return this document to this office as soon as possible. For your convenience, you may fax it to us at 617-367-2624.

Sincerely,

David C. Hooper, MD

Editor

Peter Weller, MD

Associate Editor 
The Journal of Infectious Diseases

225 Friend St., 7th Floor

Boston, MA 02114

Phone: 617-367-1848

Fax: 617-367-2624

E-mail: jid@press.uchicago.edu

$* * * * * * * * * * * * * * * *$ PLEASE SCROLL DOWN TO DOCUMENT

BELOW $* * * * * * * * * * * * * * * * * * * * * * * *$

From: Martin S. Hirsch, MD, Editor, The Journal of Infectious Diseases

To: Rajendranath Ramasawmy, PhD; Fabiana M LEORATTI, PhD; Lilian FARIAS, BSc; Fabiana P ALVES, PhD; Fabiana M LEORATTI, PhD; Lilian FARIAS, BSc; Fabiana P ALVES, PhD; Martha C SUAREZ-MUTIZ, PhD; Jose R Coura, Phd; Jorge Kalil, Phd; Erney P CAMARGO, PhD; Sandra L MORAES Contribution: 40948R1 Variants in the Toll-like receptor pathway signaling are associated with clinical outcomes of malaria

\section{Agreement:}

The Infectious Diseases Society of America ("the Society"), acting through The University of Chicago Press ("the Press"), is pleased to consider for publication your contribution identified above ("the Contribution"), in its journal, The Journal of Infectious Diseases ("the Journal").

In consideration of the publication of your Contribution, we ask you to assign the copyright to the Society, thus granting us all rights in the Contribution. The Society, in turn, grants to you as author several rights described herein and in the Guidelines for Journal Authors' Rights After Acceptance available on the Web site of the Press (as in effect from time to time, the "Guidelines"). The Press may amend the Guidelines at any time with or without notice to you, and your rights in the Contribution shall be governed by this agreement and the Guidelines in ffect at the time of your proposed use. You will receive no monetary compensation from the Society for the assignment of copyright and publication of the Contribution. By signing below, you and the Society agree as follows:

Copyright Assignment:

The Society undertakes to publish the Contribution, subject to approval by the editor(s), in its Journal named above. In consideration of such publication, you hereby grant and assign to the consideration of such publication, you hereby grant and assign to the Society the entire copyright in the Contribution, including any and all rights of whatever kind or nature now or hereafter protected by the copyright laws of the United States and of all foreign countries, in all languages and forms of communication. It is understood that the copyright to the Contribution has not been registered with the Library of Congress, but that in the event such registration has taken place you will promptly transfer the copyright registration to the Society. If the Contribution is deemed unacceptable for Publication, you will be notified and all rights will revert to you. 
Grant of Rights to Author:

The Society grants to you the following non-exclusive rights, subject to your giving proper credit to the original publication of the Contribution in the Journal, including reproducing the exact copyright notice as it appears in the Journal:

(i) to reprint the Contribution, in whole or in part, in any book, article, or other scholarly work of which you are the author or editor, (ii) to use the Contribution for teaching purposes in your classes, including making multiple copies for all students, either as individual copies or as part of a printed course pack, provided that these are to be used solely for classes you teach, (iii) to post a copy of the Contribution on your personal or institutional Web server, provided that the server is non-commercial and there are no charges for access, and (iv) to deposit a copy of the Contribution in a non-commercial data repository maintained by an institution of which you are a member, after the embargo period identified in the Guidelines and provided all relevant conditions described in the Guidelines have been met.

The rights granted in clauses (i) and (ii) above are intended to benefit the original creators of the Contribution only. Accordingly, if you claim ownership of or rights in the Contribution because it was created by your employee or as a work made for hire, as defined in the Copyright Act, the rights granted in clauses (i) and (ii) above shall not apply to you, and you must contact the Press for permission to make these uses.

Warranties and Indemnifications:

You warrant to the Society as follows:

(i) that the Contribution is your original work;

(ii) that it contains no matter which is defamatory or is otherwise unlawful or which invades rights of privacy or publicity or infringes any proprietary right (including copyright);

(iii) that you have the right to assign the copyright to the Society and that no portion of the copyright to the Contribution has been assigned previously;

(iv) that the Contribution has not been published elsewhere in whole or in part (except as may be set out in a rider annexed hereto and signed by the Press) and that no agreement to publish is outstanding other than this agreement; and

(v) that all funding sources and conflicts of interest have been disclosed. You agree to indemnify and hold the Society harmless against any claim arising from or related to the breach or inaccuracy of any of the warranties listed above.

Requirements for Publication:

You agree to prepare and revise the Contribution according to the instructions of the editor(s) and to meet all other requirements for publication communicated to you by the editor(s) or the Press. It is your responsibility to determine whether the Contribution includes material that requires written permission for publication in the Journal, including any material that is supplementary or ancillary to the Contribution; to obtain such permission, at your own expense, from the copyright owner; and to submit that permission to the editor(s) with the manuscript. 
Please complete, sign, and date this agreement, and return it to the editor(s) by mail, fax, or email, retaining a copy for your files. An electronic signature may be used. You agree that an electronic signature shall be valid and binding for all purposes, and hereby waive any objection

to use of an electronic version of this agreement as a substitute for the original for any legally recognized purpose.

All joint authors must sign, each on a separate form if necessary.

40948R1

\section{AUTHOR SIGNATURE:}

Name: Date:

(Please print or type)

Address:

Telephone: Fax:

Email:

FOR THE INFECTIOUS DISEASES SOCIETY OF AMERICA:

Martin S. Hirsch, MD, Editor

Please return to:

The Journal of Infectious Diseases

225 Friend Street

7th Floor

Boston, MA 02114-1812 USA

Phone: (617) 367-1848

Fax: (617) 367-2624

Email: jid@press.uchicago.edu

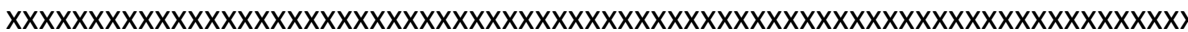

\section{PUBLICATION AGREEMENT-ALTERNATE SIGNATURE FORM}

Use this form only if you belong to one of the categories below. All other authors should sign the Publication Agreement. Return the completed form with the Publication Agreement by mail, fax, or email, retaining a copy for your files.

Contribution: 40948R1 Variants in the Toll-like receptor pathway signaling are associated with clinical outcomes of malaria 
U.S. Government employees: Your signature below indicates that you were an employee of the United States Government at the time the Contribution was prepared and its preparation was undertaken as part of your official duties. Accordingly, you agree to the terms of the attached Publication Agreement with the exception of the section entitled Copyright Assignment, which does not apply to you.

Institution or Agency:

(Please print or type)

Signature of author or agency representative:

Name: Date:

(Please print or type)

Please note that in the case of a Contribution jointly authored by government employees and non-government employees, only the government employees should sign this form; all non-government authors should sign the Publication Agreement.

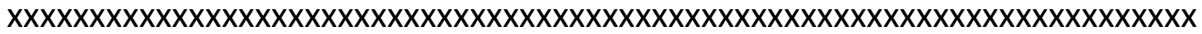

Work made for hire: Your signature below indicates that the Contribution was prepared as a "work made for hire" on your behalf and you are thereby entitled to grant and assign copyright as requested in the Publication Agreement. You understand that the rights granted in clause (i) and (ii) of the Grant of Rights to Author do not apply to you.

Employer:

(Please print or type)

Signature of employer representative:

Name: Date:

(Please print or type)

Title:

(Please print or type)

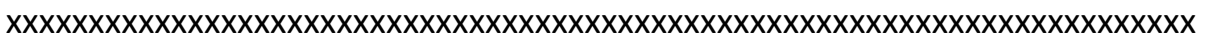

Author signing on behalf of joint author(s): Your signature below indicates that you have assigned copyright in the Contribution on behalf of the joint author(s) named below. You warrant that you have been granted by each such joint author the authority to act as his or her agent in this behalf and indemnify the Journal, its sponsor (if applicable), and the University of Chicago Press from any claim arising from the breach or inaccuracy of this warranty. It is your responsibility to communicate the terms of publication to each author named below. 
Names of joint author(s):

(Please print or type)

Your signature:

Your name:

Date:

(Please print or type)

40948R1 Variants in the Toll-like receptor pathway signaling are associated with clinical outcomes of malaria 
1. World Health Organization: Malaria. WHO Fact Sheet, 2008; nº 94.

2. Ministério da Saúde. Situação epidemiológica da malária no Brasil, ano de 2006. www.saude.gov.br/svs, 2007.

3. Knell, AJ. (ed) Malaria Oxford university press, Oxford, 1991.

4. Bruce-Chwatt LJ. In: Essential Malariology, 1985; $2^{\mathrm{a}}$ ed., William Heiseman Medical Books, London.

5. Good MF. Towards a blood-stage vaccine for malaria: are we following all the leads? Nat Rev Immunol. 2001; 1(2):117-25.

6. World Health Organization: Malaria. WHO, 2006.

7. Miller LH, Baruch DI, Marsh K, Doumbo OK. The pathogenic basis of malaria. Insight Review articles Nature. 2002; 415(7):673-9.

8. Kwiatkowski D, Bate CA, Scragg IG, Beattie P, Udalova I, Knight JC. The malarial fever response - pathogenesis, polymorphism and prospects for intervention. Ann Trop Med Parasitol. 1997; 91: 533-42.

9. Hunt N, Grau G E. Cytokines: accelerators and brakes in the pathogenesis of cerebral malaria. Trends Immunol. 2003; 24: 491-9.

10. McCall MB, Netea MG, Hermsen CC, Jansen T, Jacobs L, Golenbock D, van der Ven AJ, Sauerwein RW. Plasmodium falciparum infection causes proinflammatory priming of human TLR responses. J Immunol. 2007; 79(1):162-71.

11. Greenwood B. What can the residents of malaria endemic countries do to protect themselves against malaria? Parassitologia. 1999; 41: 295-9.

12. Greenwood BM. Asymptomatic malaria infections - Do they matter? Parasitol Today. 1987; 3(7): 206-14.

13. Baird JK. Age-dependent characteristics of protection v. susceptibility to Plasmodium falciparum. Ann Trop Med Parasitol. 1998; 92(4):367-90.

14. Baird JK. Host age as a determinant of naturally acquired to Plasmodium falciparum. Parasitol Today. 1995; 11(3):105-11.

15. Artavanis-Tsakonas K, Riley EM. Innate immune response to malaria: rapid induction of IFN-gamma from human NK cells by live Plasmodium falciparum-infected erythrocytes. J Immunol. 2002; 169(6):2956-63. 
16. Stevenson MM, Riley EM. Innate immunity to malaria. Nature Rev Immunol. 2004; 4:169-80.

17. Favre N, Ryffel B, Bordmann G, Rudin W. The course of Plasmodium chabaudi chabaudi infections in interferon-gamma receptor deficient mice. Parasite Immunol. 1997; 19(8):375-83.

18. Shear HL, Srinivasan R, Nolan $\mathrm{T}, \mathrm{Ng}$ C. Role of IFN-gamma in lethal and nonlethal malaria in susceptible and resistant murine hosts. J Immunol. 1989 Sep 15;143(6):2038-44.

19. Stevenson MM, Tam MF, Wolf SF, Sher A. IL-12-induced protection against blood-stage Plasmodium chabaudi AS requires IFN-gamma and TNF-alpha and occurs via a nitric oxide-dependent mechanism. $J$ Immunol. 1995; 155(5):2545-56.

20.De Souza JB, Williamson KH, Otani T.,Playfair JHL. Early Y-interferon responses in lethal and nonlethal murine blood stage malaria. Infect Immun. 1997; 65:1593-8.

21. Jacobs $P$, Radzioch $D$, Stevenson MM. In vivo regulation of nitric oxide production by tumor necrosis factor alpha and gamma interferon, but not by interleukin-4, during blood stage malaria in mice. Infect Immun. 1996; 64(1):44-9.

22. Rockett KA, Awburn MM, Cowden WB, Clark IA. Killing of Plasmodium falciparum in vitro by nitric oxide derivatives. Infect Immun. 1991; 59(9):3280-3.

23. Mohan K, Moulin P, Stevenson MM. Natural killer cell cytokine production, not cytotoxicity, contributes to resistance against blood-stage Plasmodium chabaudi AS infection. J Immunol. 1997; 159:4990-8.

24.Scragg IG, Hensmann M, Bate CA, Kwiatkowski D. Early cytokine induction by Plasmodium falciparum is not a classical endotoxin-like process. Eur J Immunol. 1999; 29(8):2636-44.

25. Hermsen CC, Konijnenberg Y, Mulder L, Loé C, Van Deuren M, Van der Meer JW, Van Mierlo GJ, Eling WM, Hack CE, Sauerwein RW. Circulating concentrations of soluble granzyme $A$ and $B$ increase during natural and 
experimental Plasmodium falciparum infections. Clin Exp Immunol. 2003; 132(3):467-72.

26. Walther M, Tongren JE, Andrews L, Korbel D, King E, Fletcher $\mathrm{H}$, Andersen RF, Bejon P, Thompson F, Dunachie SJ, Edele F, de Souza JB, Sinden RE, Gilbert SC, Riley EM, Hill AV. Upregulation of TGF-beta, FOXP3, and $\mathrm{CD} 4^{+} \mathrm{CD} 25^{+}$regulatory $\mathrm{T}$ cells correlates with more rapid parasite growth in human malaria infection. Immunity. 2005 ;23(3):287-96.

27. Bruce M, Day KP. Cross-species regulation of Plasmodium parasitemia in semi-immune children from Papua New Guinea. Trends Parasitol. 2003; 19(6): 271-7.

28. Ritchie TL. Interactions between malaria parasites infecting the same vertebrate hosts. Parasitololgy. 1988; 96:607-39.

29. Maitland K, Williams TN, Newbold C. Plasmodium vivax and $P$. falciparum: biological interactions and the possibility of cross-species immunity. Parasitol Today. 1997; 13: 227-31.

30. McGuinness DH, Dehal PK, Pleass RJ. Pattern recognition molecules and innate immunity to parasites. Trends Parasitol. 2003; 19(7): 312-9.

31. Teixeira MM, Almeida IC, Gazzinelli RT.Introduction: innate recognition of bacteria and protozoan parasites. Microbes Infect. 2002;4(9):883-6.

32. Jarrossay D, Napolitani G, Colonna M, Sallusto F, Lanzavecchia A. Specialization and complementarity in microbial molecule recognition by human myeloid and plasmacytoid dendritic cells. Eur J Immunol. 2001; 31:3388-93.

33. Hemmi, H, Takeuchi O, Kawai T, Kaisho T, Sato S, Sanjo H, Matsumoto M, Hoshino K, Wagner H, Takeda K, Akira S. A Toll-like receptor recognizes bacterial DNA. Nature. 2000; 408:740-5.

34. Ito T, Amakawa R, Kaisho T, Hemmi H, Tajima K, Uehira K, Ozaki Y, Tomizawa H, Akira S, Fukuhara S. Interferon and interleukin-12 are induced differentially by Toll-like receptor 7 ligands in human blood dendritic cell subsets. J Exp Med. 2002; 195:1507-12. 
35. Urban BC, Ferguson DJ, Pain A, Willcox N, Plebanski M, Austyn JM, Roberts DJ. Plasmodium falciparum-infected erythrocytes modulate the maturation of dendritic cells. Nature. 1999; 400(6739):73-7.

36. Seixas E, Cross C, Quin S, Langhorne J. Direct activation of dendritic cells by the malaria parasite, Plasmodium chabaudi chabaudi. Eur J Immunol. 2001; 31: 2970-8.

37. Pichyangkul S, Saengkrai P, Webster HK. Plasmodium falciparum pigment induces monocytes to release high levels of tumor necrosis factor-alpha and interleukin-1 beta. Am J Trop Med Hyg. 1994; 51: 430-5.

38. Yamada-Tanaka MS, Ferreira-da-Cruz MF, Alecrim MG, Mascarenhas LA, Daniel-Ribeiro CT. Tumor necrosis factor alpha interferon gamma and macrophage stimulating factor in relation to the severity of Plasmodium falciparum malaria in the Brazilian Amazon. Trop Geogr Med. 1995; 47: 282-5.

39. Prada J, Malinowski J, Muller S, Bienzle U, Kremsner PG. Effects of Plasmodium vinckei haemozoin on the production of oxygen radicals and nitrogen oxides in murine macrophages. Am J Trop Med Hyg. 1996; 54:620-4.

40. Schwarzer E, Turrini F, Ulliers D, Giribaldi G, Ginsburg H, Arese P. Impairment of macrophage functions after ingestion of Plasmodium falciparum-infected erythrocytes or isolated malarial pigment. J Exp Med. 1992; 176: 1033-41.

41. Taramelli D, Basilico N, Pagani E, Grande R, Monti D, Ghione M, Olliaro $P$. The heme moiety of malaria pigment (beta-hematin) mediates the inhibition of nitric oxide and tumor necrosis factor-alpha production by lipopolysaccharide-stimulated macrophages. Exp Parasitol. 1995; 81(4):501-11.

42. Ojo-Amaize E, Vilcek J, Cochrane A, Nussenzweig R. Plasmodium berghei sporozoites are mitogenic for murine $\mathrm{T}$ cells, induce interferon, and activate natural killer cells. J Immunol. 1984; 133:1005-9. 
43. Choudhury, H, Sheikh N, Bancroft G, Katz D, De Souza J. Early nonspecific immune responses and immunity to blood-stage nonlethal Plasmodium yoelii malaria. Infect Immun. 2000; 68:6127-32.

44. Pasquetto V, Guidotti L, Kakimi K, Tsuji M, Chisari F. Host-virus interactions during malaria infections in hepatitis $B$ virus transgenic mice. $J$ Exp Med. 2000; 192: 529-36.

45. Artavanis-Tsakonas K, Eleme K, McQueen KL, Cheng NW,Parham P, Davis DM,Riley EM. Activation of a subset of human NK Cells upon contact with Plasmodium falciparum-infected erythrocytes. J Immunol. 2003; 171:5396-405.

46. Bouyou-Akotet MK, Issifou S, Meye JF, Kombila M, Ngou-Milama E, Luty AJ, Kremsner PG, Mavoungou E. Depressed natural killer cell cytotoxicity against Plasmodium falciparum-infected erythrocytes during first pregnancies. Clin Infect Dis. 2004; 38:342-7.

47. Gonzalez-Aseguinolaza G, Kaer LC, Bergmann CC, Wilson JM, Schmieg J, Kronenberg M, Nakayama T, Taniguchi M, Koezuka Y, Tsuji M. Natural Killer $\mathrm{T}$ cell ligand $\alpha$-galactosylceramide enhances protective immunity induced by malaria vaccines. J Exp Med. 2002; 195(5): 617-24.

48. Elloso MM, Van der Heyde HC, Vande Waa JÁ, Manning DD, Weidanz WP. Inhibition of Plasmodium falciparum in vitro by human $\gamma \alpha \mathrm{T}$ cells. $J$ Immunol. 1994; 153:1187-94.

49. Troye-Blomberg M,Worku S, TangteerawatanaP, Jamshaid R, Söderström K, EIGahazali G, Moretta L, Hammarström ML,Mincheva-Nilsson L. Human $\gamma \alpha \mathrm{T}$ cells that inhibit the in vitro growth of the asexual blood stages of the Plasmodium falciparum parasite express cytolytic and proinflammatory molecules. Scand J Immunol. 1999; 50:642-50.

50. Perlmann P, Troye-Blomberg M. Malaria and the immune system in human. Chem Immunol. 2002; 80:229-42.

51. Kwiatkowski D. Malarial toxins and regulation of parasite density. Parasitol Today 1995; 11: 115-23. 
52. Perlmann P, Bjökman A. Malaria Research: Host-parasite Interactions and New Developments in Chemotherapy, Immunology and Vaccinology. Curr Opin Infect Dis. 2000; 13:431-43.

53. Wipasa J, Elliot S, Xu H, Good MF. Immunity to Asexual Blood Stage Malaria and Vaccine Approaches. Immunol Cell Biol. 2002; 80:401-14.

54. Wassmer SC, de Souza JB, Frère C, Candal FJ, Juhan-Vague I, Grau GE. TGF-beta1 released from activated platelets can induce TNF-stimulated human brain endothelium apoptosis: a new mechanism for microvascular lesion during cerebral malaria. J Immunol. 2006; 176(2):1180-4.

55. Malaguarnera L, Musumeci S. Role of proinflammatory and antiinflammatory cytokines in the immune response to Plasmodium falciparum malaria. Lancet Infect Dis. 2002; 2:719-20.

56. Belkaid Y, Piccirillo CA, Mendez S, Shevach EM, Sacks DL. CD4 ${ }^{+}$CD $25^{+}$ regulatory $\mathrm{T}$ cells control Leishmania major persistence and immunity. Nature. 2002; 420: 502-7.

57. Suvas S, Azkur AK, Kim BS, Kumaraguru U, Rouse BT.CD4 ${ }^{+}$CD $25^{+}$ regulatory $\mathrm{T}$ cells control the severity of viral immunoinflammatory lesions. J Immunol. 2004; 172(7):4123-32.

58. Hisaeda H, Hisaeda $H$, Maekawa $Y$, Iwakawa D, Okada H, Himeno K, Kishihara K, Tsukumo S, Yasutomo K. Escape of malaria parasites from host immunity requires $\mathrm{CD}^{+} \mathrm{CD}^{+} 5^{+}$regulatory T cells. Nat Med. 2004; 10(1):29-30.

59. Bouharoun-Tayoun H, Attanath P, Sabchareon A, Chongsuphajaisiddhi T, Druilhe P. Antibodies that protect humans against Plasmodium falciparum blood stages do not on their own inhibit parasite growth and invasion in vitro, but act in cooperation with monocytes. J Exp Med. 1990; 172:163341.

60. Bouharoun-Tayoun H, Druilhe P. Plasmodium falciparum Malaria: evidence for an isotype imbalance which may be responsible for delayed acquisition of protective immunity. Infect Immun. 1992; 60(4): 1473-81.

61. Aribot G, Rogier C, Sarthou JL, Trape JF, Balde, AT, Druilhe P, Roussilhon C. Pattern of immunoglobulin isotype response to Plasmodium 
falciparum blood-stage antigens in individuals living in a holoendemic area of Senegal (Dielmo, West Africa). Am J Trop Med Hyg 1996; 54(5):449-57.

62. Aucan C, Traoré Y, Tall F, Nacro B, Traoré-Leroux T, Fumoux F, Rihet $P$. High immunoglobulin G2 (IgG2) and low G4 (lgG4) levels are associated with human resistance to Plasmodium falciparum malaria. Infect Immun. 2000; 68(3): 1252-8.

63. Perlmann H, Helmby $\mathrm{H}$, Hagstedt M, Carlson J, Larsson PH, TroyeBlomberg M, Perlmann P. IgE elevation and IgE anti-malarial antibodies in Plasmodium falciparum malaria: association of high $\lg \mathrm{E}$ levels with cerebral malaria. Clin Exp Immunol. 1994; 97:284-92.

64.Perlmann P, Perlmann H, ElGhazali G, Blomberg MT. IgE and tumor necrosis factor in malaria infection. Immunol Lett. 1999; 65(1-2):29-33.

65.Perlmann $\mathrm{H}$, Troye-Blomberg $\mathrm{M}$, Perlmann $\mathrm{P}$. IgE antibodies to P.falciparum and severity of malaria in children of one ethnic group living in Burkina Faso. Am J Trop Med Hyg. 2003; 69:31-5.

66. Seka-Seka J, Brouh Y, Yapo-Crezoit AC, Atseye NH. The role of serum immunoglobulin $\mathrm{E}$ in the pathogenesis of Plasmodium falciparum malaria in Ivorian children. Scand J Immunol. 2004; 59:228-30.

67. Calissano C, Modiano D, Sirima BS, Konate A, Sanou I, Sawadogo A, Perlmann $\mathrm{H}$, Troye-Blomberg $\mathrm{M}$, Perlmann $\mathrm{P}$. IgE antibodies to Plasmodium falciparum and severity of malaria in children of one ethnic group living in Burkina Faso. Am J Trop Med Hyg. 2003; 69(1):31-5.

68. Duarte J, Deshpande P, Guiyedi V, Mécheri S, Fesel C, Cazenave P-A, Mishra GC, Kombila M, Pied S. Total and functional parasite specific IgE responses in Plasmodium falciparum-infected patients exhibiting different clinical status. Malar J. 2007; 6:1.

69. Rich SM, Ayala FJ. Population structure and recent evolution of Plasmodium falciparum. Proc Natl Acad Sci USA. 2000; 97: 6994-01.

70. Volkman SK, Barry AE, Lyons EJ Nielsen KM, Thomas SM, Choi M, Thakore SS, Day KP, Wirth DF, Hartl DL. Recent origin of Plasmodium falciparum from a single progenitor. Science. 2001; 293:482-4. 
71. Haldane JBS. The rate of mutations of human genes. Proceedings of the Eighth International Congress of Genetics and Heredity. Hereditas. 1948; 35:267-73.

72. Flint J, Hill AV, Bowden DK, Oppenheimer SJ, Sill PR, Serjeantson SW, Bana-Koiri, J, Bhatia K, Alpers MP, Boyce AJ. High frequencies of alphathalassaemia are the result of natural selection by malaria. Nature. 1986; 321(6072): 744-50.

73. Allen SJ, O'donnell A, Alexander NDE, Alpers MP, Peto TEA, Clegg JB, Weatherall DJ. $\alpha+-$ Thalassemia protects children against disease caused by other infections as well as malaria. Proc Natl Acad Sci USA.1997; 94: 14736-741.

74. Carter R, Mendis KN. Evolutionary and historical aspects of the burden of malaria. Clin Microbiol Rev. 2002; 15(4): 564-94.

75. Gilles HM, Fletcher KA, Hendrickse RG, Lindner R, Reddy S, Allan N. Glucose 6 phosphate dehydrogenase deficiency, sickiling and malaria in African children in South Western Nigeria. Lancet. 1967; 138-40.

76. Agarwal A, Guindo A, Cissoko Y, Taylor JG, Coulibaly D, Kone A, Kayentao K, Djimde A, Plowe CV, Doumbo O, Wellems TE, Diallo D.Hemoglobin $\mathrm{C}$ associated with protection from severe malaria in the Dogon of Mali, a west African population with a low prevalence of hemoglobin S. Blood. 2000; 96(7):2358-63.

77. Modiano D, Luoni G, Sirima BS, Simpore J, Verra F, Konate A, Rastrelli E, Olivieri A, Calissano C, Paganotti GM, D'Urbano L, Sanou I, Sawadogo A, Modiano G, Coluzzi M. Haemoglobin C protects against clinical Plasmodium falciparum malaria. Nature. 2001; 414(6861): 305-8.

78. Jarolim P, Palek J, Amato D, Hassan K, Sapak P, Nurse GT, Rubin HL, Zhai S, Shar KE, Liu SC. Deletion in the erythrocyte band 3 gene in malaria-resistant Southeast Asian ovalocytosis. Proc Natl Acad Sci USA. 1991; 88: 11022-6.

79. Genton B, Al-Yaman F, Mgone CS, Alexander N, Paniu MM,Alpers MP. Ovalocytosis and cerebral malaria. Nature. 1995; 378:564-5. 
80. Allen SJ, O'donnell A, Alexander NDE, Mgone CS, Peto TEA, Clegg JB, Alpers MP, Weatherall DJ. Prevention of cerebral malaria in children in Papua New Guinea by Southeast Asian ovalocytosis band 3. Am J Trop Med Hyg. 1999; 66(6): 1056-60.

81. Miller LH, Carter R. A review. Innate Resistance in Malaria. Exp Parasitol. 1976; 40(1):132-46.

82. Hamblin MT, Di Rienzo A. Detection of the signature of natural selection in humans: evidence from the duffy blood group locus. Am J Hum Genet. 2000; 66: 1669-79.

83. Luzatto L, Sodeinde O, Martini G. In: Malaria and the red cell. Genetic Variation in the Host and Adaptive Phenomena in Plasmodium falciparum Infection, 1983.

84. Roth EF, Raventos-Suarez C, Rinaldi A, Nagel RL. Glucose-6-phosphate dehydrogenase deficiency inhibits in vitro growth of Plasmodium falciparum. Proc Natl Acad Sci USA. 1983; 80: 298-9.

85. Pasvol G, Wilson RJ. The interaction of malaria parasites with red blood cells. Br. Med Bull. 1982; 38(2):133-40.

86. Mombo L-E, Ntoumi F, Bisseye C, Ossari S, Lu CY, Nagel RL, Krishnamoorthy R. Human genetic polymorphisms and asymptomatic Plasmodium falciparum malaria in Gabonese schoolchildren. Am J Trop Med Hyg. 2003; 68(2): 186-90.

87. Schröder NW, Schumann RR. Single nucleotide polymorphisms of Tolllike receptors and susceptibility to infectious disease. Lancet Infect Dis. 2005 5(3):156-64.

88.Zhang DX, Hewitt GM. Nuclear DNA analyses in genetic studies of populations: practice, problems and prospects. Mol Ecol. 2003; 12(3):56384.

89. Marth G, Yeh R, Minton M, Donaldson R, Li Q, Duan S, Davenport R, Miller RD, Kwok PY. Single-nucleotide polymorphisms in the public domain: how useful are they? Nat Genet. 2001; 27(4):371-2.

90. Lander ES, Linton LM, Birren B, Nusbaum C, Zody MC, Baldwin J, Devon K, Dewar K, Doyle M, FitzHugh W, Funke R, Gage D, Harris K, Heaford A, 
Howland J, Kann L,Lehoczky J, LeVine R, McEwan P, McKernan K, Meldrim J, Mesirov JP, Miranda C,Morris W, Naylor J, Raymond C, Rosetti M, Santos R, Sheridan A, Sougnez C,Stange-Thomann N, Stojanovic N, Subramanian A, Wyman D, Rogers J, Sulston J,Ainscough R, Beck S, Bentley D, Burton J, Clee C, Carter N, Coulson A, Deadman R,Deloukas P, Dunham A, Dunham I, Durbin R, French L, Grafham D, Gregory S, Hubbard T, Humphray S, Hunt A, Jones M, Lloyd C, McMurray A, Matthews L, Mercer S, Milne S, Mullikin JC, Mungall A, Plumb R, Ross M, Shownkeen R, Sims S, Waterston RH,Wilson RK, Hillier LW, McPherson JD, Marra MA, Mardis ER, Fulton LA, Chinwalla AT, Pepin KH, Gish WR, Chissoe SL, Wendl MC, Delehaunty KD, Miner TL, Delehaunty A, Kramer JB, Cook LL, Fulton RS, Johnson DL, Minx PJ, Clifton SW, Hawkins T,Branscomb E, Predki P, Richardson P, Wenning S, Slezak T, Doggett N, Cheng JF,Olsen A, Lucas S, Elkin C, Uberbacher E, Frazier M, Gibbs RA, Muzny DM, SchererSE, Bouck JB, Sodergren EJ, Worley KC, Rives CM, Gorrell JH, Metzker ML, NaylorSL, Kucherlapati RS, Nelson DL, Weinstock GM, Sakaki Y, Fujiyama A, Hattori M,Yada T, Toyoda A, Itoh T, Kawagoe C, Watanabe H, Totoki Y, Taylor T, Weissenbach J, Heilig R, Saurin W, Artiguenave F, Brottier P, Bruls T, Pelletier E, Robert C, Wincker P, Smith DR, Doucette-Stamm L, Rubenfield M, Weinstock K, Lee HM, Dubois J, Rosenthal A, Platzer M, Nyakatura G, Taudien S, Rump A, Yang H, Yu J, Wang J, Huang G, Gu J, Hood L, Rowen L, Madan A, Qin S, Davis RW, Federspiel NA, Abola AP, Proctor MJ, Myers RM, Schmutz J, Dickson M, Grimwood J, Cox DR, Olson MV, Kaul R, Raymond C, Shimizu N, Kawasaki K, Minoshima S, Evans GA, Athanasiou M, Schultz R, Roe BA, Chen F, Pan H, Ramser J, Lehrach H, Reinhardt R, McCombie WR, de la Bastide M, Dedhia N, Blöcker $H$, Hornischer K, Nordsiek G, Agarwala R,Aravind L, Bailey JA, Bateman A, Batzoglou S, Birney E, Bork P, Brown DG, Burge CB, Cerutti L, Chen HC, Church D, Clamp M, Copley RR, Doerks T, Eddy SR, Eichler EE, Furey TS, Galagan J, Gilbert JG, Harmon C, Hayashizaki Y, Haussler D,Hermjakob H, Hokamp K, Jang W, Johnson LS, Jones TA, Kasif S, 
Kaspryzk A, Kennedy S, Kent WJ, Kitts P, Koonin EV, Korf I, Kulp D, Lancet D, Lowe TM, McLysaght A,Mikkelsen T, Moran JV, Mulder N, Pollara VJ, Ponting CP, Schuler G, Schultz J,Slater G, Smit AF, Stupka E, Szustakowski J, Thierry-Mieg D, Thierry-Mieg J, Wagner L, Wallis J, Wheeler R, Williams A, Wolf YI, Wolfe KH, Yang SP, Yeh RF, Collins F, Guyer MS, Peterson J, Felsenfeld A, Wetterstrand KA, Patrinos A, Morgan MJ, de Jong P, Catanese JJ, Osoegawa K, Shizuya H, Choi S, Chen YJ. Initial sequencing and analysis of the human genome. Nature. 2001; 409(6822):860-921.

91.Luty AJF, Kun JFJ. Mannose-Binding Lectin Plasma levels and gene polymorphisms in Plasmodium falciparum malaria. J Infect Dis. 1998; 178 : 1221-4.

92. Mockenhaupt FP, Cramer JP, Hamann L,Stegemann MS, Eckert J, Oh NR, Otchwemah RN, Dietz E, Ehrhardt S, Schröder NW, Bienzle U, Schumann RR. Toll-like receptor (TLR) polymorphisms in African children: Common TLR-4 variants predispose to severe malaria. Proc Natl Acad Sci USA 2006; 103:177-82.

93. Mockenhaupt FP, Hamann L, Von Gaertner C, Bedu-Addo G, Cordula Von Kleinsorgen C, Schumann RR, Bienzle U. Common polymorphisms of Toll-Like receptors 4 and 9 are associated with the clinical manifestation of malaria during pregnancy. J Infec Dis. 2006 194:184-8.

94. Nagayasu E, Ito M, Akaki M, Nakano Y, Kimura M, Looareesuwan S, Aikawa M. CR1 density polymorphism on erythrocytes of falciparum malaria patients in Thailand. Am J Trop Med Hyg. 2001; 64(1-2):1-5.

95. Burgner D, Usen S, Rockett K, - Jallow M, Ackerman H, Cervino A, Pinder M, Kwiatkowski PD. Nucleotide and haplotypic diversity of the NOS2A promoter region and its relationship to cerebral malaria. Hum. Genet. 2003; 112: 379-86.

96. Burgner D, Usen S, Rockett K, - Jallow M, Ackerman H, Cervino A, Pinder M, Kwiatkowski PD. Nucleotide and haplotypic diversity of the NOS2A promoter region and its relationship to cerebral malaria. Hum Genet. 2003; 112: $379-86$. 
97. Kun JF, Mordmüller B, Perkins DJ, May J, Mercereau-Puijalon O, Alpers M, Weinberg JB, Kremsner PG. Nitric oxide synthase 2(Lambaréné) (G954C), increased nitric oxide production, and protection against malaria. $J$ Infect Dis. 2001; 184(3):330-6.

98. Hobbs MR, Udhayakumar V, Levesque MC, Booth J, Roberts JM, Tkachuk AN, Pole A,Coon H, Kariuki S, Nahlen BL, Mwaikambo ED, Lal AL, Granger DL, Anstey NM,Weinberg JB. A new NOS2 promoter polymorphism associated with increased nitric oxide production and protection from severe malaria in Tanzanian and Kenyan children. Lancet 2002; 360(9344):1468-75.

99. Hill AVS, Allsopp CEM, Kwiatkowski D, Anstey NM, Twumasi P, Rowe PA, Bennett S, Brewster D, McMichael AJ Greenwood BM. Common West African HLA antigens are associated with protection from severe malaria. Nature 1991; 352: 595-600.

100. May J, Lell B, Luty AJF, Meyer CG, Kremsner PG. HLA-DQB1* 0501Restricted Th1 type immune responses to Plasmodium falciparum liver stage antigen 1 protect against malaria anemia and reinfections. J. Infect. Dis. 2001; 183: 168-72.

101. Riley EM, Olerup O, Bennett S, Rowe P, Allen SJ, Blackman MJ, Troye-Blomberg M, Holder AA, Greenwood BM. MHC and malaria: the relationship between HLA class II alleles and immuneresponses to Plasmodium falciparum. Int Immunol. 1992; 4(9):1055-63.

102. Patarroyo ME, Vinasco J, Amador R, Espejo F, Silva Y, Moreno A, Rojas M, Mora AL, Salcedo M, Valero V, Goldberg AK, Kalil J. Genetic control of the immune response to a synthetic vaccine against Plasmodium falciparum. Parasite Immunol. 1991; 13(5): 509-16.

103. Koch O, Awomoyi A, Usen S, Jallow M,Richardson A, Hull J, Pinder M, Newport M, Kwiatkowski D. IFNGR1 gene promoter polymorphisms and susceptibility to cerebral malaria. J Infect Dis. 2002; 185:1684-7.

104. Aucan C, Walley AJ, Hennig BJW, Fitness J, Frodsham A, Zhang L, Kwiatkowski D, Hill AVS. Interferon-alpha receptor-1 (IFNAR1) variants 
are associated with protection against cerebral malaria in the Gambia. Genes Immun. 2003; 4:275-82.

105. Omi K, Ohashi J, Patarapotikul J, Hananantachai H, Naka I, Looareesuwan S, Tokunaga K. CD36 Polymorphism is associated with protection from cerebral malaria. Am J Hum Genet. 2003; 72: 364-74.

106. Aitman TJ, Cooper LD, Norsworthy PJ, Wahid FN, JGray JK, Curtis BR, McKeigue PM, Kwiatkowski D, Greenwood BM, Snow RW|, Hill AV, Scott J. Malaria susceptibility and CD36 mutation. Nature. 2000; 405(6790):1015-6.

107. Pain A, Urban BC, Kai O, Casals-Pascual C, Shafi J, Marsh K, Roberts DJ. A non-sense mutation in CD36 gene is associated with protection from severe malaria. Lancet. 2001; 357:1502-03.

108. Sabeti P, Usen S, Farhadian S, Jallow M, Doherty T, Newport M, Pinder M, Ward R, Kwiatkowski D. CD40L association with protection from severe malaria. Genes Immun. 2002; 3(5):286-91.

109. Mcguire W, Hill AVS, Allsopp CEM, Greenwood BM, Kwiatkowski D. Variation in the TNF- $\alpha$ promoter region associated with susceptibility to cerebral malaria. Nature. 1994; 371: 508-11.

110. Knight J, Udalova I, Hill AVS, Greenwood BM, Peshu N, Marsh K, Kwiatkowski D. A Polymorphism that affects OCT-1 binding to the TNF promoter region is associated with severe malaria. Nat Genet. 1999; 22: 145-50.

111. Luoni G, Verra F, Arcà B, Sirima BS, Troye-Blomberg M, Coluzzi M, Kwiatkowski D, Modiano D. Antimalarial antibody levels and IL4 polymorphism in the Fulani of West Africa. Genes Immun. 2001; 2(7):4114.

112. Morahan G, Boutlis CS, Huang D, Pain A, Saunders JR, Hobbs MR, Granger DL,Weinberg JB, Peshu N, Mwaikambo ED, Marsh K, Roberts DJ, Anstey NM.A promoter polymorphism in the gene encoding interleukin-12 p40 (IL12B) is associated with mortality from cerebral malaria and with reduced nitric oxide production. Genes Immun. 2002; 3(7):414-8. 
113. Medzhitov R, Preston-Hurlburt $P$, Janeway CA Jr. A human homologue of the Drosophila Toll protein signals activation of adaptive immunity. Nature. 1997; 388(6640):394-7.

114. Lemaitre B. The road to Toll. Nat Rev Immunol. 2004; 4(7):521-7.

115. Trinchieri G, Sher A. Cooperation of Toll-like receptor signals in innate immune defence. Nat Rev Immunol. 2007; 7(3):179-90.

116. Takeda K, Kaisho T, Akira S. Toll-like receptors. Annu Rev Immunol. 2003; 21:335-76.

117. O'Neill LA, Bowie AG. The family of five: TIR-domain-containing adaptors in Toll-like receptor signalling. Nat Rev Immunol. 2007; 7(5):35364.

118. Ropert C, Franklin BS, Gazzinelli RT. Role of TLRs/MyD88 in host resistance and pathogenesis during protozoan infection: lessons from malaria Semin. Immunopathol. 2008; 30(1):41-51.

119. Kanzler H, Barrat FJ, Hessel EM, Coffman RL. Therapeutic targeting of innate immunity with Toll-like receptor agonists and antagonists. Nat Med. 2007; 13(5):552-9.

120. Coban C, Ishii KJ, Horii T, Akira S. Manipulation of host innate immune responses by the malaria parasite. Trends Microbiol. 2007; 15(6):271-8.

121. Miller LH, Good MF, Milon G. Malaria pathogenesis. Science. 1994; 264(5167):1878-83.

122. Akira S, Takeda K. Toll-like receptor signalling. Nat Rev Immunol. 2004; 4(7):499-511.

123. Gazzinelli RT, Ropert C, Campos MA. Role of the Toll/interleukin-1 receptor signaling pathway in host resistance and pathogenesis during infection with protozoan parasites. Immunol Rev. 2004; 201:9-25.

124. Campos MA, Almeida IC, Takeuchi O, Akira S, Valente EP, Procopio DO, Travassos LR, Smith JA, Golenbock DT, Gazzinelli RT. Activation of Toll-like receptor-2 by glycosylphosphatidylinositol anchors from a protozoan. J Immunol. 2001; 167(1): 416-23. 
125. Ouaissi A, Guilvard E, Delneste Y, Caron G, Magistrelli G, Herbault N, Thieblemont N, Jeannin P. The Trypanosoma cruzi Tc52-released protein induces human dendritic cell maturation, signals via toll-like receptor 2 , and confers protection against lethal infection. J Immunol. 2002; 168(12): 6366-74.

126. Van der Kleij D, Latz E, Brouwers JF, Kruize YC, Schmitz M, KurtJones EA, Espevik T, de Jong EC, Kapsenberg ML, Golenbock DT, Tielens AG, Yazdanbakhsh M. A novel host-parasite lipid cross-talk. schistosomal lyso-phosphatidylserine activates toll-like receptor 2 and affects immune polarization. J Biol Chem. 2002; 277(50): 48122-9.

127. Scanga CA, Aliberti J, Jankovic D, Tilloy F, Bennouna S, Denkers EY, Medzhitov R, Sher A. Cutting edge: Myd88 is required for resistance to Toxoplasma gondii infection and regulates parasite-induced IL-12 Production by dendritic cells. J Immunol. 2002; 168(12): 5997-6001.

128. Zhu J, Krishnegowda G, Gowda DC. Induction of proinflammatory responses in macrophages by the glycosylphosphatidylinositols of Plasmodium falciparum: the requirement of extracellular signal-regulated kinase, p38, c-Jun N-terminal kinase and NF-kappaB pathways for the expression of proinflammatory cytokines and nitric oxide. $\mathrm{J}$ Biol Chem. 2005; 280(9):8617-27.

129. Coban C, Ishii KJ, Kawai T, Hemmi H, Sato S, Uematsu S, Yamamoto M, Takeuchi O,Itagaki S, Kumar N, Horii T, Akira S. Toll-like receptor 9 mediates innate immune activation by the malaria pigment hemozoin. $J$ Exp Med. 2005; 201(1):19-25.

130. Parroche P, Lauw FN, Goutagny N, Latz E, Monks BG, Visintin A, Halmen KA, Lamphier M, Olivier M, Bartholomeu DC, Gazzinelli RT, Golenbock DT. Malaria hemozoin is immunologically inert but radically enhances innate responses by presenting malaria DNA to Toll-like receptor 9. Proc Natl Acad Sci USA. 2007; 104(6):1919-24.

131. Schofield L, Hackett F.Signal transduction in host cells by a glycosylphosphatidylinositol toxin of malaria parasites. J Exp Med. 1993; 177(1):145-53. 
132. Schofield L, Novakovic S, Gerold P, Schwarz RT, McConville MJ, Tachado SD. Suvas S, Azkur AK, Kim BS, Kumaraguru U, Rouse BT (2004). $\mathrm{CD}^{+} \mathrm{CD} 25^{+}$regulatory $\mathrm{T}$ cells control the severity of viral immunoinflammatory lesions. J Immunol. 2004; 172: 4123-32.

133. Tachado SD, Gerold P, McConville MJ, Baldwin T, Quilici D, Schwarz RT, Schofield L. Glycosylphosphatidylinositol toxin of Plasmodium induces nitric oxide synthase expression in macrophages and vascular endothelial cells by a protein tyrosine kinase-dependent and protein kinase Cdependent signaling pathway. J Immunol. 1996; 156:1897-07.

134. Nebl T, De Veer MJ, Schofield L. Stimulation of innate immune responses by malarial glycosylphosphatidylinositol via pattern recognition receptors. Parasitology. 2005; 130:S45-62.

135. Krishnegowda G, Hajjar AM, Zhu J, Douglass EJ, Uematsu S, Akira S, Woods AS, Gowda DC. Induction of proinflammatory responses in macrophages by the glycosylphosphatidylinositols of Plasmodium falciparum: cell signaling receptors, glycosylphosphatidylinositol (GPI) structural requirement, and regulation of GPI activity. J Biol Chem. 2005; 280(9):8606-16.

136. Adachi K, Tsutsui H, Kashiwamura S-I, Seki E, Nakano H, Takeuchi O, Takeda K, Okumura K, Kaer LV, Okamura H, Akira S, Nakanishi K. Plasmodium berghei infection in mice induces liver injury by an il-12- and toll-like receptor/myeloid differentiation factor 88 -dependent mechanism. $J$ Immunol. 2001; 5929-34.

137. Lu Z, Serghides L, Patel SN, Degousee N, Rubin BB, Krishnegowda G, Gowda DC, Karin M, Kain KC. Disruption of JNK2 decreases the cytokine response to Plasmodium falciparum glycosylphosphatidylinositol in vitro and confers protection in a cerebral malaria model. $J$ Immunol. 2006; 177: 6344-52.

138. Coban C, Ishii KJ, Sullivan DJ, Kumar N. Purified malaria pigment (hemozoin) enhances dendritic cell maturation and modulates the isotype of antibodies induced by a DNA vaccine. Infect Immun. 2002; 70(7):393943. 
139. Pichyangkul S, Yongvanitchit K, Kum-arb U, Hemmi H, Akira S, Krieg AM, Heppner DG, Stewart VA, Hasegawa H, Looareesuwan S, Shanks GD, Miller RS. Malaria blood stage parasites activate human plasmacytoid dendritic cells and murine dendritic cells through a Toll-like receptor 9dependent pathway. J Immunol. 2004; 172(8):4926-33.

140. Hisaeda H, Tetsutani K, Imai T, Moriya C, Tu L, Hamano S, Duan X, Chou B, Ishida H, Aramaki A, Shen J, Ishii KJ, Coban C, Akira S, Takeda K, Yasutomo K, Torii M, Himeno K. Malaria parasites require TLR9 signaling for immune evasion by activating regulatory $\mathrm{T}$ cells. $\mathrm{J}$ Immunol. 2008; 180(4):2496-503.

141. Togbe D, Schofield L, Grau GE, Schnyder B, Boissay V, Charron S, Rose S, Beutler B, Quesniaux VFJ, Ryffel B. Murine cerebral malaria development is independent of toll-like receptor signaling. Am J Pathology. 2007; 107(5): 1640-8.

142. Lepenies B, Cramer JP, Burchard GD, Wagner H, Kirschning CJ, Jacobs T. Induction of experimental cerebral malaria is independent of TLR2/4/9. Med Microbiol Immunol. 2007; 197(1): 39-44.

143. Loharungsikul S, Troye-Blomberg M, Amoudruz P, Pichyangkul S, Yongvanitchit K, Looareesuwan S, Mahakunkijcharoen Y, Sarntivijai S, Khusmith S. Expression of toll-like receptors on antigen-presenting cells in patients with falciparum malaria. Acta Trop. 2008; 105(1):10-15.

144. Turvey SE, Hawn TR. Towards subtlety: understanding the role of Toll-like receptor signaling in susceptibility to human infections. Clin Immunol. 2006; 120:1-9.

145. Cook DN, Pisetsky DS, Schwartz DA. Toll-like receptors in the pathogenesis of human disease. Nat Immunol. 2004; 5(10):975-9.

146. Khor CC, Chapman SJ, Vannberg FO, Dunne A, Murphy C, Ling EY, Frodsham AJ, Walley AJ, Kyrieleis O, Khan A, Aucan C, Segal S, Moore CE, Knox K, Campbell SJ, Lienhardt C, Scott A, Aaby P, Sow OY, Grignani RT, Sillah J, Sirugo G, Peshu N, Williams TN, Maitland K, Davies RJ, Kwiatkowski DP, Day NP, Yala D, Crook DW, Marsh K, Berkley JA, O'Neill LA, Hill AV. A Mal functional variant is associated with protection 
against invasive pneumococcal disease, bacteremia, malaria and tuberculosis. Nat Genet. 2007; 39(4):523-8.

147. Hawn TR, Misch EA, Dunstan SJ Thwaites GE, Lan NT, Quy HT, Chau TT, Rodrigues S, Nachman A, Janer M, Hien TT, Farrar JJ, Aderem A. A common human TLR1 polymorphism regulates the innate immune response to lipopeptides. Eur J Immunol. 2007; 3798): 2280-9.

148. Thuong NT, Hawn TR, Thwaites GE, Chau TT, Lan NT, Quy HT, Hieu NT, Aderem A, Hien TT, Farrar JJ, Dunstan SJ. A polymorphism in human TLR2 is associated with increased susceptibility to tuberculous meningitis. Genes Immun. 2007; 8: 422-8.

149. Bochud PY, Hawn TR, Siddiqui MR Saunderson P, Britton S, Abraham I, Argaw AT, Janer M, Zhao LP, Kaplan G, Aderem A. Toll-like receptor 2 polymorphisms are associated with reversal reaction in leprosy $J$ Infect Dis. 2008; 197(2):253-61.

150. Tantisira K, Klimecki WT, Lazarus R, Palmer LJ, Raby BA, Kwiatkowski DJ, Silverman E, Vercelli D, Martinez FD, Weiss ST. Toll-like receptor 6 gene (TLR6): single-nucleotide polymorphism frequencies and preliminary association with the diagnosis of asthma. Genes Immun. 2004; 5(5):343-6.

151. Cooke GS, Segal S, Hill AV. Toll-like receptor 4 polymorphisms and atherogenesis. N Engl J Med. 2002; 347: 1978-80.

152. Newport MJ, Allen A, Awomoyi AA Dunstan SJ, McKinney E, Marchant A, Sirugo $G$. The toll-like receptor 4 Asp299Gly variant: no influence on LPS responsiveness or susceptibility to pulmonary tuberculosis in The Gambia. Tuberculosis. 2004; 84(6): 347-52.

153. Moens L, Verhaegen J, Pierik M Vermeire S, De Boeck K, Peetermans WE, Bossuyt X. Toll-like receptor 2 and Toll-like receptor 4 polymorphisms in invasive pneumococcal disease. Microbes Infect. 2007; 9 (1): 15-20.

154. Jüliger S, Kremsner PG, Alpers MP, Reeder JC, Kun JFG. restricted polymorphisms of the mannose-binding gene in a population of Papua New Guinea. Mutat Res. 2002; 505:87-91. 
155. Garred P, Nielsen MA, Kurtzhals JA, Malhotra R, Madsen HO, Goka $B Q$, Akanmori BD, Sim RB, Hviid L. Mannose-binding lectin is a disease modifier in clinical malaria and may function as opsonin for Plasmodium falciparum-infected erythrocytes. Infect Immun. 2003; 71(9): 5245-53.

156. Van Emmerik LC, Kuijper EJ, Fijen CA, Dankert J, Thiel S. Binding of mannan-binding protein to various bacterial pathogens of meningitis, Clin Exp Immunol. 1994; 97:411-6.

157. Neth O, Jack DL, Dodds AW, Holzel H, Klein NJ, Turner MW. Mannose-binding lectin binds to a range of clinically relevant microorganisms and promotes complement deposition. Infect Immun. 2000; 68:688-93.

158. Green PJ, Feizi T, Stoll MS, Thiel S, Prescott A, McConville MJ. Recognition of the major cell surface glycoconjugates of leishmania parasites by the human serum manna-binding protein. Mol Biochem Parasitol. 1994; 66:319-28.

159. Peters C, Kawakami M, Kaul M, Ilg T, Overath P, Aebischer T. Secreted proteophosphoglycan of Leishmania mexicana amastigotes activates complement by triggering the mannan binding lectin pathway. Eur J Immunol. 1997; 27:2666-72.

160. Klabunde J, Uhlemann A-C, Tebo AE, kimmel J, Schwarz PG, Kun JFJ. Recognition of Plasmodium falciparum proteins by mannan-binding lectin, a component of the human innate immune system. Parasitol Res. 2002; 88: 113-7.

161. Kahn SJ, Wleklinski M, Ezekowitz RA, Coder D, Aruffo A, Farr A. The major surface glycoprotein of Trypanosoma cruzi amastigotes are ligands of the human serum mannose-binding protein. Infect Immun. 1996; 64(7):2649-56.

162. Turner MW. Mannose-binding Lectin: The pluripotent molecule of the innate immune system. Immunol Today. 1996; 17:532-40.

163. Turner MW. The role of mannose-binding lectin in health and disease. Mol Immunol. 2003; 40(7):423-9. 
164. Sastry K, Herman GA, Day L, Deignan E, Bruns G, Morton CC, Ezekowitz RA. The human mannose-binding protein gene. exon structure reveals its evolutionary relationship to a human pulmonary surfactant gene and localization to chromosome 10. J Exp Med. 1989; 170:1175-89.

165. Taylor ME, Brickell KK, Craig JA, Summerfield JA. structure and evolutionary origin of the encoding a human serum mannose-binding protein. Biochem J. 1989; 262:763-71.

166. Endo $\mathrm{Y}$, Takahashi M, Fujita T. Lectin complement system and pattern recognition. Immunobiology. 2006; 211(4):283-93.

167. Garred P, Harboe M, Oettinger T, Koch C, Svejgaard A. Dual role of mannan-binding protein in infections: another case of heterosis? Eur $J$ Immunogenet. 1994; 21:125-31.

168. De Miranda Santos IKF, Costa CH, Krieger H, Feitosa MF, Zurakowski D, Fardin B, Gomes RB, Weiner DL, Harn DA, Ezekowitz RA, Epstein JE. Mannan-binding lectin enhances susceptibility to visceral leishmaniasis. Infect Immun. 2001; 69:5212-5.

169. Kumar $\mathrm{N}$, Zheng $\mathrm{H}$. Nucleotide sequence of a Plasmodium falciparum stress protein with similarity to mammalian $78-\mathrm{kDa}$ glucoseregulated protein. Mol Biochem Parasitol. 1992; 52:353-6.

170. Kumar N, Koski G, Harada M, Aikawa M, Zheng H. Induction and localization of falciparum stress proteins related to the heat shock protein 70 family. Mol Biochem Parasitol. 1991; 48:47-58.

171. Madsen HO, Garred P, Kurtzhals JA, Lamm LU, Ryder LP, Thiel S, Svejgaard A. A new frequent allele is the missing link in the structural polymorphism of the human mannan-binding protein. Immunogenetics. 1994; 40(1):37-44.

172. Lipscombe RJ, Lau YL, Levinsky RJ, Sumiya M, Summerfield JA, Turner MW. Identical point mutation leading to low levels of mannose binding protein and poor $\mathrm{C} 3 \mathrm{~b}$ mediated opsonization in Chinese and Caucasian populations. Immunol Lett. 1992; 32(3): 253-7. 
173. Sumiya M, Super M, Tabona P, Levinsky RJ, Arai T, Turner MW, Summerfield JA. Molecular basis of opsonic defect in immunodeficient children. Lancet. 1991; 337: 1569-70.

174. Bouwman LH, Roep BO, Roos A. Mannose-Binding Lectin: clinical implications for infection, transplantation, and autoimmunity. Hum Immunol. 2006; 67: 247-56.

175. Boldt ABW, Luty A, Grobusch MP, Dietz K, Dzeing A, Kombila M, Kremsner PG, Kun JFJ. Association of a new mannose-binding lectin variant with severe malaria in Gabonese children. Genes Immun. 2006; 7; 393-400.

176. Madsen HO, Garred P, Thiel S, Kurtzhals JA, Lamm LU, Ryder LP, Svejgaard A. Interplay between promoter and structural gene variants control basal serum level of mannan-binding protein. J Immunol. 1995; 155: 3013-20.

177. Madsen HO, Satz ML, Hogh B, Svejgaard A, Garred P. Different molecular events result in low protein levels of mannan-binding lectin in populations from southeast Africa and South America. J Immunol. 1998; 161: 3169-75.

178. Bellamy $R$, Ruwende C, McAdam KP, Thursz M, Sumiya M, Summerfield J, Gilbert SC,Corrah T, Kwiatkowski D, Whittle HC, Hill AV. Mannose binding protein deficiency is not associated with malaria, hepatitis B carriage nor tuberculosis in Africans. QJM. 1998; 91(1):13-8.

179. Holmberg V, Schuster F, Dietz E, Sagarriga Visconti JC, Anemana SD, Bienzle U, Mockenhaupt FP. Mannose-binding lectin variant associated with severe malaria in young African children. Microbes Infect. 2008; 10(4):342-8.

180. Fearon DT. Identification of the membrane glycoprotein that is the C3b receptor of the human erythrocyte, polymorphonuclear leukocyte, B lymphocyte, and monocyte. J Exp Med. 1980; 152:20-30.

181. Wilson JG, Tedder TF, Fearon DT. Characterization of human $t$ lymphocytes that express the C3b receptor. J Immunol. 1983; 131: 684-9. 
182. Krych-Goldberg M, Atkinson JP. Structure-function relationships of complement receptor type 1. Immunol Rev. 2001; 180:112-22.

183. Klickstein LB, Wong WW, Smith JA, Weis JH, Wilson JG, Fearon DT. Human $\mathrm{C} 3 \mathrm{~b} / \mathrm{C} 4 \mathrm{~b}$ receptor (CR1). Demonstration of long homologous repeating domains that are composed of the short consensus repeats characteristics of C3/C4 binding proteins. J Exp Med. 1987; 165(4):1095112.

184. Krych-Goldberg M, Moulds JM, Atkinson JP. Human complement receptor type 1 (CR1) binds to a major malarial adhesin. Trends Mol Med. 2002; 8(11):531-7.

185. Krych M, Hourcade D, Atkinson JP. Sites within the complement $\mathrm{C} 3 \mathrm{~b} / \mathrm{C} 4 \mathrm{~b}$ receptor important for the specificity of ligand binding. Proc NatI Acad Sci USA. 1991; 88(10):4353-7.

186. Krych M, Clemenza L, Howdeshell D, Hauhart R, Hourcade D, Atkinson JP. Analysis of the functional domains of complement receptor type 1 (C3b/C4b receptor; CD35) by substitution mutagenesis. J Biol Chem. 1994; 269(18):13273-8.

187. Klickstein LB, Bartow TJ, Miletic V, Rabson LD, Smith JA, Fearon DT. Identification of distinct $\mathrm{C} 3 \mathrm{~b}$ and $\mathrm{C} 4 \mathrm{~b}$ recognition sites in the human $\mathrm{C} 3 \mathrm{~b} / \mathrm{C} 4 \mathrm{~b}$ receptor (CR1, CD35) by deletion mutagenesis. J Exp Med. 1988; 168(5):1699-717.

188. Kalli KR, Hsu PH, Bartow TJ, Ahearn JM, Matsumoto AK, Klickstein LB, Fearon DT. Mapping of the C3b-binding site of CR1 and construction of a (CR1)2-F(ab')2 chimeric complement inhibitor. J Exp Med. 1991; 174(6):1451-60.

189. Birmingham DJ, Hebert LA. CR1 and CR1-like: the primate immune adherence receptors. Immunol Rev. 2001; 180:100-11.

190. Krych-Goldberg M, Hauhart RE, Subramanian VB, Yurcisin BM 2nd, Crimmins DL, Hourcade DE, Atkinson JP. Decay accelerating activity of complement receptor type 1 (CD35). Two active sites are required for dissociating C5 convertases. J Biol Chem. 1999; 274(44):31160-8. 
191. Klickstein LB, Barbashov SF, Liu T, Jack RM, Nicholson-Weller A. Complement receptor type 1 (CR1, CD35) is a receptor for $\mathrm{C} 1 \mathrm{q}$. Immunity. $1997 ; 7(3): 345-55$.

192. Ghiran I, Barbashov SF, Klickstein LB, Tas SW, Jensenius JC, Nicholson-Weller A. Complement receptor $1 /$ CD35 is a receptor for mannan-binding lectin. J Exp Med. 2000; 192(12):1797-808.

193. Rowe JA, Rogerson SJ, Raza A, Moulds JM, Kazatchkine MD, Marsh $\mathrm{K}$, Newbold $\mathrm{Cl}$, Atkinson JP, Miller LH. Mapping of the region of complement receptor (CR) 1 required for Plasmodium falciparum rosetting and demonstration of the importance of CR1 in rosetting in field isolates. $J$ Immunol. 2000; 165(11):6341-6.

194. Chen Q, Barragan A, Fernandez V, Sundström A, Schlichtherle $M$, Sahlén A, Carlson J, Datta S, Wahlgren M. Identification of Plasmodium falciparum erythrocyte membrane protein 1 (PfEMP1) as the rosetting ligand of the malaria parasite P. falciparum. J Exp Med. 1998; 187(1):1523.

195. Rowe JA, Moulds JM, Newbold CI, Miller LH. P. falciparum rosetting mediated by a parasite-variant erythrocyte membrane protein and complement-receptor 1. Nature. 1997; 388(6639):292-5.

196. Barragan A, Kremsner PG, Wahlgren M, Carlson J. Blood group A antigen is a coreceptor in Plasmodium falciparum rosetting. Infect Immun. $2000 ; 68(5): 2971-5$.

197. Carlson J, Helmby H, Hill AV, Brewster D, Greenwood BM, Wahlgren M. Human cerebral malaria: association with erythrocyte rosetting and lack of anti-rosetting antibodies. Lancet. 1990; 336(8729):1457-60.

198. Ringwald P, Peyron F, Lepers JP, Rabarison P, Rakotomalala C, Razanamparany M, Rabodonirina M, Roux J, Le Bras J. Parasite virulence factors during falciparum malaria: rosetting, cytoadherence, and modulation of cytoadherence by cytokines. Infect Immun. 1993; 61(12):5198-204.

199. Al-Yaman F, Genton B, Mokela D, Raiko A, Kati S, Rogerson S, Reeder J, Alpers M. Human cerebral malaria: lack of significant 
association between erythrocyte rosetting and disease severity. Trans $R$ Soc Trop Med Hyg. 1995; 89(1):55-8.

200. Rowe A, Obeiro J, Newbold Cl, Marsh K. Plasmodium falciparum rosetting is associated with malaria severity in Kenya. Infect Immun. 1995; 63(6):2323-6.

201. Newbold C, Warn P, Black G, Berendt A, Craig A, Snow B, Msobo M, Peshu N, Marsh K. Receptor-specific adhesion and clinical disease in Plasmodium falciparum. Am J Trop Med Hyg. 1997; 57(4):389-98.

202. Udomsanpetch R, Thanikkul K, Pukrittayakamee S, White NJ. Rosette formation by Plasmodium vivax. Trans $R$ Soc Trop Med Hyg. 1995; 89(6):635-7.

203. Moulds JM, Zimmerman PA, Doumbo OK, Kassambara L, Sagara I, Diallo DA, Atkinson JP, Krych-Goldberg M, Hauhart RE, Hourcade DE, McNamara DT, Birmingham DJ, Rowe JA, Moulds JJ, Miller LH. Molecular identification of Knops blood group polymorphisms found in long homologous region D of complement receptor 1. Blood. 2001; 97(9):287985.

204. Xiang L, Rundles JR, Hamilton DR, Wilson JG. Quantitative alleles of CR1: coding sequence analysis and comparison of haplotypes in two ethnic groups. J Immunol. 1999; 163(9): 4939-45.

205. Wilson JG, Murphy EE, Wong WW, Klickstein LB, Weis JH, Fearon DT. Identification of a restriction fragment length polymorphism by a CR1 cDNA that correlates with the number of CR1 on erythrocytes. $J$ Exp Med. 1986; 164(1):50-9.

206. Herrera AH, Xiang L, Martin SG, Lewis J, Wilson JG. Analysis of complement receptor type 1 (CR1) expression on erythrocytes and of CR1 allelic markers in Caucasian and African American populations. Clin Immunol Immunopathol. 1998; 87(2):176-83.

207. Moulds JM, Nickells MW, Moulds JJ, Brown MC, Atkinson JP. The $\mathrm{C} 3 \mathrm{~b} / \mathrm{C} 4 \mathrm{~b}$ receptor is recognized by the Knops, McCoy, Swain-langley, and York blood group antisera. J Exp Med. 1991;173(5):1159-63. 
208. Rao N, Ferguson DJ, Lee SF, Telen MJ. Identification of human erythrocyte blood group antigens on the $\mathrm{C} 3 \mathrm{~b} / \mathrm{C} 4 \mathrm{~b}$ receptor. $\mathrm{J}$ Immunol. 1991; 146(10):3502-7.

209. Moulds JM, Kassambara L, Middleton JJ, Baby M, Sagara I, Guindo A, Coulibaly S, Yalcouye D, Diallo DA, Miller L, Doumbo O. Identification of complement receptor one (CR1) polymorphisms in west Africa. Genes Immun. 2000; 1(5):325-9.

210. Bellamy R, Kwiatkowski D, Hill AVS. Absence of an association between intercellular adhesion molecule 1, complement receptor 1 and interleukin 1 receptor antagonist gene polymorphism and severe malaria in a west African population. Trans R Soc Trop Med Hyg. 1998; 92: 312-6.

211. Rowe JA, Raza A, Diallo DA, Baby M, Poudiougo B, Coulibaly D, Cockburn IA, Middleton J, Lyke KE, Plowe CV, Doumbo OK, Moulds JM. Erythrocyte CR1 expression level does not correlate with a HindIII restriction fragment length polymorphism in Africans; implications for studies on malaria susceptibility. Genes Immun. 2002; 3(8):497-500.

212. Zimmerman PA, Fitness J, Moulds JM, McNamara DT, Kasehagen LJ, Rowe JA, Hill AV. CR1 Knops blood group alleles are not associated with severe malaria in the Gambia. Genes Immun. 2003; 4(5):368-73.

213. Cockburn IA, Mackinnon MJ, O'Donnell A, Allen SJ, Moulds JM, Baisor M, Bockarie M, Reeder JC, Rowe JA. A Human complement receptor 1 polymorphism that reduces Plasmodium falciparum rosetting confers protection against severe malaria. Proc Natl Acad Sci USA. 2004; 101(1): 272-7.

214. Thathy V, Moulds JM, Guyah B, Otieno W, Stoute JA. Complement receptor 1 polymorphisms associated with resistance to severe malaria in Kenya. Malar J. 2005; 4:54.

215. Cockburn IA, Rowe JA. Erythrocyte complement receptor 1 (CR1) expression level is not associated with polymorphisms in the promoter or 3' untranslated regions of the CR1 gene. Int J Immunogenet. 2006; 33(1):17-20. 
216. Fowkes FJ, Michon P, Pilling L, Ripley RM, Tavul L, Imrie HJ, Woods CM, Mgone CS, Luty AJ, Day KP. Host erythrocyte polymorphisms and exposure to Plasmodium falciparum in Papua New Guinea. Malar J. 2008; $7: 1$.

217. Birmingham DJ, Hebert LA. CR1 and CR1-like: the primate immune adherence receptors. Immunol Rev. 2001; 180:100-11.

218. Frodsham AJ, Hill AV. Genetics of infectious diseases. Hum $\mathrm{Mol}$ Genet. 2004; 13 Spec N²:R187-94.

219. Snounou G, Viriyakosol S, Jarra W, Thaithong S, Brown KN. Identification of the Four Human Malaria Parasite Species in Field Samples by the Polymerase Chain Reaction and Detection of a High Prevalence of Mixed Infections. Mol Biochem Parasitol 1993; 58: 283-92.

220. Ferreira MU, Liu Q, Zhou M, Kimura M, Kaneko O, Thien HV, Isomura S, Tanabe K, Kawamoto, F. Stable Patterns of Allelic Diversity at the Merozoite Surface Protein-1 Locus of Plasmodium falciparum in Clinical Isolates from Southern Vietnam J Eukaryot Microbiol. 1998; 45: 131-6.

221. Kimura M, Kaneko O, Liu Q, Zhou M, Kawamoto F, Wataya Y, Otani S, Yamaguchi Y, Tanabe K. Identification of the Four Species of Human Malaria Parasites by Nested PCR that Targets Variant Sequences in the Small Subunit rRNA Gene. Parasitol Int. 1997; 46: 91-5.

222. Akira S, Uematsu S, Takeuchi O. Pathogen recognition and innate immunity. Cell. 2006; 124:783-801.

223. Schofield L, Hewitt MC, Evans K, Siomos MA, Seeberger PH. Synthetic GPI as a candidate anti-toxic vaccine in a model of malaria. Nature. 2002; 418:785-9.

224. Johnson CM, Lyle EA, Omueti KO, et al. Cutting edge: A common polymorphism impairs cell surface trafficking and functional responses of TLR1 but protects against leprosy. J Immunol. 2007; 178:7520-4.

225. Hawn TR, Dunstan SJ, Thwaites GE, Simmons CP, Thuong NT, Lan NT, Quy HT, Chau TT, Hieu NT, Rodrigues S, Janer M, Zhao LP, Hien TT, Farrar JJ, Aderem A. A polymorphism in Toll-interleukin 1 receptor domain 
containing adaptor protein is associated with susceptibility to meningeal tuberculosis. J Infect Dis. 2006; 194(8):1127-34.

226. Roach JC, Glusman G, Rowen L, Kaur A, Purcell MK, Smith KD, Hood LE, Aderem A. The evolution of vertebrate Toll-like receptors. Proc Natl Acad Sci USA. 2005; 102(27):9577-82.

227. Marsik C, Jilma B, Joukhadar C, Mannhalter C, Wagner O, Endler G. The Toll-like receptor 4 Asp299Gly and Thr399lle polymorphisms influence the late inflammatory response in human endotoxemia. Clin Chem. 2005; 51(11):2178-80.

228. Smirnova I, Hamblin MT, McBride C, Beutler B, Di Rienzo A. Excess of rare amino acid polymorphisms in the Toll-like receptor 4 in humans. Genetics. 2001; 158(4):1657-64.

229. Ferwerda B, McCall MB, Verheijen K, Kullberg BJ, van der Ven AJ, Van der Meer JW, Netea MG. Functional consequences of toll-like receptor 4 polymorphisms. Mol Med. 2008; 14(5-6):346-52.

230. Moormann AM, Sullivan AD, Rochford RA, Chensue SW, Bock PJ, Nyirenda T, Meshnick SR. Malaria and pregnancy: placental cytokine expression and its relationship to intrauterine growth retardation. $J$ Infect Dis. 1999; 180: 1987-93.

231. Perry JA, Olver CS, Burnett RC, Avery AC. Cutting edge: the acquisition of TLR tolerance during malaria infection impacts $T$ cell activation. J Immunol. 2005; 174(10):5921-5.

232. Millington OR, Di Lorenzo C, Phillips RS, Garside P, Brewer JM. Suppression of adaptive immunity to heterologous antigens during Plasmodium infection through hemozoin-induced failure of dendritic cell function. J Biol. 2006; 5(2):5.

233. Cramer JP, Mockenhaupt FP, Ehrhardt S, Burkhardt J, Otchwemah RN, Dietz E, Gellert S, Bienzle U. iNOS promoter variants and severe malaria in Ghanaian children. Trop Med Int Health. 2004; 9(10):1074-80.

234. Lipscombe RJ, Sumiya M, Hill AV, Lau YL, Levinsky RJ, Summerfield JA, Turner MW. High frequencies in African and non-African populations 
of independent mutations in the mannose binding protein gene. Hum Mol Genet. 1992; 1(9):709-15.

235. Lipscombe RJ, Beatty DW, Ganczakowski M, Goddard EA, Jenkins T, Lau YL, Spurdle AB, Sumiya M, Summerfield JA, Turner MW.Mutations in the human mannose-binding protein gene: frequencies in several population groups. Eur J Hum Genet. 1996; 4(1):13-9.

236. Jüliger S, Luckner D, Mordmüller B, May J, Weierich A, Lell B, Luty A, Kremsner PG, Kun JF. Promoter variants of the human mannose-binding lectin gene show different binding. Biochem Biophys Res Commun. 2000; 275(2):617-22.

237. Jack DL, Turner MW. Anti-microbial activities of mannose-binding lectin. Biochem Soc Trans. 2003; 31(Pt 4):753-7.

238. Jack DL, Read RC, Tenner AJ, Frosch M, Turner MW, Klein NJ. Mannose-binding lectin regulates the inflammatory response of human professional phagocytes to Neisseria meningitidis serogroup B. J Infect Dis. 2001; 184(9):1152-62.

239. Ip WK, Chan SY, Lau CS, Lau YL. Association of systemic lupus erythematosus with promoter polymorphisms of the mannose-binding lectin gene. Arthritis Rheum. 1998; 41(9):1663-8.

240. Mullighan CG, Marshall SE, Bunce M, Welsh KI. Variation in immunoregulatory genes determines the clinical phenotype of common variable immunodeficiency. Genes Immun. 1999; 1(2):137-48.

241. Seibold F, Konrad A, Flogerzi B, Seibold-Schmid B, Arni S, Jüliger S, Kun JF. Genetic variants of the mannan-binding lectin are associated with immune reactivity to mannans in Crohn's disease. Gastroenterology. 2004; 127(4):1076-84.

242. Soborg C, Madsen HO, Andersen AB, Lillebaek T, Kok-Jensen A, Garred P. Mannose-binding lectin polymorphisms in clinical tuberculosis. $J$ Infect Dis. 2003; 188(5):777-82.

243. Garred P, Madsen HO, Hofmann B, Svejgaard A. Increased frequency of homozygosity of abnormal mannan-binding protein alleles in patients with suspected immunodeficiency. Lancet. 1995; 346:941-3. 
244. Garred P, Madsen HO, Balslev U, Hofmann B, Pedersen C, Gerstoft J, Svejgaard A. Susceptibility to HIV infection and progression of AIDS in relation to variant alleles of mannose-binding lectin. Lancet. 1997; 349: 236-40.

245. Rector A, Lemey P, Laffut W, Keyaerts E, Struyf F, Wollants E, Vermeire S, Rutgeerts $\mathrm{P}$, Van Ranst M. Mannan-binding lectin (MBL) gene polymorphisms in ulcerative colitis and Crohn's disease. Genes Immun. $2001 ; 2(6): 323-8$.

246. Schafranski MD, Stier A, Nisihara R, Messias-Reason IJ. Significantly increased levels of mannose-binding lectin (MBL) in rheumatic heart disease: a beneficial role for MBL deficiency. Clin Exp Immunol. 2004; 138(3):521-5.

247. Ramasawmy R, Spina GS, Fae KC, Pereira AC, Nisihara R, Messias Reason IJ, Grinberg M, Tarasoutchi F, Kalil J, Guilherme L. Association of mannose-binding lectin gene polymorphism but not of mannose-binding serine protease 2 with chronic severe aortic regurgitation of rheumatic etiology. Clin Vaccine Immunol. 2008; 15(6):932-6.

248. Herrera AH, Xiang L, Martin SG, Lewis J, Wilson JG. Analysis of complement receptor type 1 (CR1) expression on erythrocytes and of CR1 allelic markers in Caucasian and African American populations. Clin Immunol Immunopathol 1998; 87:176-83.

249. Zorzetto M, Bombieri C, Ferrarotti I, Medaglia S, Agostini C, Tinelli C, Malerba G, Carrabino N, Beretta A, Casali L, et al. Complement receptor 1 gene polymorphisms in sarcoidosis. Am J Respir Cell Mol Biol. 2002; 27:17-23.

250. Chotivanich KT, Pukrittayakamee S, Simpson JA, White NJ, Udomsangpetch R. Characteristics of Plasmodium vivax-infected erythrocyte rosettes. Am J Trop Med Hyg. 1998; 59(1):73-6.

251. Snow RW, Omumbo JA, Lowe B, Molyneux CS, Obiero JO, Palmer A, Weber MW, Pinder M, Nahlen B, Obonyo C, Newbold C, Gupta S, Marsh K. Relation between severe malaria morbidity in children and level of 
Plasmodium falciparum transmission in Africa. Lancet. 1997; 349(9066):1650-4. 